\title{
A History of Tectono-Magmatism along the Parga Chasma Rift System on Venus
}

\author{
by \\ Jamie Graff
}

A thesis submitted to the Faculty of Graduate and Postdoctoral Affairs in partial fulfillment of the requirements for the degree of

\author{
Master of Science \\ in \\ Earth Sciences \\ Carleton University \\ Ottawa, Ontario \\ (C)2016 \\ Jamie Graff
}




\begin{abstract}
Parga Chasma is a discontinuous rift system marking the southern boundary of the BAT region on Venus. Along a 1,500 km section of Parga Chasma, detailed mapping has revealed 5 coronae, 11 local rift segments distinct from a regional extension pattern, and 47 graben-fissure systems. These systems are often centred within coronae or large volcanoes, but many are isolated and indicate cryptic centres. Some of these magmatic centres are further observed as the loci of triple-junction rifting, collectively comprising the 11 local rift segments. Cross-cutting relationships between the corresponding grabenfissures and rift faults reveal synchronous formation, implying a genetic association. Additionally, cross-cutting relationships reveal these local events to postdate the regional extension, further indicating multiple stages of rifting. This provides an explanation for the discontinuous morphology of Parga Chasma, and its result has implications to explain the morphologies of other rift systems, both on Venus and Earth.
\end{abstract}




\section{Acknowledgements}

To begin I especially thank my supervisors, Dr. Richard Ernst and Dr. Claire Samson, for offering me the M.Sc. opportunity to further my Venus research. Their careful guidance throughout the years helped keep me well on track with steadily producing new ideas, insights, and results from my work. I thank them for providing edits and suggestions when producing a number of abstracts, posters, and oral presentations for various conferences over the last two years, and especially for providing financial support to allow me to attend and present my research at the Lunar and Planetary Science Conference in Houston, Texas. I am also incredibly appreciative for their suggestions, comments, and careful edits during the process of developing the ideas for and writing this thesis.

I thank everyone involved in our Venus Working Group, featuring representative attendance from the GSC and a variety of universities, including: Carleton, Ottawa, Mount Royal, Wesleyan, Brown, and Rey Juan Carlos. Discussions with students, professors, and research scientists from these institutions provided valuable feedback on multiple research directions, ideas, and insights involved when developing this thesis.

I thank Dr. Ellen Stofan and Dr. David Miller for meeting with our Venus research group at the CASI ASTRO 2016 conference in Ottawa. Dr. Stofan's expertise on Venusian geology provided wonderful insights regarding my research topics.

Thank you to Erin Bethell for the informative discussions regarding Venusian geology, research methods and ideas, and for her assistance when exploring some unfamiliar territory in ArcMap. Thank you to Kim Klausen for her assistance as I was learning to use CorelDraw to produce great quality figures for this thesis. Additionally, I offer tremendous thanks to Sarah Davey for her expertise and assistance regarding each these topics, from geological concepts and research methods to her assistance with both ArcMap and CorelDraw on countless occasions. I also thank Sarah for providing me with well modified figures and diagrams that have found a place in this thesis (with acknowledgement). 
I thank the entire faculty and staff of the Earth Sciences Department and of course my fellow graduate students who have and continue to make my experience here at Carleton truly enjoyable and memorable.

Lastly, my deepest thanks goes to my Mom, Dad, and my brother, Kevin for providing me with continuous and unwavering encouragement and support throughout my academic career. I also thank my whole extended family - my grandparents, aunts, uncles, and cousins - in British Columbia, Washington, and Nevada, for their interest in my work and their similar support throughout the years. I also thank Bruce Foreman for his interest and curiosity regarding my research, and Rick Nelson - who will always be a part of the family and like an uncle to me. 


\section{Table of Contents}

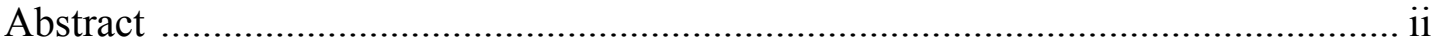

Acknowledgements ........................................................................................... iii

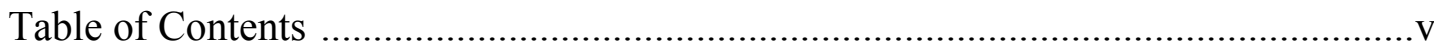

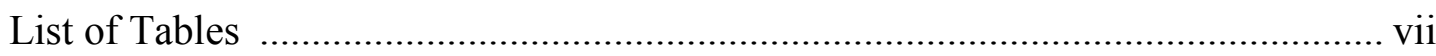

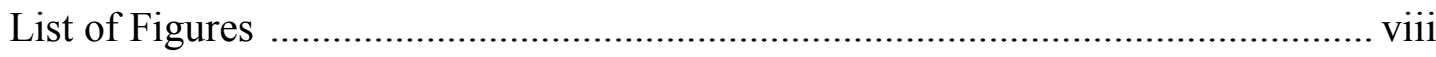

1. Chapter: Introduction .................................................................................................1

1.1. Our Sister Planet, Venus ..........................................................................

1.2. Research Objectives ..................................................................................

2. Chapter: Background Information ...............................................................9

2.1. Venus' Geologic and Volcanic History ......................................................

2.2. Tectono-Magmatic Structures on Venus ……………................................ 10

2.2.1. Volcanic Edifices ............................................................................11

2.2.2. Graben-Fissure Systems .............................................................13

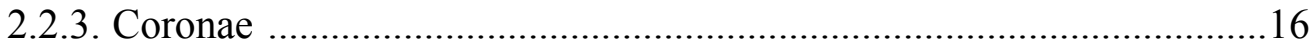

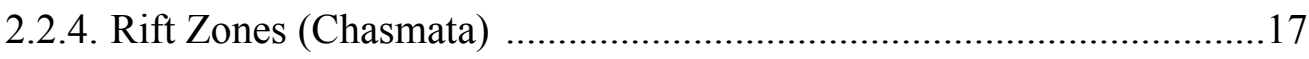

2.2.4.1. Chasmata of the BAT Region ..................................................19

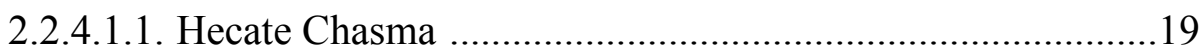

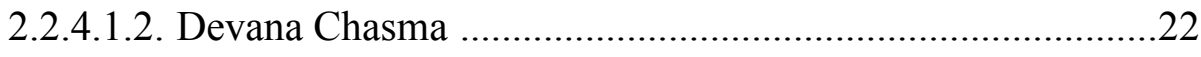

2.2.4.1.3. Parga Chasma ………………………………………..........23

3. Chapter: Methodology ………….........................................................................24

3.1. Magellan Images Used ........................................................................24

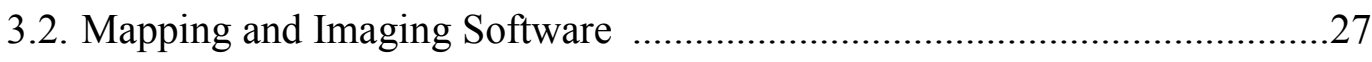

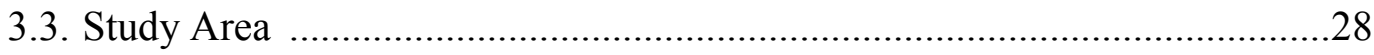

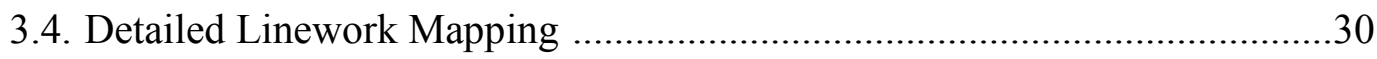

4. Chapter: Tectono-Magmatic History of Study Area ..........................................33

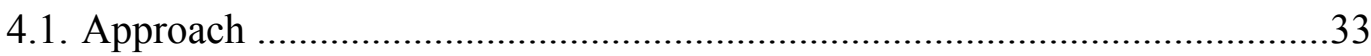

4.2. Overview of Tectono-Magmatic Structures in the Study Area ......................34

4.2.1. Extensional Lineaments Interpreted as Graben-Fissures .......................34

4.2.2. Extensional Lineaments Interpreted as Rift Faults ..............................39

4.2.3. Descriptions of Most Significant Graben-Fissure Systems ..................40

4.2.3.1. Systems R04, R09, R20: Ts'an Nu Mons ..................................41

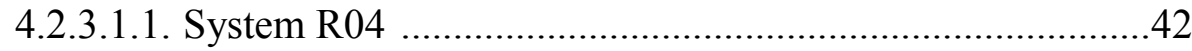

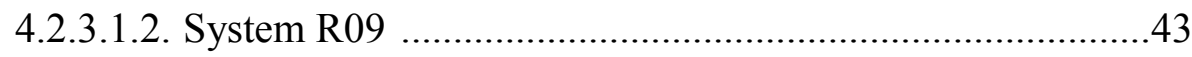

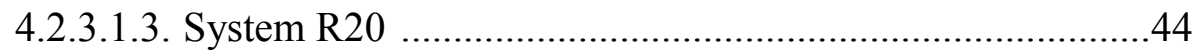


4.2.3.2. Systems R03, R18, L05: Obiemi Corona ……………...............4

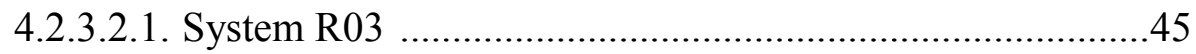

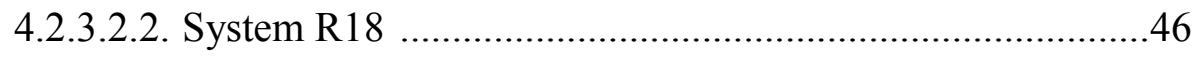

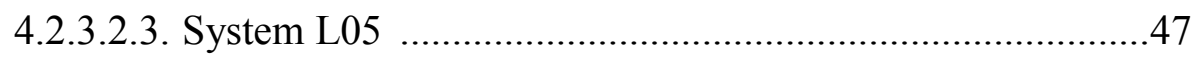

4.2.3.3. System R01 and Xmukane Corona ............................................47

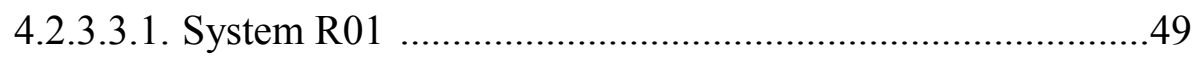

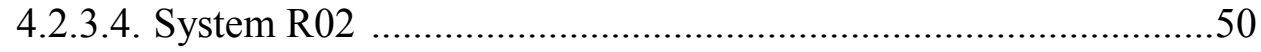

4.2.3.5. Systems R07, R11, R15, R23, R24, L09, L11 ……………......51

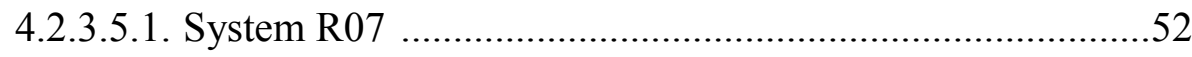

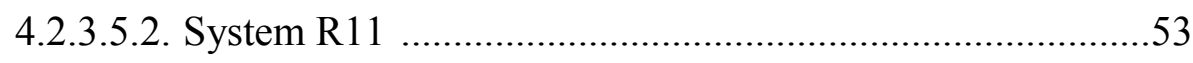

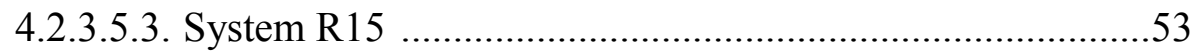

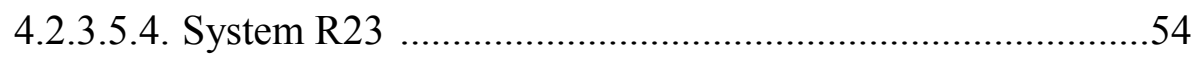

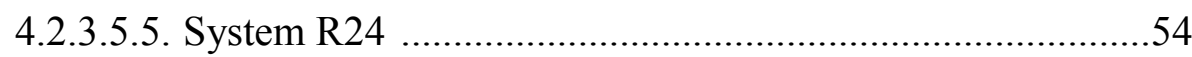

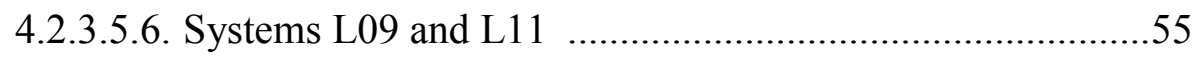

4.2.3.6. System R17 and Chuku Corona ………………........................56

4.2.3.7. Systems R05, R06, R12, R13, R22, L08: Kulimina Corona ......57

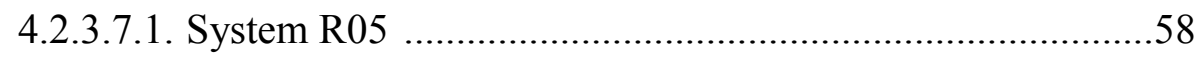

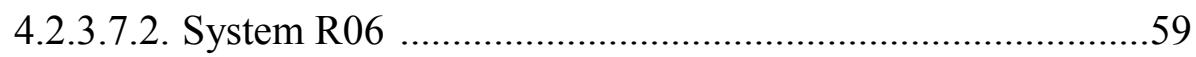

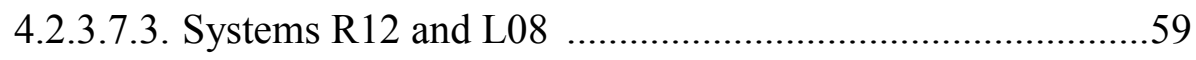

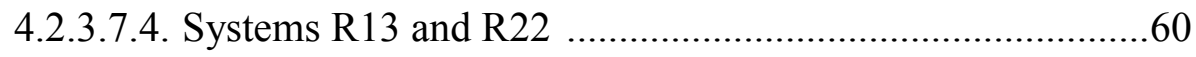

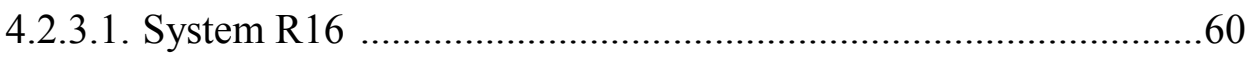

4.2.3.2. System L07 and Gertjon Corona ……………….......................62

4.2.3.3. System R25 and Otohime Tholus ………………......................63

4.2.4. System Size Distribution throughout the Study Area ............................64

4.2.5. Topographic Variations throughout the Study Area ............................65

4.3. Relative Chronology of Tectono-Magmatic Events ......................................66

4.4. Implications of the Relative Chronology .....................................................72

5. Chapter: Relationship between Rifting and Magmatic Centres .....................74

5.1. Regional and Local Rifting in the Study Area ...........................................74

5.2. BAT Region Rift Systems as Collections of Local Rifting ............................8 80

5.3. Terrestrial Analogue to Hecate and Parga Chasmata ....................................85

6. Chapter: Conclusions .........................................................................................90

7. References ......................................................................................................................93 


\section{List of Tables}

Table 4.1. Properties of Radiating Graben-Fissure Systems ..................................36

Table 4.2. Properties of Linear Graben-Fissure Systems .....................................37

Table 4.3. Properties of Circumferential Graben-Fissure Systems ...........................37

Table 4.4. Summary of Observed Cross-Cutting Relationships .............................69

Table 5.1. Local Rift Segments Catalogued in the Study Area ...............................77

Table 5.2. Local Rift Segment Groups along Hecate Chasma ..............................84

Table 5.3. Local Rift Segment Groups along Parga Chasma ...................................84 


\section{List of Figures}

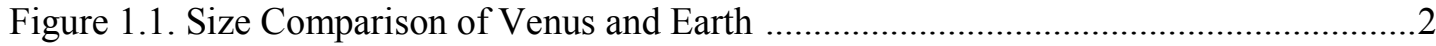

Figure 1.2. True and False Colour Radar Images of Venus .................................................4

Figure 1.3. Magellan SAR and Topography Image of the BAT Region ..............................6

Figure 2.1. Three-Dimensional Perspective View of Ma'at Mons on Venus ..........................12

Figure 2.2. Lateral Emplacement of Dykes (Schematic) ..................................................... 14

Figure 2.3. Surface Deformation from Underlying Dykes (Schematic) .................................14

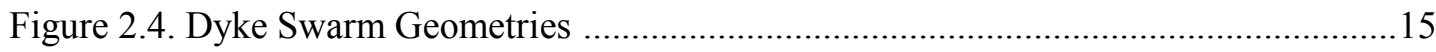

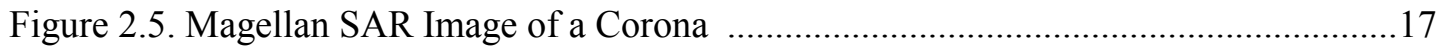

Figure 2.6. Magellan SAR Image of a Rift Zone (Chasmata) ...............................................18

Figure 2.7. Chasmata Linked to BAT Region Volcanic Rises ............................................20

Figure 2.8. Hecate Chasma Rift Segments and Coronae ...................................................21

Figure 2.9. Devana Chasma Rift Segments and Coronae ..................................................22

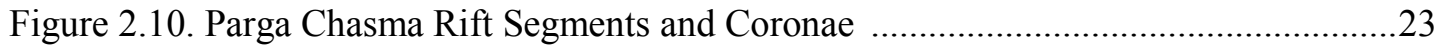

Figure 3.1. Magellan Spacecraft and SAR Imaging Schematics ......................................25

Figure 3.2. Magellan Topography and Meter Scale Slope Images ....................................26

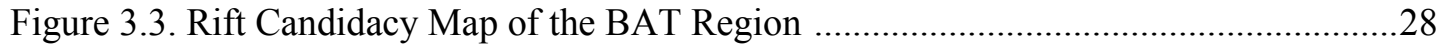

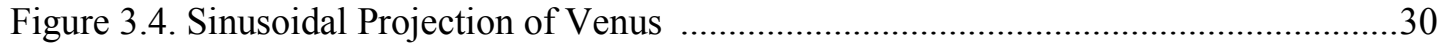

Figure 3.5. SAR Imaging Parallel vs. Perpendicular Lineament Orientations ......................31

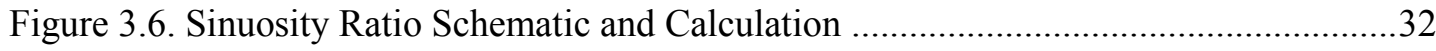

Figure 4.1. Distribution of Graben-Fissure Systems in the Study Area ................................35

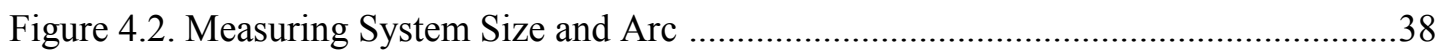

Figure 4.3. Distribution of Rift-Related Lineaments in the Study Area ...............................39

Figure 4.4. Designated Locations for Subsequent Figures $(4.5-4.14)$.................................40

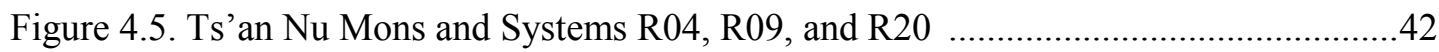

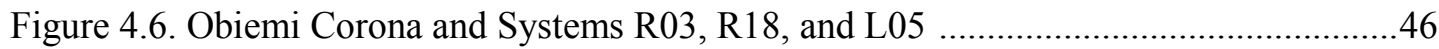


Figure 4.7. Xmukane Corona and Systems R01, R02, R04, R07, R14, R19, and R23 .........48

Figure 4.8. System R02 and Systems R01, R16, R26, and L01 .......................................51

Figure 4.9. System R07 and Systems R11, R15, R23, R24, L09, and L11 …......................52

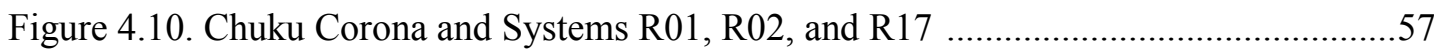

Figure 4.11. Kulimina Corona and Systems R05, R06, R12, R13, R22, and L08 ................58

Figure 4.12. System R16 and System R02, R06, R13, L02, and L10 ...............................61

Figure 4.13. Gertjon Corona and Systems R03, R04, R18, and L07 .................................63

Figure 4.14. Otohime Tholus and Systems R07, R15, and R25 .......................................64

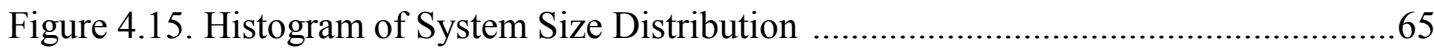

Figure 4.16. Relationship between System Size and Elevation ........................................66

Figure 4.17. Timeline of Tectono-Magmatic Events in the Study Area ...............................68

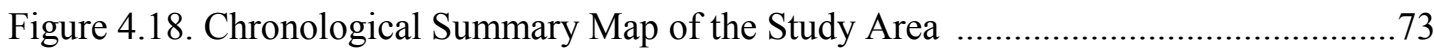

Figure 5.1. Magellan SAR Image of Regional Rifting in the Study Area .............................74

Figure 5.2. Magellan SAR Image of Local Rifting in the Study Area ................................75

Figure 5.3. Local Rift Faults and Segments Linked to Magmatic Centres ...........................76

Figure 5.4. Ts'an Nu Mons and Associated Local Rift Segments .......................................78

Figure 5.5. Xmukane Corona and Associated Local Rift Segments ...................................78

Figure 5.6. Kulimina Corona and Associated Local Rift Segments ....................................78

Figure 5.7. Unnamed Centres and Associated Local Rift Segments ...................................79

Figure 5.8. Local Rifting and Magmatic Centres Summary Map ......................................79

Figure 5.9. Hecate Chasma - Local Rifting and Magmatic Centres ...................................82

Figure 5.10. Parga Chasma - Local Rifting and Magmatic Centres ....................................83

Figure 5.11. Atlantic Rift System Pre-Spreading (Schematic) ...........................................86

Figure 5.12. Comparison between Atlantic Rift System and Hecate Chasma .......................87

Figure 5.13. Comparison between Atlantic Rift System and Parga Chasma .........................8 88 


\section{Chapter: Introduction}

\subsection{Our Sister Planet, Venus}

The celestial object which would later become known as the planet Venus was first observed with the naked eye by Babylonian astronomers as early as 3000 BCE. This planet, or "wandering star", would be visible either prior to sunrise or just after sunset, depending on the season and geographic location of the observer - leading ancient civilizations to name it as the "morning" and "evening" stars. Venus was known as the morning star Phosphoros (the "Bringer of Light") and the evening star Hesperos (the "star of the evening") to the ancient Greeks; and likewise known as Lucifer and Vesper to the ancient Romans. It was not until the sixth century BCE that the ancient Greeks identified it as a single planet and named it after their goddess of love and beauty, Aphrodite. The name it is known as today comes from the Roman goddess of love and beauty, Venus. Confirmation of Venus' planetary status, however, was not obtained until the year 1610 when Galileo Galilei observed the celestial object and detected that it had phases similar to those of the Moon. These observations also helped to support the emerging Copernican model of the Solar System (Waerden, 1974; Phillips and Hansen, 1994; Chaisson and McMillan, 2010; Taylor, 2014).

Venus is known as Earth's sister planet because they both have similar size, mass, and density (Figure 1.1). It is the second planet from the Sun, and third brightest celestial object in the sky, preceded only by the Moon and Sun. Venus' brightness is due to the high reflectivity of its thick atmosphere (Donahue and Russell, 1997; ESA, 2007a,b; Chaisson and McMillan, 2010). Similar to all other planets in our Solar System, Venus 
orbits the Sun in a counter clockwise, prograde motion. It is the only planet, however, which rotates in a clockwise fashion with respect to its axis of rotation. A well-accepted theory to explain this unusual retrograde rotation invokes a large impact during the early years of the Solar System. The impact would have hit the young planet with enough force to stop its original prograde rotation and initiate a slow retrograde rotation. Because of its slow rotation, an average Venus day (approximately 243 Earth days) is longer than an average Venus year (approximately 225 Earth days) (Chaisson and McMillan, 2010). A combination of slow rotational velocity and the lack of a convecting core is likely preventing the formation of a dynamo force within its core, thereby hindering the generation of a sustainable intrinsic magnetic field. A weak extrinsic magnetic field is present due to interactions between charged particles within its upper atmosphere and the incoming solar wind (ESA, 2007b; Chaisson and McMillan, 2010).
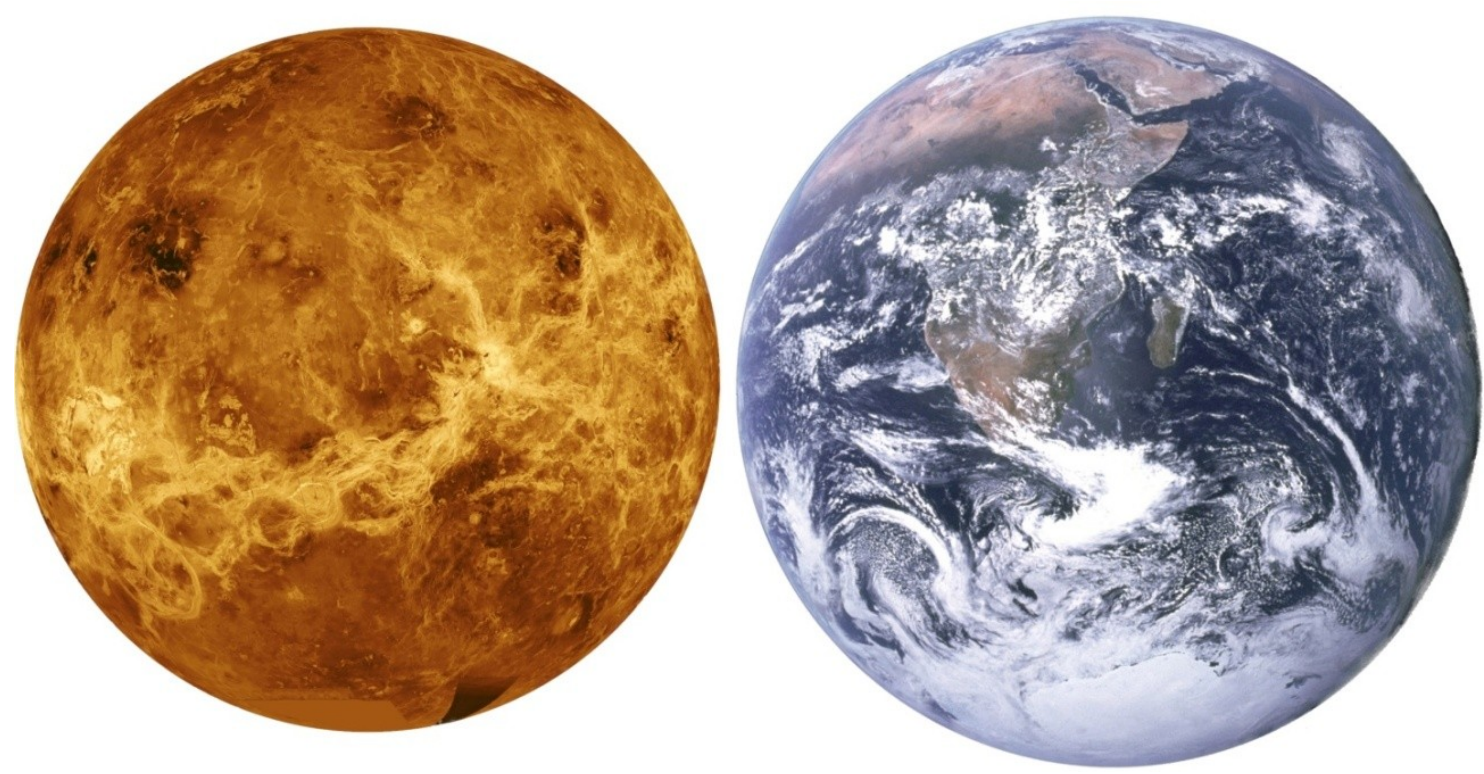

Figure 1.1. Size comparison of Venus and Earth. Venus (6051 km mean radius) shown on the left, imaged using the microwave spectrum; Earth (6371 km mean radius) on the right, imaged at the visible spectrum. 
Before the Soviet Union began the Venera project in the early 1960's, existing knowledge of Venus' surface conditions and topography remained purely speculative. Because of Venus' similarities to Earth with respect to bulk properties, scientists initially believed that their internal dynamic processes and geologic evolution would also be similar. Following early investigations by the space organizations of both the Soviet Union and the United States, significant differences between Venus and the Earth became clear. Venus exhibits average surface temperatures of $460^{\circ} \mathrm{C}$ and average near-surface atmospheric pressures of $9000 \mathrm{kPa}$. These values, much higher than the corresponding values for Earth, are largely due to Venus' thick atmosphere which is composed of large amounts of carbon dioxide $\left(\mathrm{CO}_{2}\right)$, with lesser quantities of nitrogen gas $\left(\mathrm{N}_{2}\right)$, hydrogen sulphide $\left(\mathrm{H}_{2} \mathrm{~S}\right)$, and low-lying cloud layers of sulphuric acid $\left(\mathrm{H}_{2} \mathrm{SO}_{4}\right)$ droplets. The abundance of these gases creates a runaway greenhouse effect by trapping nearly all of the Sun's incoming radiation, in addition to any internal heat dissipated from the planetary interior (Donahue and Russell, 1997; Chaisson and McMillan, 2010; Taylor, 2014).

In 1989, NASA launched the Magellan spacecraft to map the surface of Venus (Figure 1.2) at a resolution of 75-100 m/pixel using Synthetic Aperture Radar (SAR) imaging (Young, 1990; Saunders et al., 1990, 1992; Saunders and Pettengill, 1991). All basemap SAR and topography images presented herein were obtained by NASA's Magellan mission and were compiled by the US Geological Survey (USGS) Astrogeology Science Center (http://astrogeology.usgs.gov/), unless otherwise noted.

Magellan SAR images have provided scientists with detailed information regarding Venus' surface geology and have primarily been used to identify and map tectono- 
magmatic structures and volcanic units (Phillips and Hansen, 1994; Ivanov and Head, 2013). From these radar images, it was also noted that plate tectonics is not currently active on Venus due to the lack of any observable plate boundaries (Phillips and Hansen, 1994). Contrary to Earth, Venus is understood to be operating predominantly in a single plate, stagnant lid regime, with all magmatism occurring in intra-plate settings (Solomatov and Moresi, 1996; Nimmo and McKenzie, 1998; Ernst and Desnoyers, 2004). However, it has been proposed that Venus may have at one time operated in a mobile lid regime due to the fact that many highland mountainous areas would have required significant crustal convergence to be formed (Kiefer, 2013). SAR images are the primary source of data used herein to identify and map the tectono-magmatic structures of Venus, most importantly the radar-bright extensional lineaments associated with graben-fissure systems and rift zones.
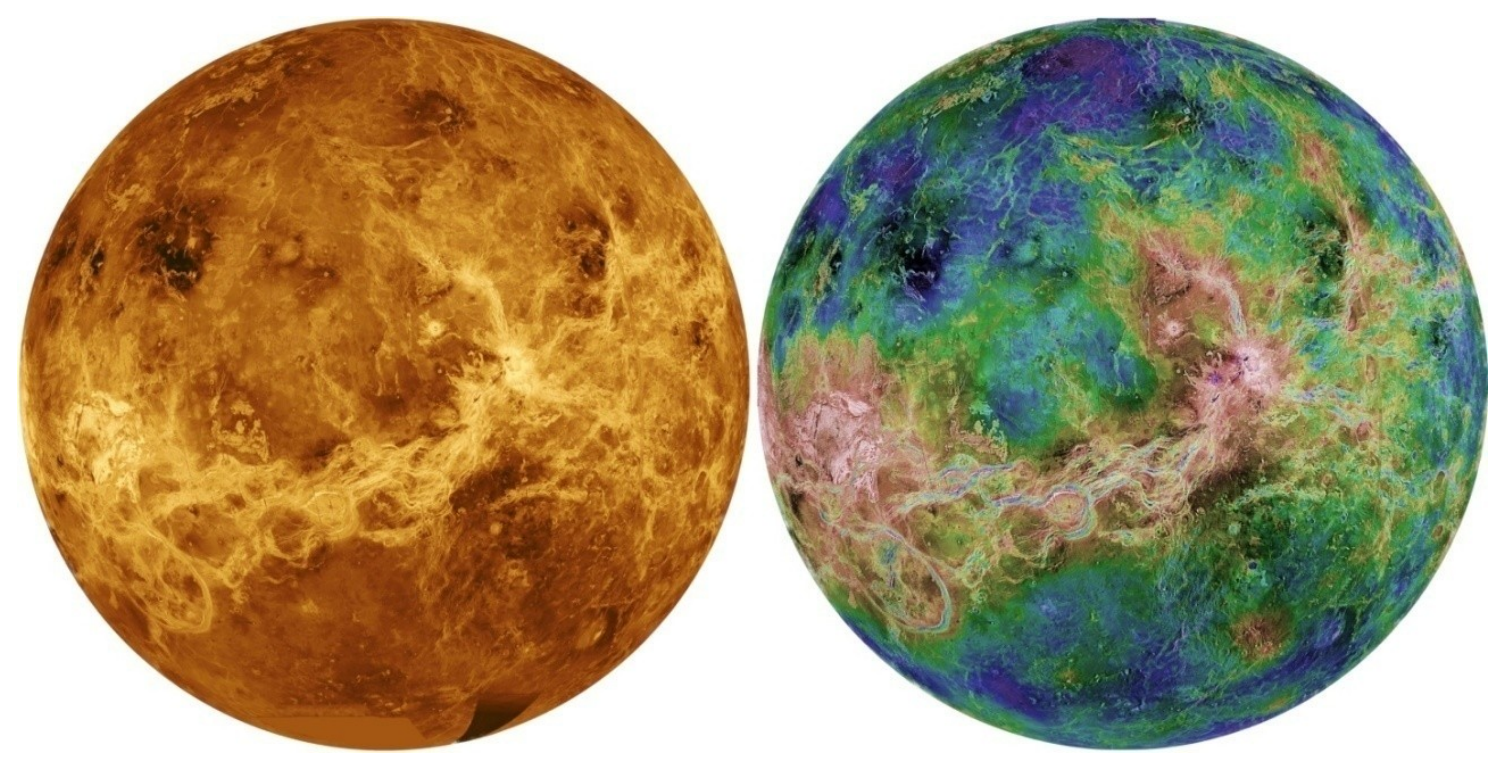

Figure 1.2. Radar images of Venus in true colour (left) and false colour (right). Both images display the same view of Venus for comparison with north at the top. False colour image uses varying shades of dark and light blue to indicate lower elevations, greens show middle elevations and reds to white display higher elevations. Source NASA/JPL. 


\subsection{Research Objectives}

On Venus, there exists a geologically complex area known as the Beta-Atla-Themis (BAT) region, located within the coordinates of $180^{\circ}-300^{\circ} \mathrm{E}$ and $50^{\circ} \mathrm{S}-50^{\circ} \mathrm{N}$ (Figure 1.3), where a diversity of tectono-magmatic structures have been preserved (Head et al., 1992; Squyres et al., 1992; Crumpler et al., 1993; Hamilton and Stofan, 1996). These structures include, but are not limited to, large volcanic rises (Stofan et al., 1995; Smrekar et al., 1997; Ivanov and Head, 2011, 2013), rift zones (often referred to as chasmata) (Hamilton and Stofan, 1996; Stofan et al., 2000; Martin and Stofan, 2004; Martin et al., 2007; Ivanov and Head, 2011, 2013; Graff et al., 2015), graben-fissure systems, believed to be underlain by mafic dyke swarms (Grosfils and Head, 1994; Ernst et al., 1995, 2001, 2003; Studd et al., 2010; Davey et al., 2013; Graff et al., 2015), pit crater chains (Davey et al., 2013; Sawford et al., 2015), and coronae (Stofan et al., 1991, 2000; Martin and Stofan, 2004; Martin et al., 2007).

The overarching goal of this study is to identify and map the extensional lineaments associated with major graben-fissure systems and rift zones, produced by internal tectonic and magmatic processes in the BAT region. The primary objectives are as follows: (1) resolving the relative chronology of tectono-magmatic events within a detailed study area along a section of the Parga Chasma rift system, a major component of the BAT region (Chapter 4); and (2) analyzing the genetic association between local rift segments and isolated magmatic centres (Chapter 5). 


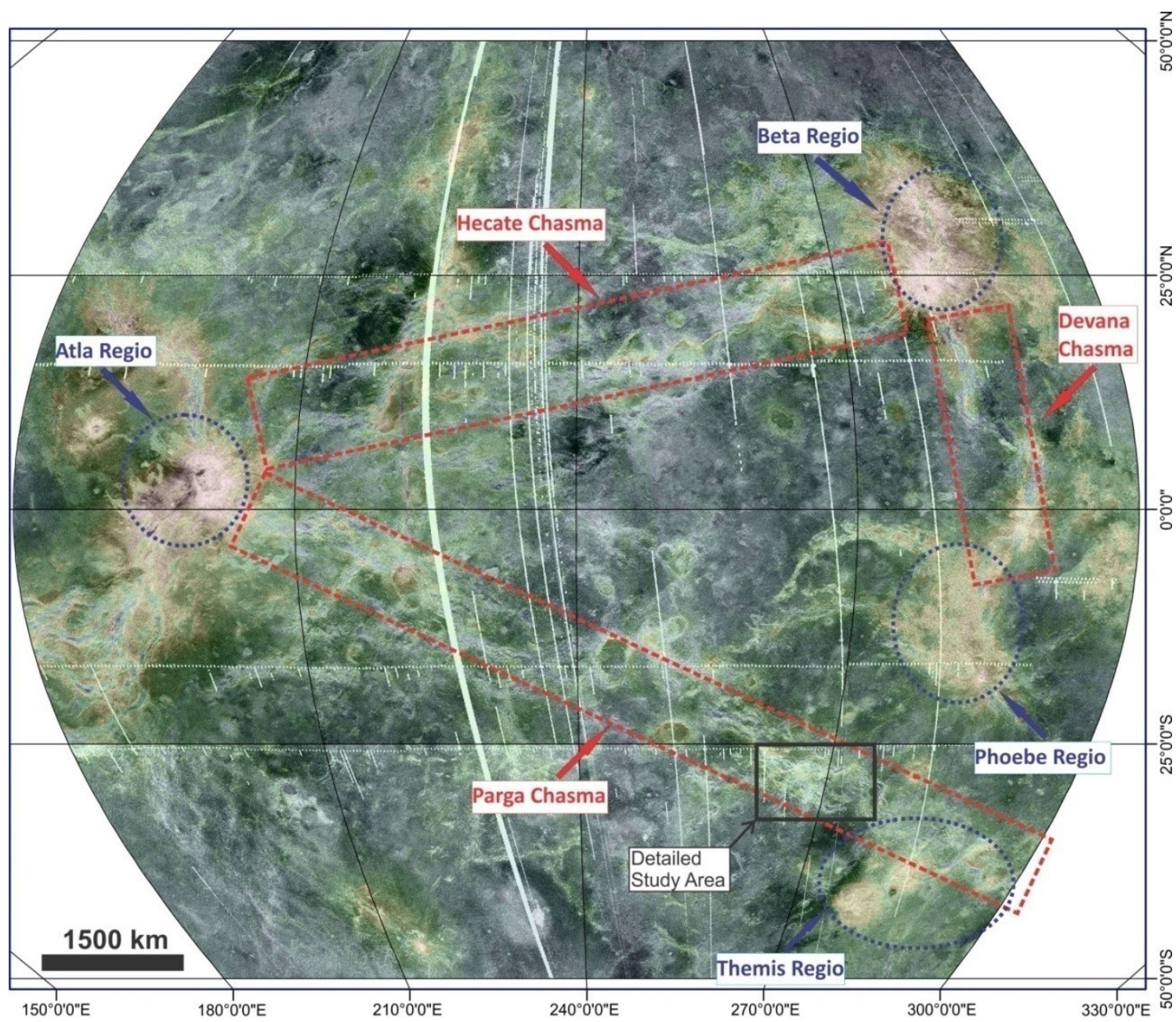

Figure 1.3. Magellan synthetic aperture radar (SAR) image of the BAT region, overlain by topography at $75 \%$ transparency. Lower elevations are displayed with faded shades of blue and green; higher elevations are displayed with faded shades of yellow and red. Identified are the prominent volcanic structures of Atla, Beta, Phoebe, and Themis Regiones, which are bounded by the three major rift systems Hecate, Devana, and Parga Chasmata. The location of the detailed study area is indicated by the black square. Basemap source: USGS.

To achieve the first objective (Chapter 4), a detailed study area has been selected in the southeast of the BAT region. Within both of the Helen Planitia and Themis Regio quadrangles, lies a complex section of the Parga Chasma rift system, located approximately within the coordinates of $260^{\circ}-275^{\circ} \mathrm{E}, 25^{\circ}-33^{\circ} \mathrm{S}$ (Figure 1.3). This location is host to a variety of tectono-magmatic structures, including many grabenfissure systems and rift segments; multiple coronae structures and large volcanoes; as well as young lava flows scattered against a radar-dark background of volcanic plains 
material. Of particular interest to this research are the following activities: detailed linework mapping of the radar-bright lineaments representing individual graben-fissures; grouping graben-fissures into separate systems of different geometries; performing crosscutting analyses to generate a relative chronology; and reconstructing the tectonomagmatic history of the study area. Radar-bright lineaments interpreted to represent local and regional rift faults associated with the regional extension of Parga Chasma were also mapped. From cross-cutting relationships, a relative chronological timeline for the formation of separate graben-fissure systems relative to the regional rifting along Parga Chasma has been created. The final detailed map of the study area will become part of the Venus Global Dyke Swarm Map project (Ernst et al., 2009; Studd et al., 2010a,b,c; Studd et al., 2011), with the ultimate goal of providing a comprehensive and detailed global map of all graben-fissure systems and dyke swarms on Venus.

The second objective (Chapter 5) concerns the differing morphology of the three major rift systems of the BAT region: Hecate, Devana, and Parga Chasmata. These rift systems form a regional enclosure between the prominent volcanic structures of the BAT region, terminating at the topographically high volcanic rises of Beta, Atla, and Phoebe Regiones, and the corona-dominated volcanic plateau of Themis Regio (Head et al., 1992; Crumpler et al., 1993; Martin et al., 2007). A quick observation of the regional morphologies of these three rift systems reveals that each exhibits different levels of continuity between their respective loci of formation (i.e. large volcanic rises, such as Beta or Atla Regio). In particular, Parga Chasma is significantly more discontinuous than Hecate and Devana Chasmata, and contains an abundance of coronae within close proximity to several individual rift segments. To explain these observations I introduce 
the hypothesis that Parga Chasma is predominantly developed as a series of local events of triple-junction style rifting from isolated magmatic centres (i.e. coronae, large volcanoes, and sources of radiating and/or circumferential graben-fissure systems). In addition to the detailed mapping in the study area (Section 4.2), I also examine Parga and Hecate Chasmata at a regional scale to further observe the relationship between isolated magmatic centres and local rift segments (Section 5.2). This rifting model is also applied to the Atlantic Rift System to serve as a terrestrial analogue to the rift system morphology observed on Venus (Section 5.3). 


\section{Chapter: Background Information}

\subsection{Venus' Geological History}

Venus, like other terrestrial planets and planetary bodies, experiences some form of mantle circulation from internal heat dissipation, resulting in large-scale magmatism, volcanism, and tectonic deformation (Turcotte, 1995; Ivanov and Head, 2013). Before the Magellan mission, preconceptions about Venus' internal processes were split between an Earth-like plate tectonics model resulting from whole mantle convection, versus global heat loss dominated by a combination of lithospheric conduction, recycling, thermal thinning, and volcanism (Kaula and Phillips, 1981; Solomon and Head, 1982; Grimm and Solomon, 1987, 1989; Head and Crumpler, 1990). Following the Magellan mission, Venus was understood to have the appropriate size, and compositional and gravitational potentials that would support long-lasting volcanism from both convection and advection (Ivanov and Head, 2013). However, with high mantle viscosity and the lack of observable plate tectonics on Venus, the currently most accepted model involves a global regime of stagnant lid convection, which inhibits transient motion of the thick lithosphere (Solomatov and Moresi, 1996; Nimmo and McKenzie, 1998). Venus may have also once operated in a mobile lid regime akin to Earth-like plate tectonics due to the fact that many highland and mountainous areas would have required significant crustal convergence from whole mantle convection to form. This model also supports the possibility that liquid water may have once flowed on the planetary surface as liquid water is a common agent that promotes the development of large-scale fault zones by lowering pore pressures and the coefficient of friction of rock materials (Kiefer, 2013). 
From crater counting, the age of Venus' surface is interpreted to be only $500-700$ Ma, supporting the well-accepted idea that Venus experiences global resurfacing events as a primary method of global heat loss (McKinnon et al., 1997; Ernst and Desnoyers, 2003; Ivanov and Head, 2013; Head, 2014). The exact style of global resurfacing is still under debate as to whether it occurs via catastrophic or steady-state processes. Catastrophic processes would involve a near-instantaneous episodic global overturn of the planetary crust, followed by short-lived global resurfacing from extreme volcanism and extensive lava flows (Turcotte, 1995; Herrick, 1999; Ivanov and Head, 2011, 2013). Steady-state resurfacing would involve Earth-like magmatic processes for which volcanic and tectonic events are randomly distributed in time and space (Phillips and Hansen, 1994; Hansen and Young, 2007). Regardless of how exactly Venus experienced resurfacing, scientists generally agree that fresh surface material is covering the majority of the planetary surface and destroyed all observable traces of older tectonic and volcanic structures, in addition to any impact craters that were emplaced earlier than $1 \mathrm{Ga}$ (Strom et al., 1992, 1994; Bindschadler, 1995; Ernst and Desnoyers, 2003; Studd et al, 2011).

\subsection{Venus' Tectono-Magmatic Structures}

Following the Magellan mission, many tectono-magmatic structures on Venus have been readily observed and studied from the analysis of SAR images (Young, 1990; Head et al., 1992; Phillips and Hansen, 1994). These structures include, but are not limited to: large volcanoes and volcanic rises; graben-fissure systems and rift zones created as a result of local and regional extensional deformation; lava flooded plains material featuring clusters of shield volcanoes; densely packed extensional lineations, and contractional groove belt structures; coronae; pit crater chains; and major highland 
mountain belts and heavily deformed tessera terrain - interpreted as the oldest units on Venus' surface (Head et al., 1992; Grosfils and Head, 1994a; Phillips and Hansen, 1994; Ernst et al., 2001, 2003; Martin et al., 2007; Ivanov and Head, 2011, 2013). Understanding the possible genetic associations between major volcanic edifices, grabenfissure systems, coronae, and rift zones are most relevant to this research and are discussed in detail below.

\subsubsection{Volcanic Edifices}

On Venus, mantle upwellings result in clusters of volcanic edifices ranging from small volcanoes $(<30 \mathrm{~km}$ in diameter) and shield plains, large volcanoes and coronae ( $>100 \mathrm{~km}$ diameters), to major volcanic rises (>1000 km diameters) (Masursky et al., 1980; McGill et al., 1981; Stofan and Head, 1990; Head et al., 1992; Stofan et al., 1992, 1995; Smrekar et al., 1997). Many volcanic edifices are associated with weakly to mildly tectonized terrains and are built up from extrusive volcanic material. Clusters of shield volcanoes are commonplace on Venus and characterize the presence of shield plains and shield cluster units (Bindschadler, 1995; Ivanov and Head, 2011, 2013). Flow units from these volcanoes produce numerous lava channels and extensive flow fields (often referred to as flucti) (McGill et al., 1981; Guest et al., 1992). Rising mantle plumes and superplumes form both individual volcanoes with diameters larger than $100 \mathrm{~km}$ (Figure 2.1) and major topographic rises dominated by one or more volcanic vents, such as the volcanic rises of Beta and Atla Regiones (Stofan et al., 1995; Smrekar et al., 1997; Ernst, 2014). These large volcanic edifices (as well as coronae) are also commonly the focal points of major radiating and circumferential graben-fissure systems, in addition to 
smaller local segments of rift zones (Head et al., 1992; Ernst et al., 1995; Martin et al., 2007).

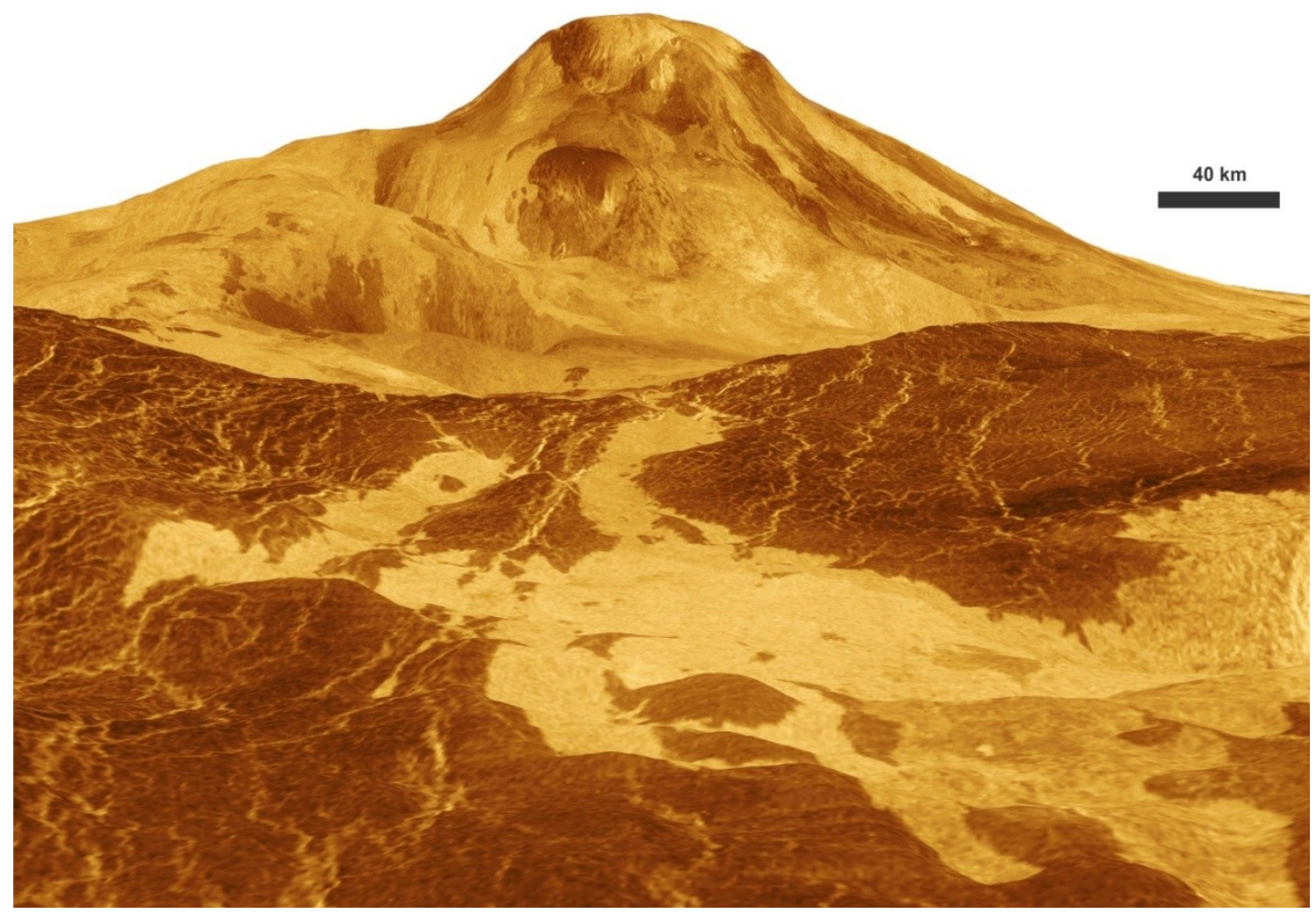

Figure 2.1. Three-dimensional perspective view of Ma'at Mons on Venus created by NASA Jet Propulsion Laboratory based on Magellan radar images. Ma'at Mons rises $5 \mathrm{~km}$ above the surrounding plains with a total elevation of $8 \mathrm{~km}$ above MPR. Vertical scale in image is exaggerated by a scale of 22.5; no exaggeration on the horizontal scale, shown to the right of the image. Source: NASA/JPL. 


\subsubsection{Graben-Fissure Systems}

Dyke swarms are interpreted to represent part of the plumbing system of flood basalts, allowing for the vertical and lateral motion of magma derived from partial melting of mantle plumes or diapirs that have ascended to the base of thinned lithosphere (Figure 2.2) (Ernst and Buchan, 1997a,b, 2001). Similarly on Venus, dyke swarms are described as laterally propagating subsurface mafic magma (Grosfils and Head, 1994a; Ernst et al., 1995b, 2001, 2003), while graben-fissures are interpreted to be the surficial expression of these underlying dykes (Figure 2.3). They are expressed as radar-bright lineaments on SAR images (Ernst et al., 2003; Studd et al., 2011; Graff et al., 2015) and commonly exhibit radiating, linear, and circumferential geometries (Figure 2.4), all of which can be readily observed on Venus (Ernst et al., 1995a,b, 2001, 2003; Ernst and Buchan, 2001; Studd et al., 2011; Grosfils et al., 2014). Multiple styles of graben-fissure systems are often found in spatial (and probable genetic) association with large volcanoes, coronae, and rift zones (Baer et al., 1994; Grosfils and Head, 1994a; Studd et al., 2011; Graff et al., 2015). 


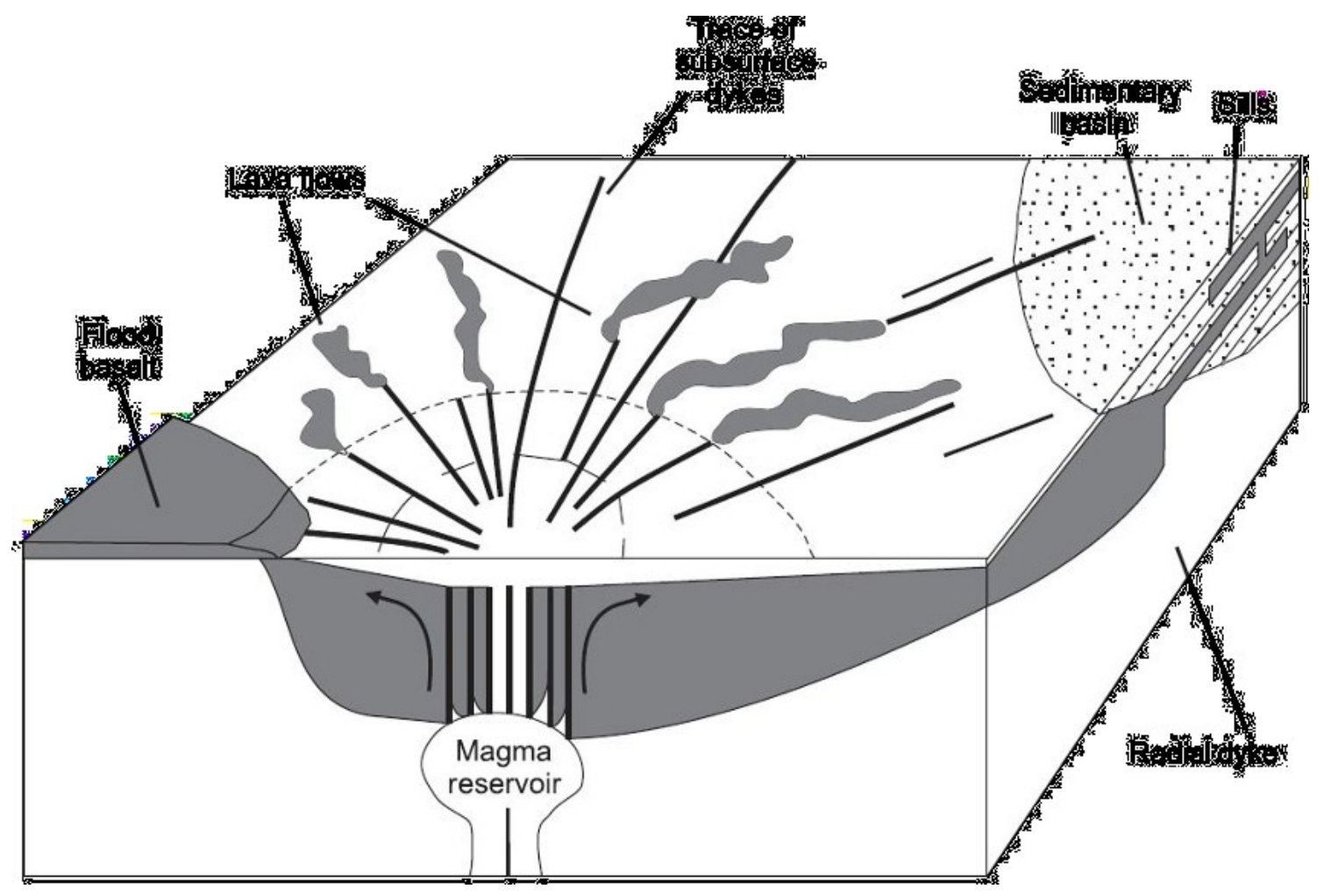

Figure 2.2. Lateral emplacement of dykes from a central magmatic upwelling. Radial subsurface dykes represent feeder systems to distal sills within sedimentary basins, and to surface lava flows and flood basalts. Source: Ernst, 2014.

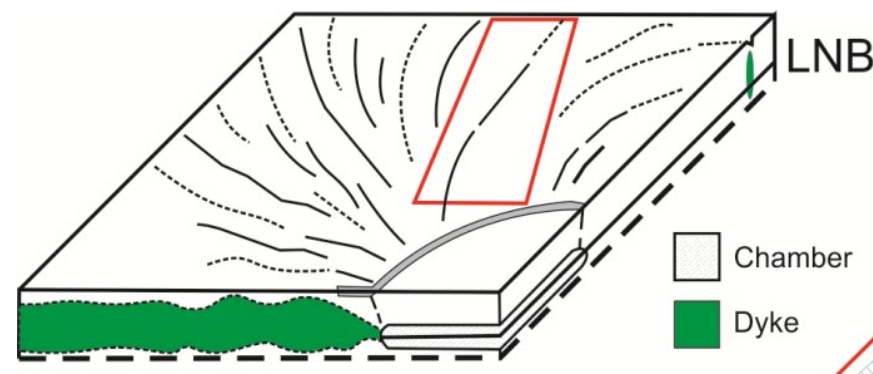

$\searrow$ Graben $\smile$ Fissure $\cdots$ Fracture

LNB = level of neutral buoyancy
RADIAL DYKE

\section{FRACTURE}

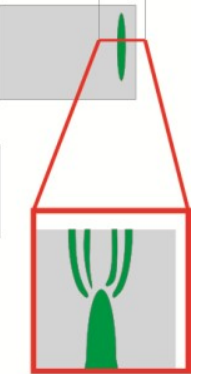

Figure 2.3. Cross-sectional view indicating how laterally propagating subsurface dykes influence surface deformation. Depending on both the proximity to the source and the volume of magma, surface deformation will respond by producing either full graben, fissures, or fractures. Source: Grosfils and Head, $1994 b$ with colours added (courtesy of S. Davey). 

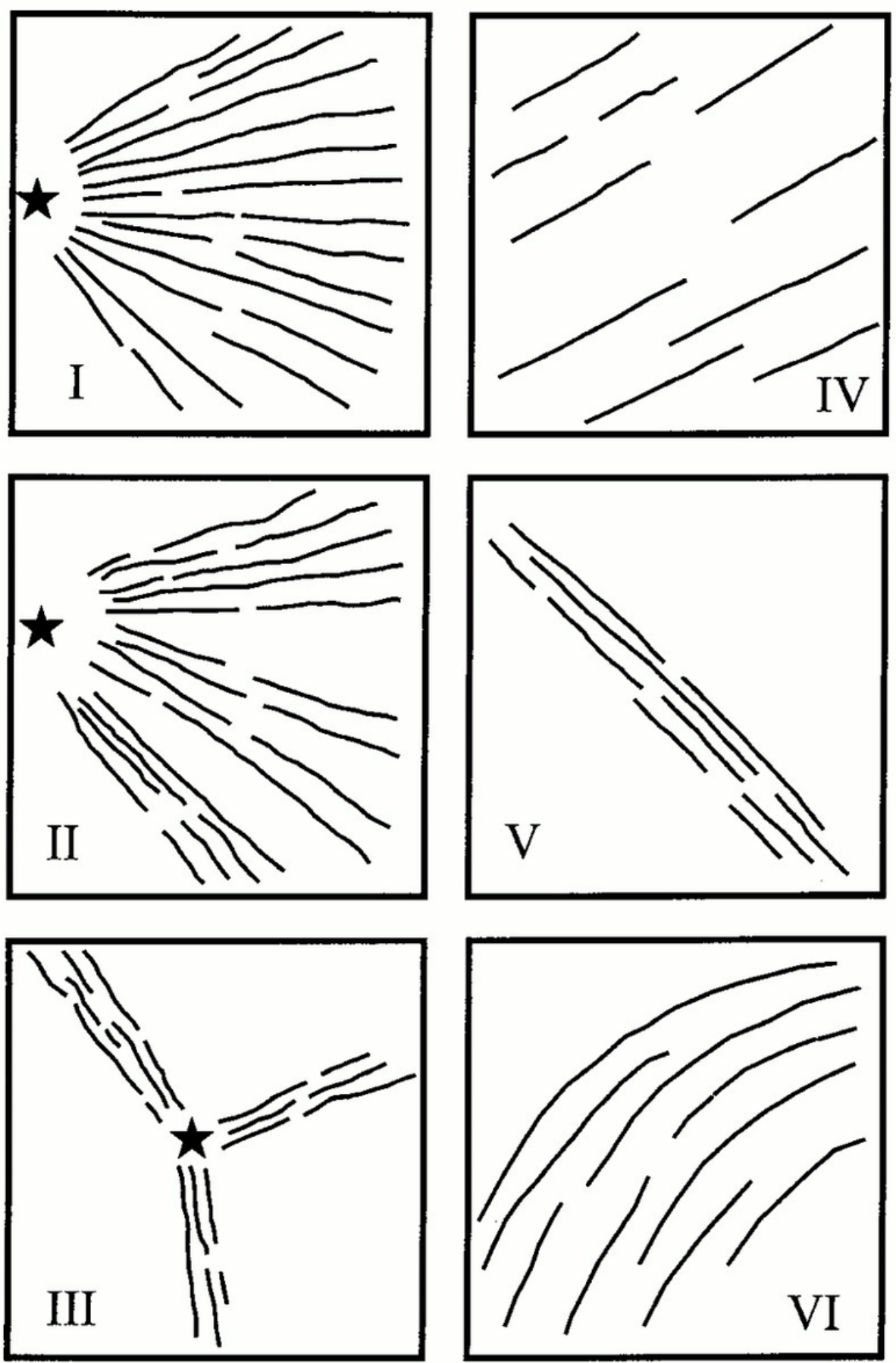

Figure 2.4. Characteristic geometries of dyke swarms or graben-fissure systems. I - continuous fanning pattern; II - fanning pattern divided into separate subswarms; III - subswarms of subparallel dykes radiating from a common point; IV - subparallel dykes over a broad area; V - subparallel dykes in a narrow zone; VI - arcuate pattern, often representing a section of a circumferential swarm. Stars indicate source centres defined by the convergence of the radial dyke pattern. Source: Ernst and Buchan, 2001. 


\subsubsection{Coronae}

Coronae are enigmatic volcanic formations initially believed to be unique to Venus but possible analogue structures (giant circumferential dyke swarms) have recently been discovered on Earth (Bethell et al., 2016; Buchan and Ernst, 2016). Coronae are quasicircular volcanic structures, often featuring a depressed centre and a raised exterior annulus of circumscribing fractures (Stofan et al., 1991; Stofan et al., 2000; Martin and Stofan, 2004; Dombard et al., 2007; Martin et al., 2007). Coronae are most commonly $200-500 \mathrm{~km}$ in diameter, although some can reach diameters larger than $1000 \mathrm{~km}$. The largest is Artemis Corona, with an outer rim diameter of $2400 \mathrm{~km}$ (Stofan et al., 1991; Hansen and Olive, 2010). Coronae are interpreted to result from mantle upwellings, such as plumes or diapirs, and frequently occur in zones of regional extensional deformation resulting in areas of thinned lithosphere (Stofan et al., 1991; Herrick, 1999). The radiating extensional fractures and those circumscribing corona annuli are interpreted to result from local lithospheric stresses generated either by the rising/collapsing mantle upwelling (Stofan et al., 1991; Grosfils and Head, 1994b), or from the intrusion of radiating and/or circumferential dyke swarms from the central magmatic source (Ernst et al., 2003, 2007; Bethell et al., 2016; Buchan and Ernst, 2016). 


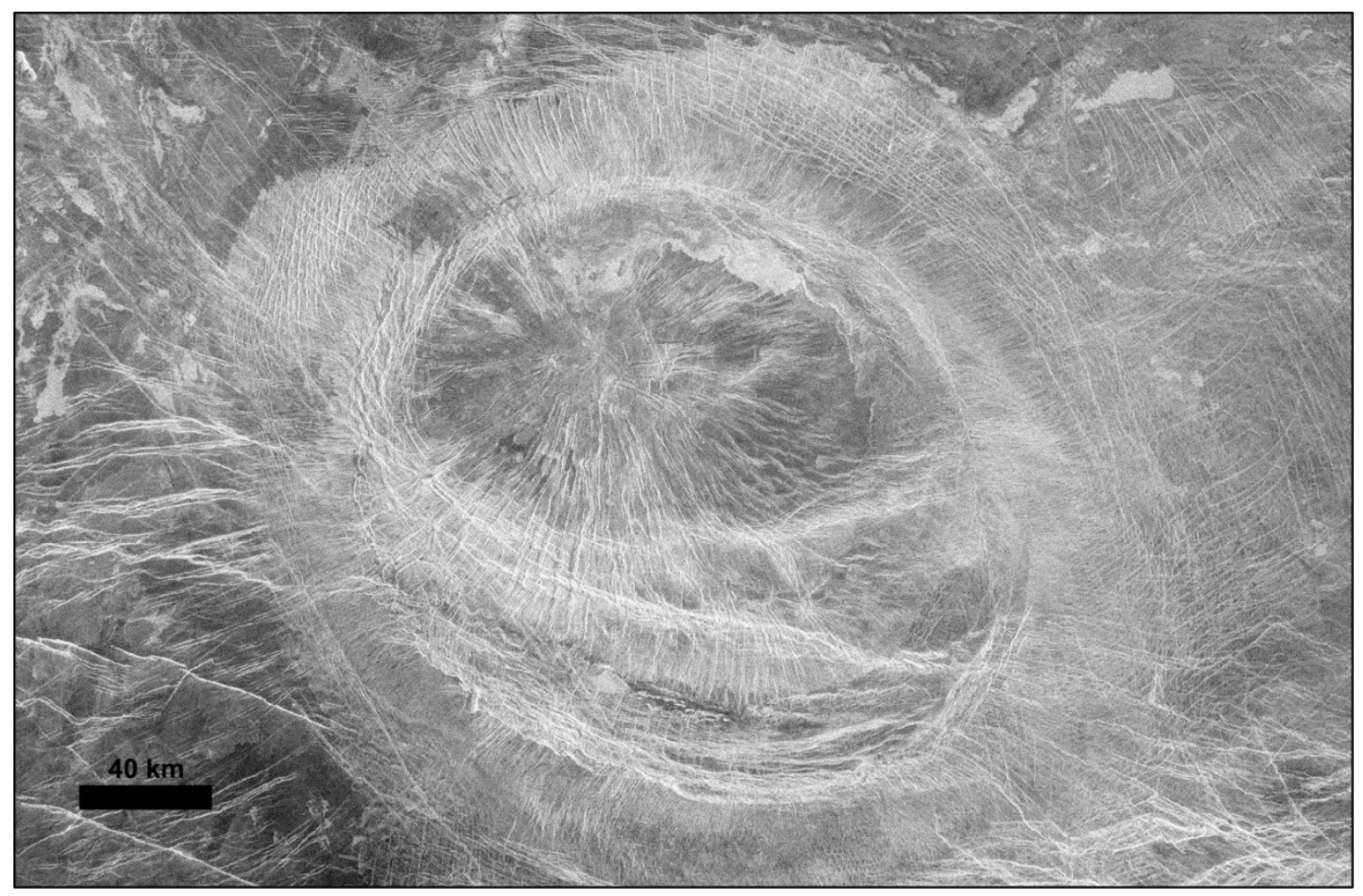

Figure 2.5. Magellan SAR image of Gashan-Ki Corona, centred at $243.5^{\circ} \mathrm{E}, 12^{\circ} \mathrm{N}$. The SAR image shows the extensional fractures circumscribing the corona rim, in addition to a major radiating dyke swarm originating from its centre. Source: USGS.

\subsubsection{Rift Zones (Chasmata)}

Rift zones on Venus generally display geomorphologies similar to those of rifts on other terrestrial planetary bodies in the Solar System. Based on the observations from Magellan SAR and altimetry data, chasmata (as catalogued by the International Astronomical Union - IAU) are large fracture zones characterized by a central valley bounded by elevated walls created as a result of normal faulting (Stofan et al., 2000; Martin and Stofan, 2004; Martin et al., 2007; Graff et al., 2015). Rift zones are also thought to be one of the youngest tectonic units in Venus' history, accounting for only 5$6 \%$ of surface area. They are composed of many broad and densely-packed extensional structures and commonly overprint underlying material unit morphologies (Ivanov and Head, 2011, 2013). On SAR images, individual rift faults appear as clusters of densely- 
packed, thicker, and more sinuous radar-bright lineaments than graben-fissures (Section

3.4) (Graff et al., 2014, 2015).

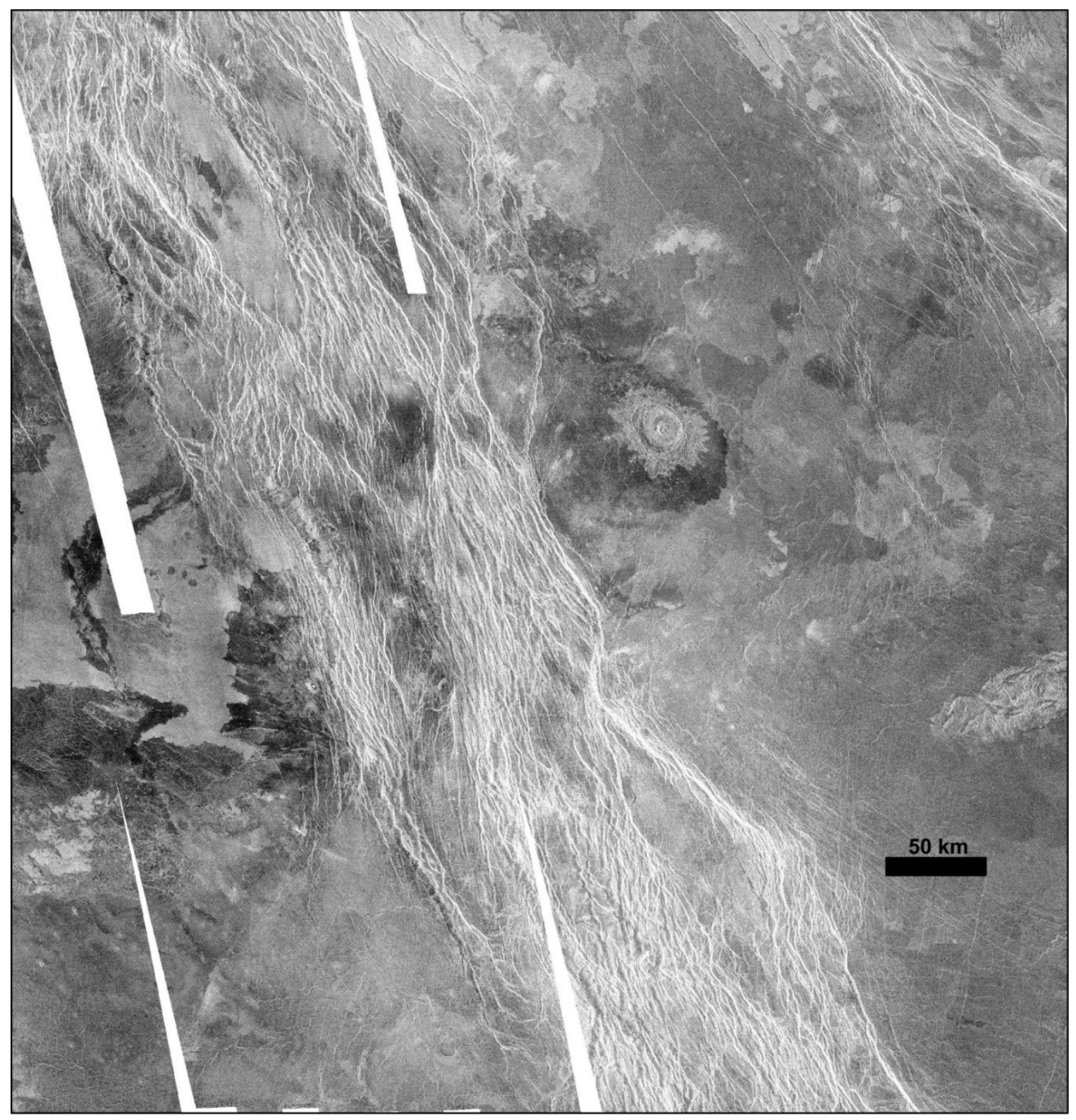

Figure 2.6. Magellan SAR image of the northern Devana Chasma rift system, centred at $282^{\circ} \mathrm{E}, 19^{\circ} \mathrm{N}$. Observable on the SAR image are the dense clustering of thick and sinuous radar-bright lineaments, interpreted as rift faults. Source: USGS. 


\subsubsection{Chasmata of the BAT Region}

The BAT region is defined by the prominent volcanic structures of the Beta, Atla, and Themis Regiones, which are enclosed by the major rift systems of Hecate, Devana, and Parga Chasmata. Each of these rift systems extend between two of these major structures, however, Devana Chasma terminates within the volcanic rise of Phoebe Regio to the north of Themis Regio. Atla, Beta, and Phoebe Regiones (Figure 2.7a-f) each host multiple local rift segments extending from their respective volcanic rises in triplejunction style rifting. Themis Regio (Figure $2.7 g-h$ ) however, is heavily dominated by an abundance of coronae and other smaller volcanic structures, with no primary magmatic centre at the southeast end of the Parga Chasma rift system.

\subsection{Hecate Chasma}

Hecate Chasma $\left(205-278^{\circ} \mathrm{E}, 3-29^{\circ} \mathrm{N}\right)$ is an $8,000 \mathrm{~km}$ long rift system that extends ENE-WSW between Atla and Beta Regiones (Figure 2.8). It is characterized as a discontinuous fracture and trough zone (Hamilton and Stofan, 1996), more so than Devana but significantly less compared to Parga. Similarly to Devana, Hecate Chasma contains prominent segments extending directly from the large volcanic rises of Atla and Beta Regiones, while the central portion of Hecate Chasma, distal from the ends of this rift system, are characterized by shorter rift segments that typically converge on local magmatic centres (often coronae). This style is similar to that observed along Parga Chasma (Section 2.2.4.1.3). 

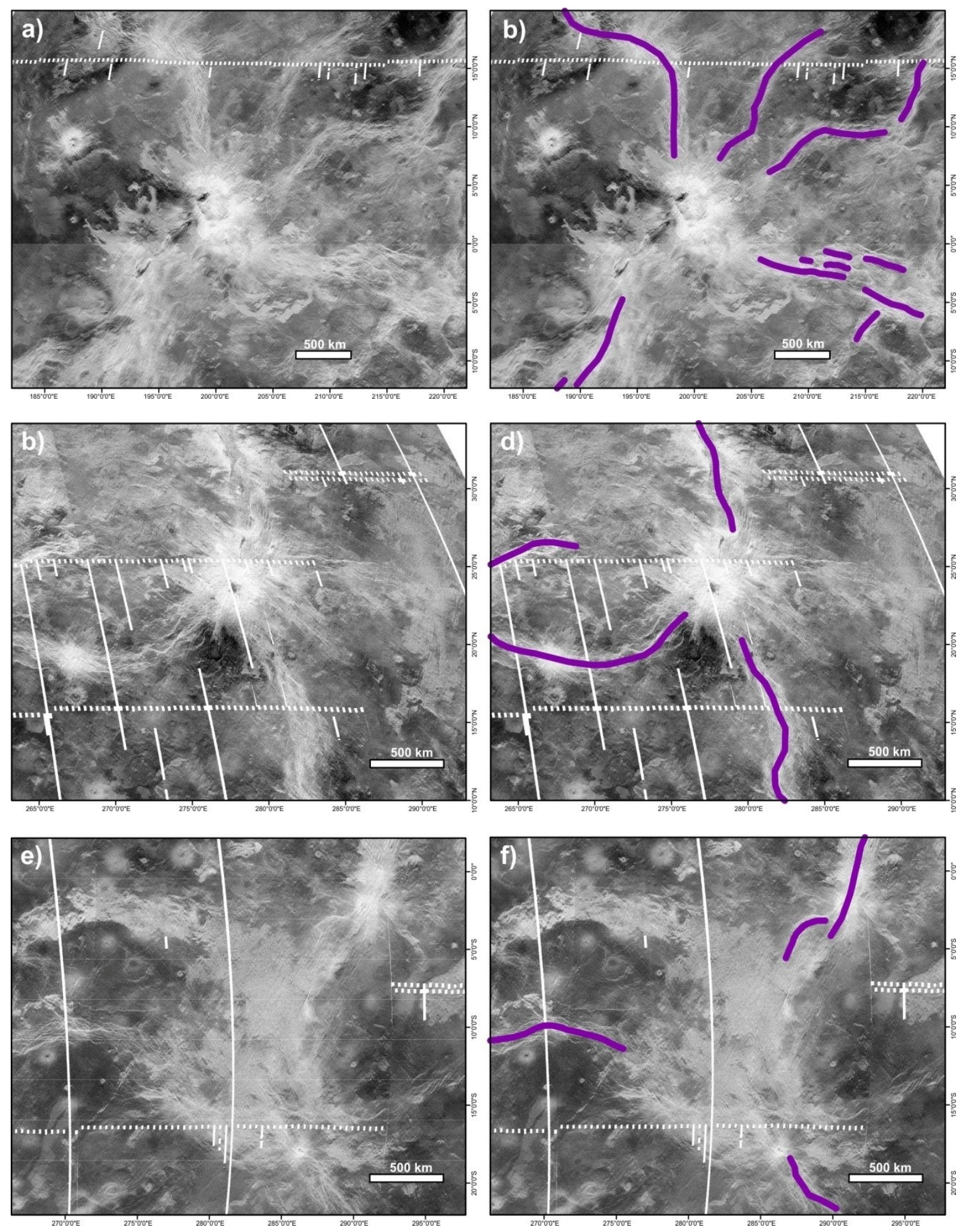

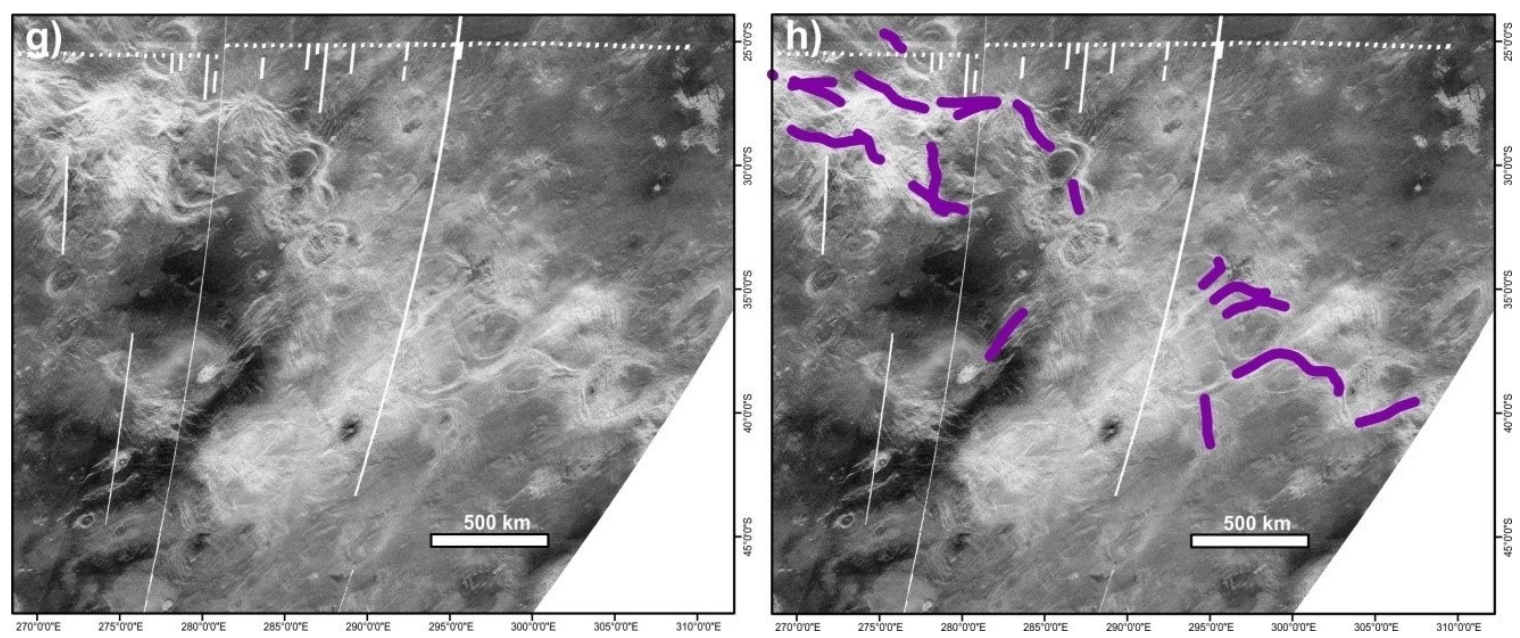

Figure 2.7. Magellan SAR images of (a, b) Atla Regio volcanic rise $\left(204^{\circ} \mathrm{E} / 2^{\circ} \mathrm{N}\right.$ centre); (c, d) Beta Regio volcanic rise $\left(280^{\circ} \mathrm{E} / 22^{\circ} \mathrm{N}\right.$ centre); (e, f) Phoebe Regio volcanic rise $\left(280^{\circ} \mathrm{E} / 9^{\circ} \mathrm{S}\right.$ centre); and $(\mathrm{g}, \mathrm{h})$ Themis Regio volcanic plateau $\left(281^{\circ} \mathrm{E} / 35^{\circ} \mathrm{S}\right.$ centre). Purple lines (b), (d), (f), and (h) denote the interpreted trend of individual rift segments focussed on their respective magmatic centres. Basemap source: USGS.

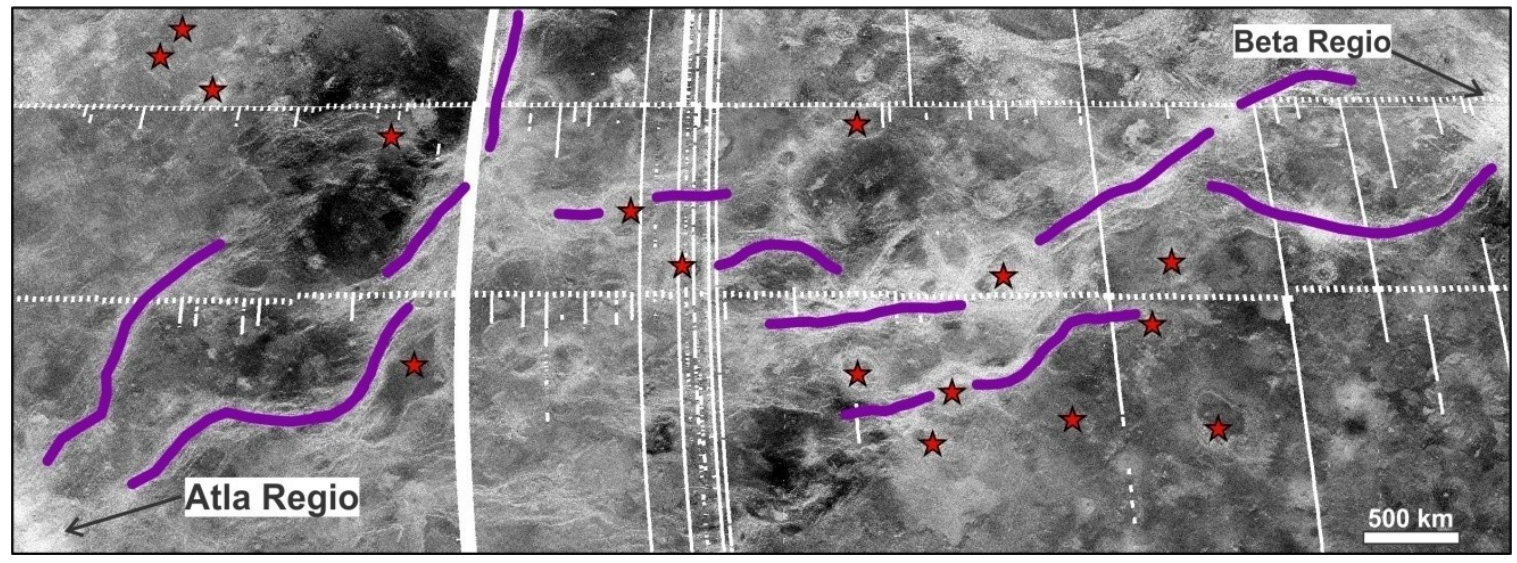

Figure 2.8. Magellan SAR image of Hecate Chasma, centred at $240^{\circ} \mathrm{E}, 16^{\circ} \mathrm{N}$. Purple lines denote interpreted individual rift segments. Red stars denote centres of IAU catalogued coronae. Basemap source: USGS. 


\subsection{Devana Chasma}

Devana Chasma $\left(280-290^{\circ} \mathrm{E},-4-21^{\circ} \mathrm{N}\right)$ is a $3,000 \mathrm{~km}$ long rift system that connects the large volcanic rises of Beta and Phoebe Regiones (Figure 2.9). This rift system exhibits a nearly continuous collection of densely clustered and near parallel rift faults, but with a clear left-lateral offset $(\sim 75 \mathrm{~km})$ at $7.5^{\circ} \mathrm{N}$. Because of this, Devana Chasma has been suggested to be composed of two separate rift segments, one segment extending southward from Beta Regio and the other extending northward from Phoebe Regio, and which meet up in the middle with a $\sim 75 \mathrm{~km}$ offset (Kiefer and Peterson, 2003; Kiefer and Swafford, 2004, 2006).

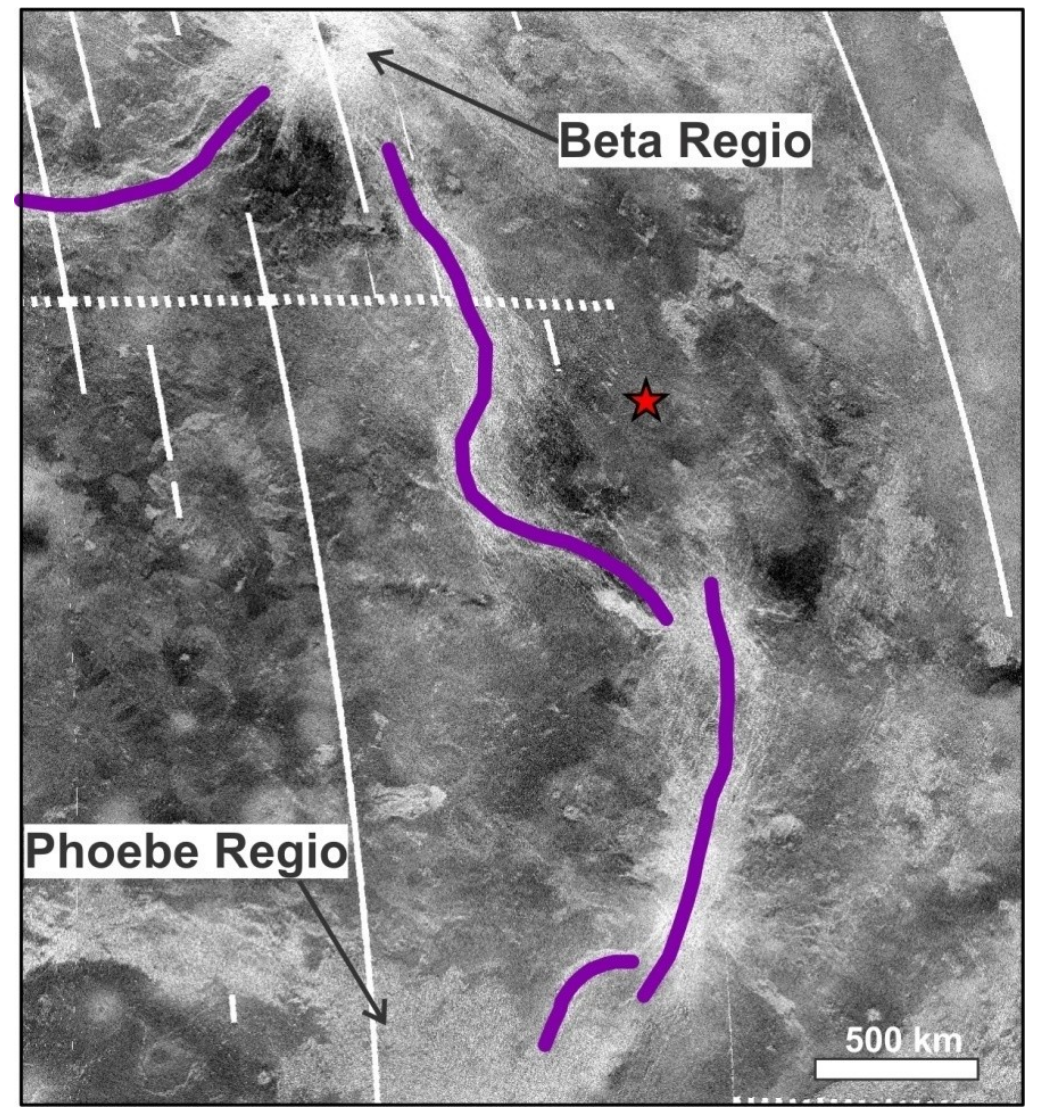

Figure 2.9. Magellan SAR image of Devana Chasma, centred at $282^{\circ} \mathrm{E}, 9^{\circ} \mathrm{N}$. Major volcanic structures are identified. Purple lines denote interpreted individual rift segments. Red stars denote centres of IAU catalogued coronae. Basemap source: USGS. 


\subsection{Parga Chasma}

Parga Chasma $\left(207^{\circ}-300^{\circ} \mathrm{E}, 0^{\circ}-40^{\circ} \mathrm{S}\right)$ is a $10,000 \mathrm{~km}$ long, NW-SE trending rift system extending between the volcanic rise of Atla Regio and the corona-dominated volcanic plateau of Themis Regio (Figure 2.10). It is characterized by discontinuous fracture and trough zones, containing up to fourteen branching segments between Atla and Themis Regiones (Stofan et al., 2000; Martin and Stofan, 2004; Martin et al., 2007). Within the Parga Chasma region, regional NE-SW extension has occurred (Section 4.2.2; Figure 4.3), interpreted to have resulted from the formation of the volcanic rise and plateau of Atla Regio and Themis Regio, respectively (Martin et al., 2007; Lopez and Hansen, 2008; Stofan and Brian, 2012). This extension caused regional rifting, resulting in crustal thinning that further allowed for subsequent mantle upwellings to occur throughout the weakened crust (Herrick, 1999) and form the many coronae, volcanoes, and graben-fissure systems observed throughout this region (Grosfils and Head, 1994a,b; Ernst et al., 2001; Martin et al., 2007).

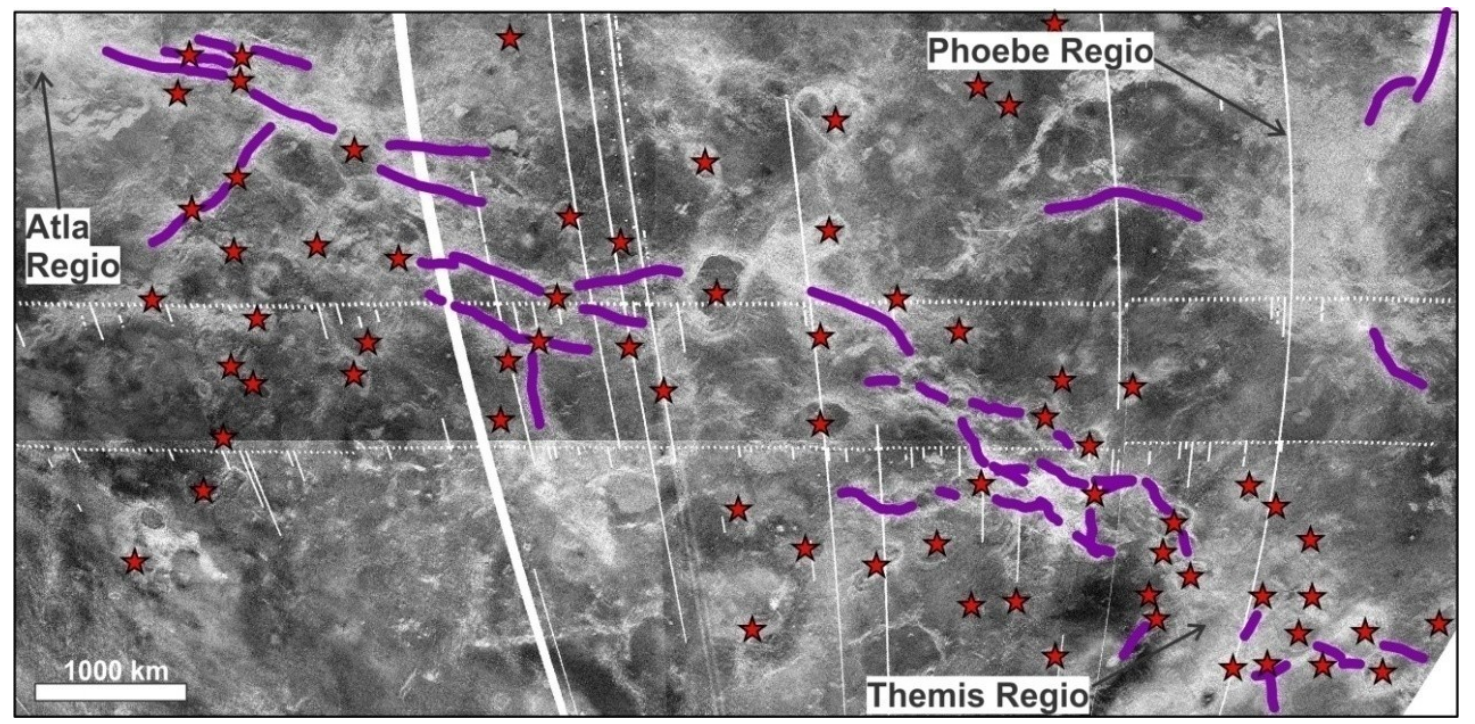

Figure 2.10. Magellan SAR image of Parga Chasma, centred at $245^{\circ} \mathrm{E}, 20^{\circ} \mathrm{S}$. Major volcanic structures are identified. Purple lines denote interpreted individual rift segments. Red stars denote centres of IAU catalogued coronae. Basemap source: USGS. 


\section{Chapter: Methodology}

\subsection{Magellan Images Used}

This research utilizes Magellan SAR, topography, and meter scale slope images to identify and map the tectono-magmatic structures of the study area in detail. Used at the highest resolution available $(75-100 \mathrm{~m} /$ pixel), the SAR images are the most useful dataset. SAR images are greyscale images that utilize pixel brightness to indicate the intensity of radar signal return, due to either surface roughness or the orientation of a structure relative to the incident radar pulse (Figure 3.1).

During the later stages of the Magellan mission, measurements were taken of Venus' surface elevation using radar altimetry. This information was then compiled into both topography and meter scale slope images (Figure 3.2) at a lower resolution of $3-5$ $\mathrm{km} /$ pixel. When analyzing large-scale areas, this altimetry data is particularly useful to identify vast zones of topographic lows - indicative of rift valleys - and to locate highland mountainous regions and elevated volcanic structures, such as large volcanoes and coronae. 


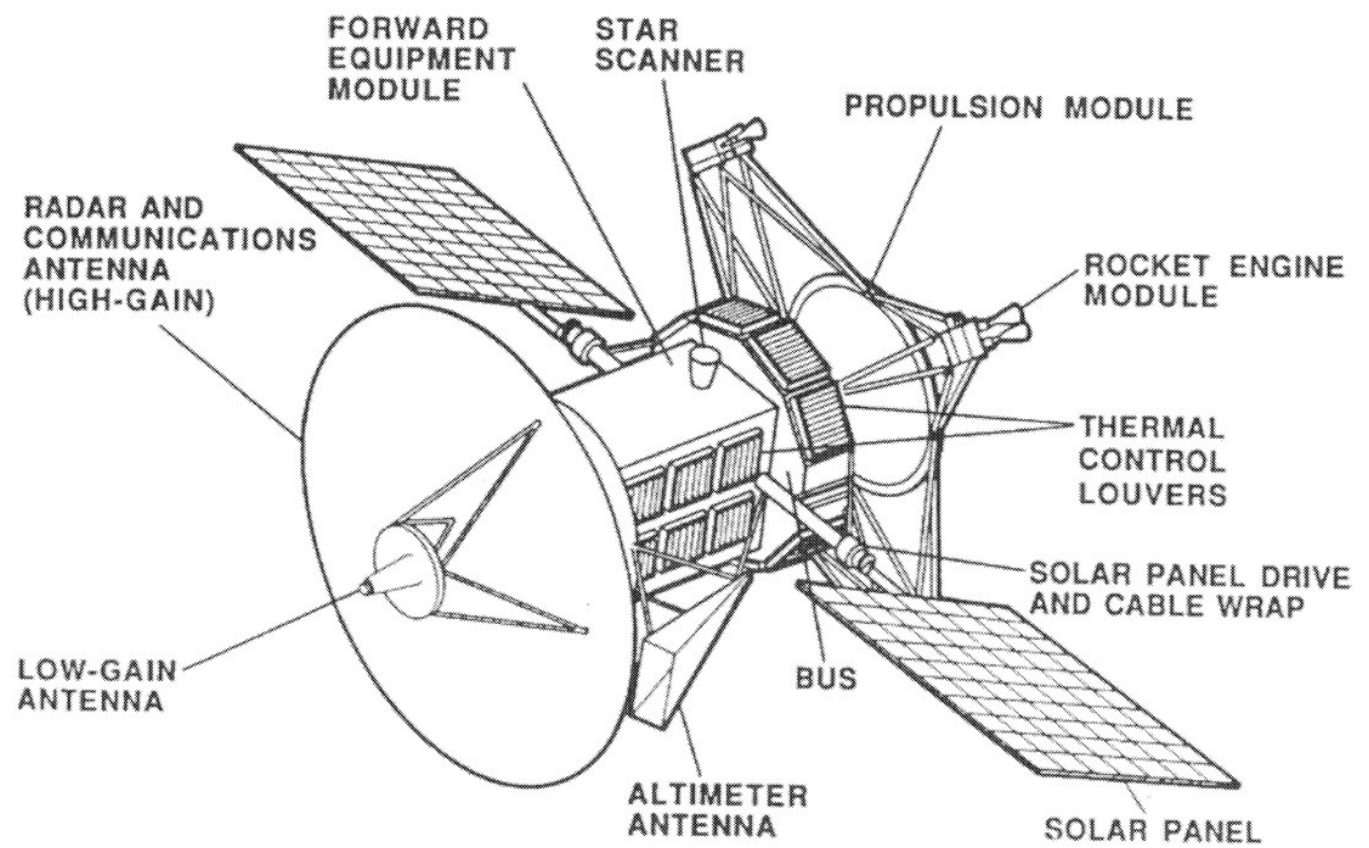

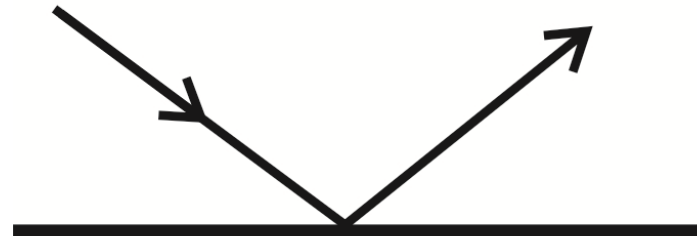

Smooth: Radar signal reflects away from spacecraft, no reflections detected by receiver; image appears dark.

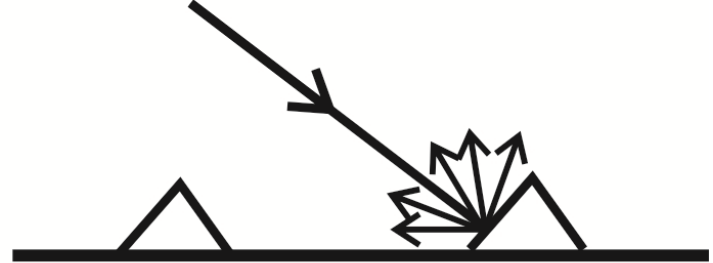

Rough: Radar signal scatters against rough or uneven surfaces, reflections detected by receiver; image appears bright.

Figure 3.1. (Top) Schematic of the Magellan spacecraft. Source: NASA/JPL. (Bottom) Schematic diagram representing how the emitted microwave radar pulses from Magellan were reflected on various surfaces. Modified from Figure 2 in Leung (2013). 

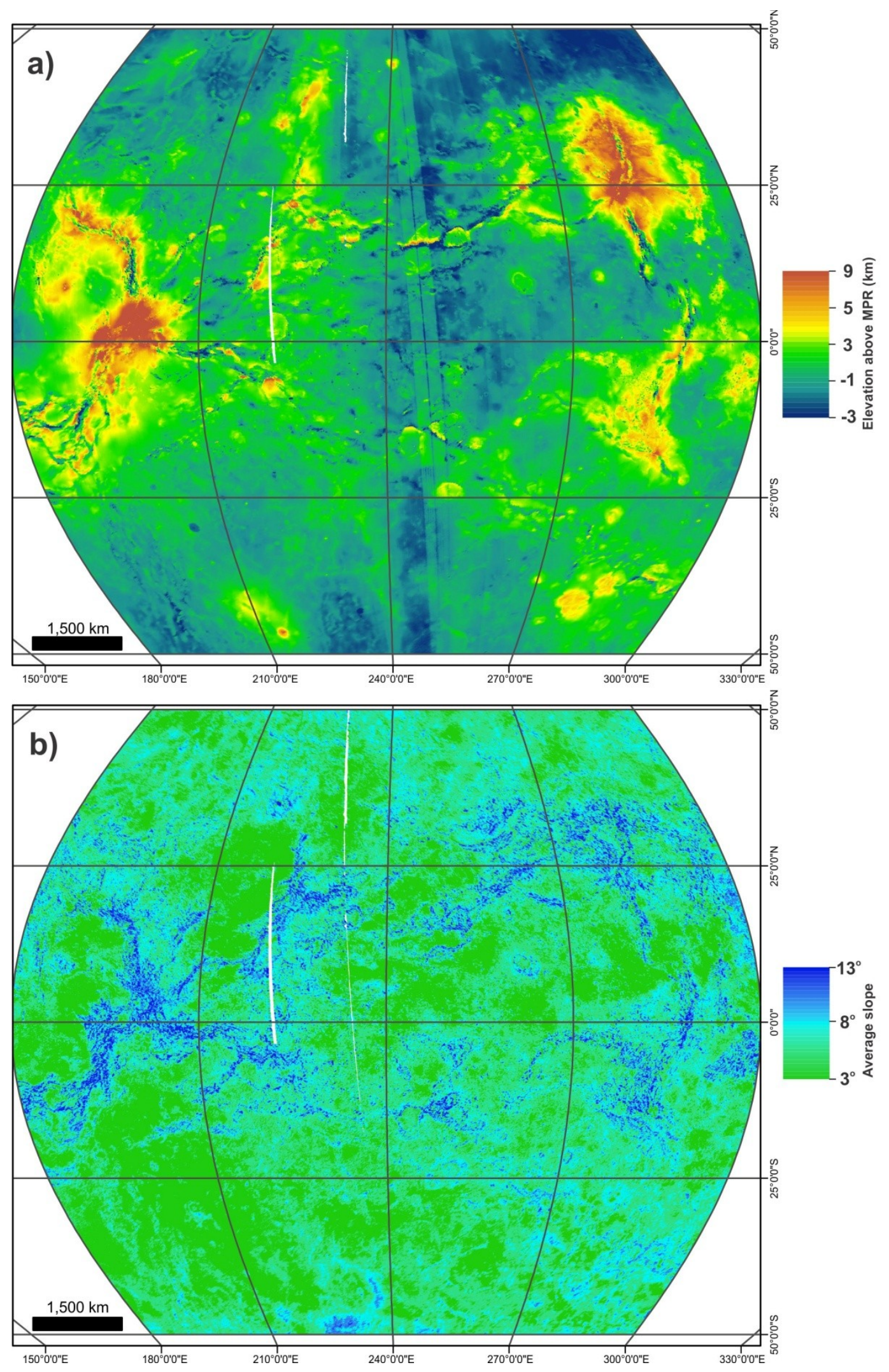

Figure 3.2. Magellan (a) topography and (b) meter scale slope images. Mean Planetary Radius (MPR) = $6051 \mathrm{~km}$. Source: USGS. 


\subsection{Mapping and Imaging Software}

This research was conducted primarily by using ArcGIS software, in particular the ArcMap and ArcCatalog programs (https://www.arcgis.com). All basemap images were imported and displayed in ArcMap 10.3, providing the framework for preliminary observations of large-scale structures and early reconnaissance mapping of a variety of tectono-magmatic structures throughout the southeastern BAT region. The ArcCatalog function allows for the creation of editable layers known as shapefiles, useful for tracing out the detailed radar-bright linework corresponding to tectono-magmatic structures, including graben-fissure systems, rift zones, coronae, and large volcanoes. Within ArcCatalog also lies the function to adjust the geographic coordinate systems of projected data, thereby ensuring all images were projected using the GCS (Global Coordinate System) Venus, as established following the Magellan mission (Davies et al., 1992).

Another function within ArcMap is the ArcToolbox, which is used for applying various edits and manipulations to the basemap images in order to satisfy the appropriate needs of the user during specific tasks. By using some of these specific functions, it was possible to automatically generate a resultant map layer that highlighted all candidate areas for hosting possible rift zones within the BAT region (Figure 3.3). This was done by manipulating and combining attributes from topography and slope datasets to highlight the locations of topographic lows and steep slopes, often indicative of zones of rifting (Graff et al., 2015).

Lastly, nearly all images and figures used for this research have been created and often modified using CorelDraw and Corel Photo-Paint software. These manipulations allow for the best possible presentation of figures for this research. 


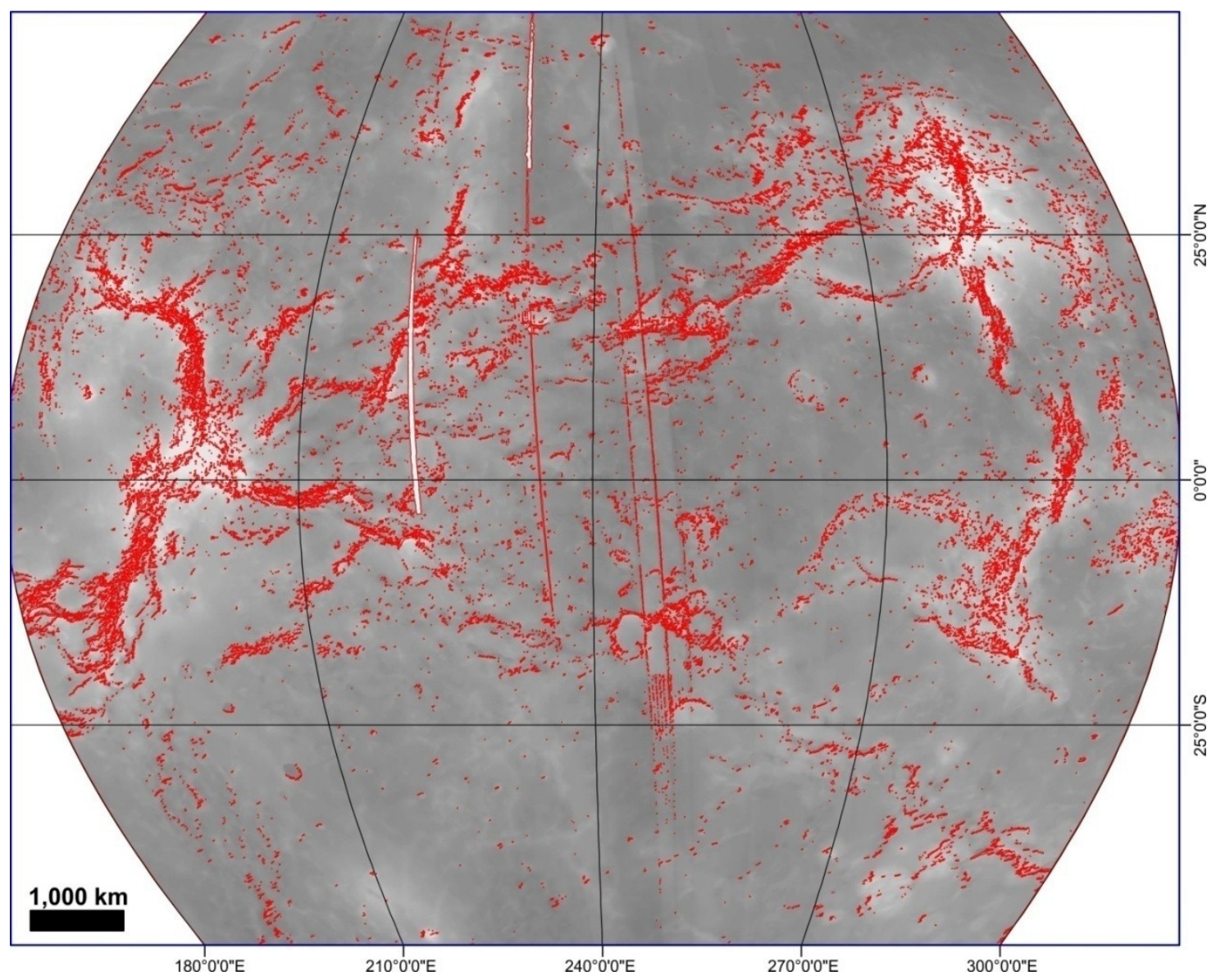

Figure 3.3. Topography map of the BAT region at 30\% transparency (source: USGS). Areas in red show the locations of major rift systems as automatically calculated using the ArcMap program. Modified from Figure 1 in Graff et al. (2015).

\subsection{Study Area}

The overarching goal of this research (Section 1.2) is to identify, map, and analyze the spatial and temporal relationships between rift faults, large volcanoes and coronae, and graben-fissure systems within the BAT region (Figure 1.3). Specifically, detailed linework mapping of the extensional lineaments associated with tectono-magmatic structures has been completed within a smaller study area located across both of the Helen Planitia and Themis Regio quadrangles (Figures 1.3 and 3.4). Mapping within this smaller area is particularly informative with regards to the first research objective (Section 1.2) as detailed linework and classification of individual graben-fissures into 
specific systems are necessary to interpret the relative chronology of magmatic events via analysis of cross-cutting relationships. This allows for temporal comparisons to be drawn between the emplacement of magmatic dyke swarms and the large-scale rifting of Parga Chasma. Parga Chasma (Figure 2.10) is a unique structure due to its discontinuous character between Atla and Themis Regiones, in addition to it containing an abundance of coronae, large volcanoes, and graben-fissure systems within close proximity - and of uncertain relationship - to the local and regional rifting.

The detailed study area, located approximately at $260^{\circ}-275^{\circ} \mathrm{E}, 25^{\circ}-33^{\circ} \mathrm{S}$ (Figures 1.3 and 3.4), contains five coronae as catalogued by the International Astronomical Union (IAU), numerous isolated segments of the Parga Chasma rift zone, and over forty graben-fissure systems (mapped herein), exhibiting radiating, linear, and circumferential geometries. This study area is also situated on the southwestern edge of the regional Parga Chasma rift system, and topography data clearly reveal an elevated plateau bounded on the southern side by a sudden down-dropped fault-like escarpment feature. The orientation of the NW-SE rift fault pattern in this area correlates with the NE-SW regional extension of the large-scale Parga Chasma rifting (Lopez and Hansen, 2008). Regional and local rift faults are grouped under separate layers but both are interpreted to be linked with the formation of Parga Chasma. Local rift faults are linked to separate smaller rift segments interpreted to be focussed on isolated magmatic centres within the study area (Section 5.1). 


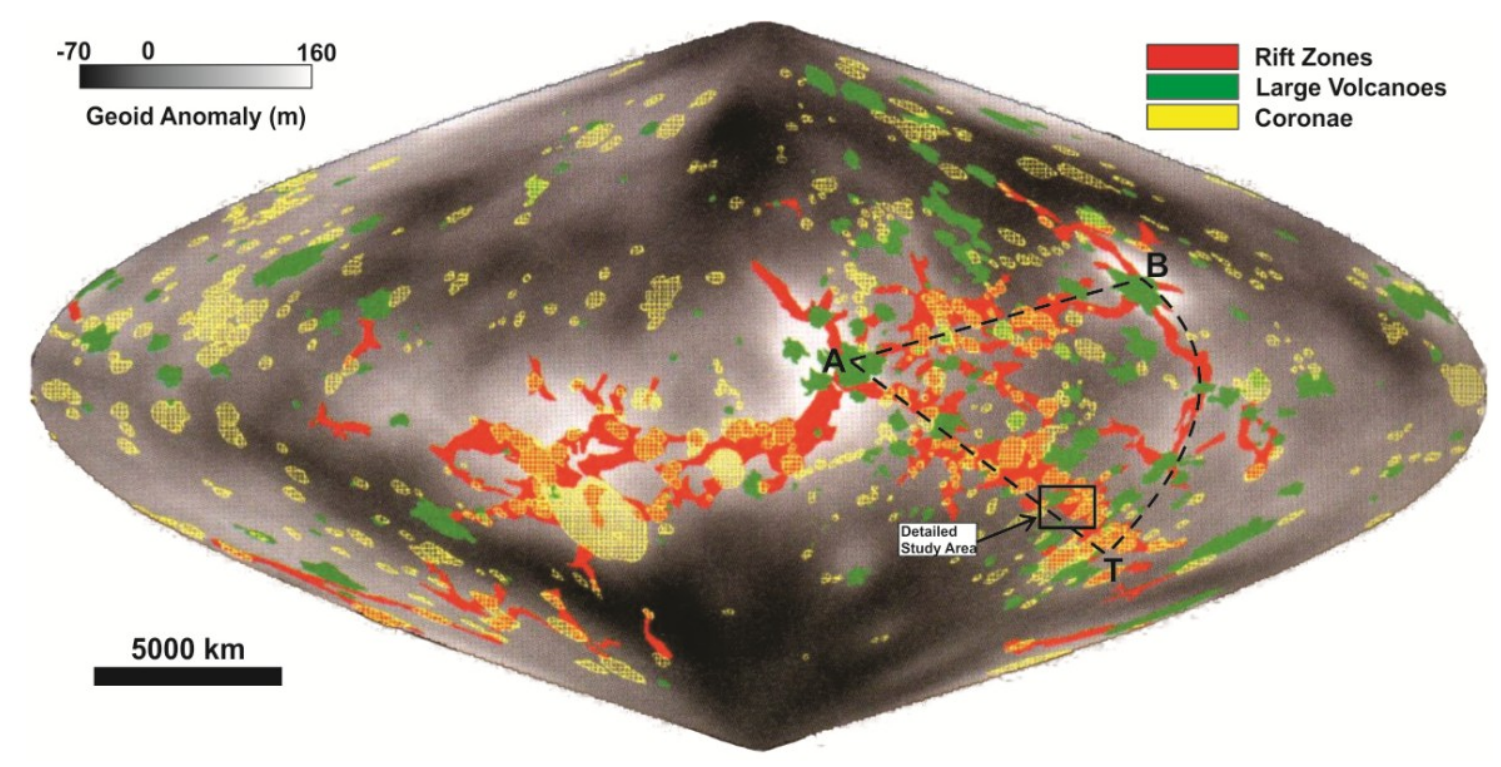

Figure 3.4. Sinusoidal projection of the entirety of Venus' surface (central meridian at $180^{\circ} \mathrm{E}$ ). Major structures, including rift zones, large volcanoes, and coronae are identified. The area confined by the BetaAtla-Themis (BAT) Region is outlined by dashed lines; the location of the study area is indicated by the open black square. Modified from Figure 2 in Herrick (1999).

\subsection{Detailed Linework Mapping}

In SAR images, graben are described as having observable floors, fissures are typically narrower than graben lineaments and appear V-shaped, while fractures display unresolved relief. Graben-fissures are formed by extensional stresses during the subsurface propagation of underlying dyke swarms, and they appear as thin sets of radarbright lineaments, displaying specific illumination dependent on their orientation relative to the radar-looking direction of the orbiting satellite (Grosfils and Head, 1994a,b; Ernst et al., 1995; Ernst et al., 2003; Studd et al., 2011; Graff et al., 2015). When observing graben-fissure lineaments perpendicular to the imaging direction only the far wall of the graben trough will be illuminated, while lineaments parallel to the imaging direction will be illuminated on both walls, often displaying the radar-dark graben floor (Figure 3.5). 


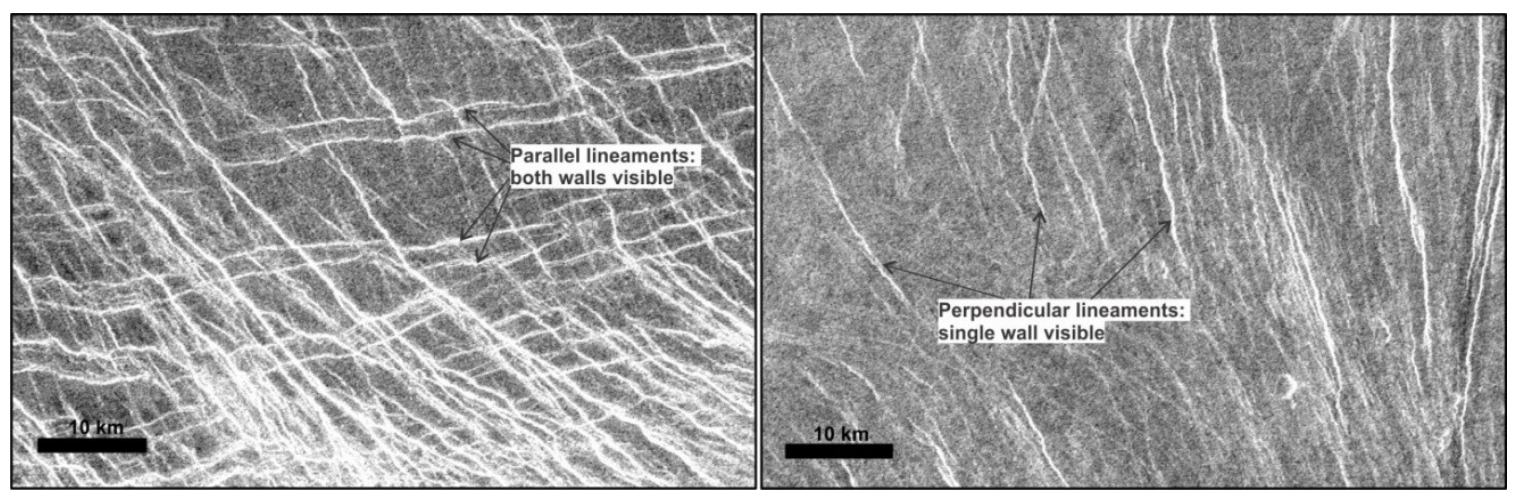

Figure 3.5. Graben-fissure lineament orientations, parallel (left image, centred on $266^{\circ} \mathrm{E}, 27^{\circ} \mathrm{S}$ ) and perpendicular (right image, centred on $273^{\circ} \mathrm{E}, 27^{\circ} \mathrm{S}$ ) to the radar looking direction. Parallel (E-W) lineaments exhibit illumination on both graben-fissure walls and the darkened trough can be observed. Perpendicular (N-S) lineaments have only a single wall illuminated.

This research also involves making a distinction between the radar-bright lineaments associated with rifting from those linked to dyke swarm emplacement (i.e. graben-fissures). This process follows the same approach as outlined in Graff et al. (2014, 2015), who developed criteria for accurate distinction of these morphologically similar features via a combination of qualitative and quantitative attributes.

Firstly, qualitative attributes from topography and slope data can be used to provisionally identify large-scale rift zones by a characteristic signature of topographically low valleys and steeply bounded walls - both of which can be observed on these images (Figure 3.2). Secondly, the quantitative characteristics of lineament thickness and sinuosity can also help to distinguish graben-fissures from rift faults. Lineament thickness represents the magnitude of exposed fault offset of either a rift fault or graben-fissure wall. Sinuosity captures the departure from a linear trend and is calculated by taking the ratio of total length measured along the lineament compared to its end-to-end length (Figure 3.6). These properties were utilized in the study by Graff et al. (2015), who drew comparisons between Venusian graben-fissures and rift faults with 
terrestrial mafic dykes and rift faults from the East African Rift System (e.g. Table 1 and Figure 3 in Graff et al., 2015).

Results show, that in general, rift faults exhibit both larger lineament thicknesses and sinuosity than graben-fissures (Graff et al., 2014, 2015). Using this approach, separate rift segments were provisionally identified based on topographic signature (Figures 3.2 and 3.3). Further analysis on SAR images then revealed the presence of densely clustered, thicker, and very sinuous radar-bright lineaments commonly observed in rift zones. Furthermore, the regional rift fault pattern of Parga Chasma extension has also been mapped out - interpreted based on a NW-SE orientation of the corresponding rift faults - following similar procedures used for mapping the local rift faults on SAR images.

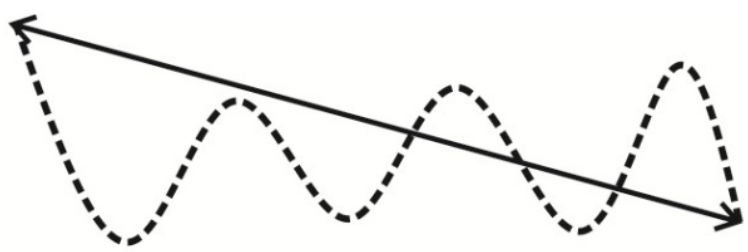

\section{Sinuosity Ratio $=\frac{\text { Total distance along line }}{\begin{array}{l}\text { Straight line distance } \\ \text { between end points }\end{array}}$}

Figure 3.6. (Top) Schematic diagram for obtaining the sinuosity of a lineament by measuring both the total distance along the line and the straight line distance between the end points. (Bottom) Ratio equation for calculating the sinuosity of a lineament.

Lastly, detailed summary maps of the study area (Figures $4.1-4.3$ ) have been completed that display the following: (1) all graben-fissure systems (radiating, linear, and circumferential); (2) the regional rift fault pattern produced from the regional NE-SW extension of Parga Chasma; and (3) the local rift segments (and associated rift faults) observed to be extending from isolated magmatic centres via triple-junction rifting. 


\section{Chapter: Tectono-Magmatic History of the Study Area}

\subsection{Approach}

A relative chronology of the events located along a $1500 \mathrm{~km}$ section of Parga Chasma was determined predominantly by examining the following: (1) cross-cutting relationships between the lineaments of separate graben-fissure systems; (2) cross-cutting relationships between graben-fissures interacting with local and regional rifting of Parga Chasma; and (3) the effect of young lava flows obscuring the trace of both grabenfissures and/or rift faults (Section 4.2). Cross-cutting between interacting graben-fissures and rift faults is observed in both direct and indirect ways. Direct interactions result when the lineaments from graben-fissure systems or rift faults are observed to be physically cross-cutting the lineaments belonging to other structures/events (i.e. younger lineaments directly overprinting older lineaments). Indirect interactions result when the lineaments from separate graben-fissure systems are observed to interact with a mutual geologic feature (e.g. a lava flow), but not directly with each other. For example, the grabenfissures from system ' $\mathrm{A}$ ' are observed extending towards and across a lava flow, while the graben-fissures from system ' $\mathrm{B}$ ' are observed extending towards the same flow but are abruptly cut and overprinted by it. Despite a lack of direct cross-cutting between the lineaments belonging to the two systems, it can be inferred that system ' $A$ ' is younger than system 'B' based on each system's relation to the lava flow.

The relative chronology of graben-fissure system formation was determined for radiating and linear systems; circumferential systems are temporally linked to the formation of an associated centrally located radiating system or geologic structure (i.e. coronae or large volcanoes). Cross-cutting relationships are the primary method of 
determining said chronology by analyzing the tectonic deformation caused to older systems via the formation of younger systems. Key characteristics that were observed included the effect of younger system lineaments creating disturbances or discontinuities in the trend of older lineaments. Contrasts in radar backscatter intensity were also observed, often when younger systems overprint older systems.

The distribution of graben-fissure system size (Section 4.2.4) and topographic variation (Section 4.2.5) within the study area was examined by generating histogram and scatter plot diagrams. Lastly, age relationships were assessed via cross-cutting relationships and used to produce a relative chronology (Section 4.3) and summary map (Section 4.4) of system formation relative to the regional rifting of Parga Chasma.

\subsection{Overview of Tectono-Magmatic Structures in the Study Area}

\subsubsection{Extensional Lineaments Interpreted as Graben-Fissures}

All extensional lineaments interpreted to represent graben-fissures have been systematically mapped within the designated study area $\left(260-275^{\circ} \mathrm{E}\right.$ and $\left.25-33^{\circ} \mathrm{S}\right)$. These lineaments were then grouped into 47 separate graben-fissure systems -28 radiating, 12 linear, and 7 circumferential systems (Figure 4.1; Tables 4.1 - 4.3). Within and closely surrounding the study area, more than 11,000 individual graben-fissure lineaments were identified and mapped, with over 10,000 assigned to the 47 grouped systems. The remaining mapped lineaments consist of isolated and/or unassigned sets of graben, fissures, or fractures. These may belong to unidentified radiating, linear, or circumferential systems, or unrecognized distal portions to already grouped systems (cf. Ernst et al., 2003). 


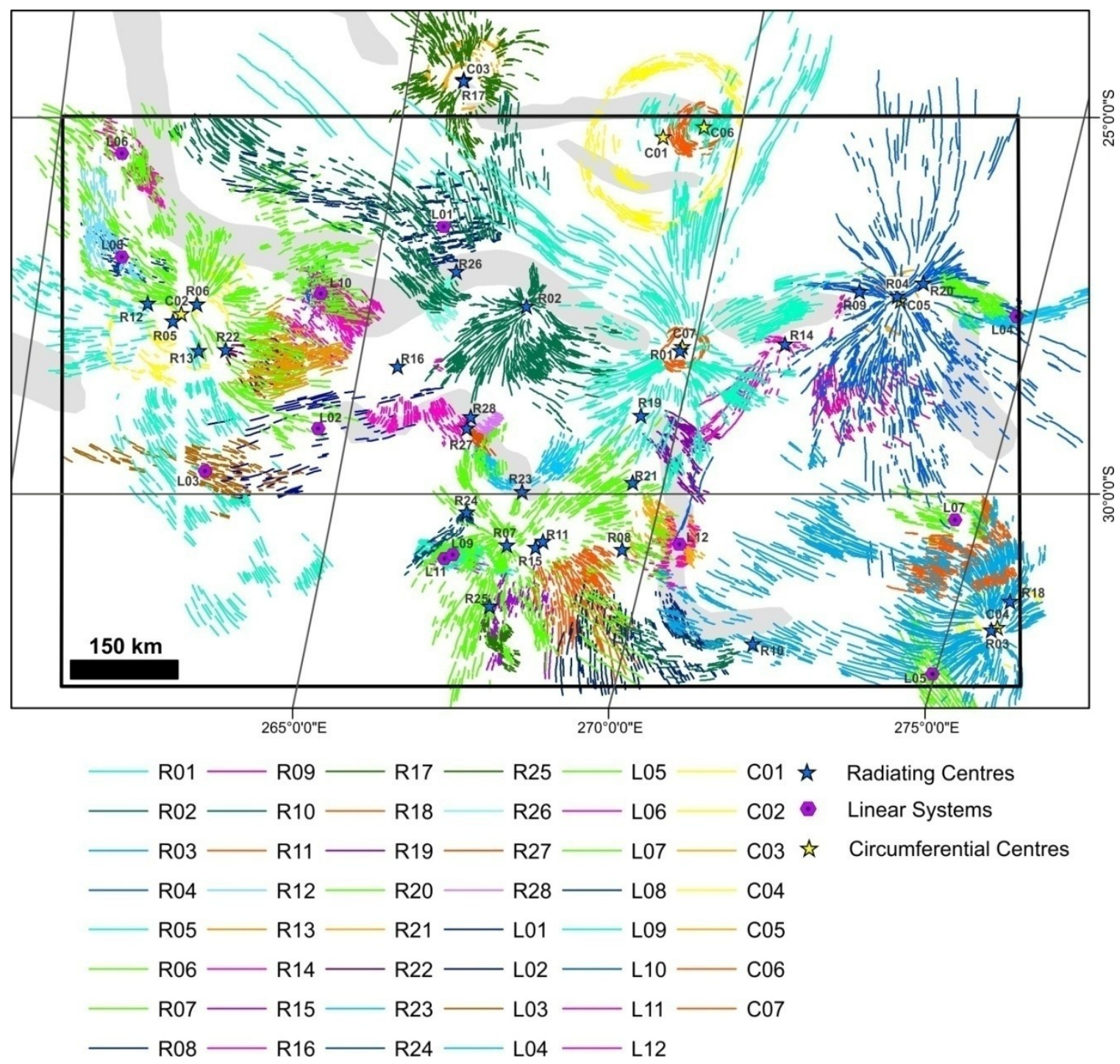

Figure 4.1. Distribution of mapped radiating (R\#), linear (L\#), and circumferential (C\#) graben-fissure systems within the study area. Blue and yellow stars denote centres of radiating and circumferential systems, respectively; purple hexagons indicate central positions of linear systems. Number coding corresponds to the mapped systems that are catalogued in Tables 4.1-4.3. The location of topographic troughs, coinciding with Parga Chasma, is indicated in grey. 
Table 4.1. Properties of the radiating graben-fissure systems mapped in the study area. See text for details on column headings.

\begin{tabular}{|c|c|c|c|c|c|c|c|c|c|}
\hline System & $\begin{array}{c}\text { Longitude } \\
\left({ }^{\circ} \mathrm{E}\right)\end{array}$ & $\begin{array}{l}\text { Latitude } \\
\qquad\left({ }^{\circ} \mathrm{S}\right)\end{array}$ & $\begin{array}{l}\text { Max } \\
\text { radius } \\
(\mathrm{km})\end{array}$ & $\begin{array}{l}\text { Arc } \\
\left({ }^{\circ}\right)\end{array}$ & $\begin{array}{c}\text { \# of } \\
\text { mapped } \\
\text { lineaments }\end{array}$ & $\begin{array}{c}\text { Central } \\
\text { elevation } \\
(\mathbf{k m})\end{array}$ & $\begin{array}{l}\text { Elevation } \\
\text { above } \\
\text { MPR } \\
\text { (km) }\end{array}$ & $\begin{array}{c}\text { Within } \\
\text { corona? }\end{array}$ & $\begin{array}{c}\text { Associated } \\
\text { Structure }\end{array}$ \\
\hline R01 & 269.75 & 28.00 & 747 & 360 & 733 & 6052.9 & 1.9 & $Y$ & $\begin{array}{c}\text { Xmukane } \\
\text { Corona }\end{array}$ \\
\hline R02 & 267.5 & 27.50 & 560 & 210 & 763 & 6051.8 & 0.8 & $\mathrm{~N}$ & \\
\hline R03 & 275.75 & 31.75 & 475 & 190 & 700 & 6052.5 & 1.5 & $Y$ & $\begin{array}{l}\text { Obiemi } \\
\text { Corona }\end{array}$ \\
\hline R04 & 273.00 & 27.25 & 471 & 320 & 634 & 6053.2 & 2.2 & $\mathrm{~N}$ & $\begin{array}{c}\text { Ts'an Nu } \\
\text { Mons }\end{array}$ \\
\hline R05 & 262.00 & 28.00 & 448 & $50 / 45$ & 344 & 6052.5 & 1.5 & $Y$ & $\begin{array}{l}\text { Kulimina } \\
\text { Corona }\end{array}$ \\
\hline R06 & 262.50 & 27.50 & 352 & 250 & 711 & 6052.2 & 1.2 & $Y$ & $\begin{array}{l}\text { Kulimina } \\
\text { Corona }\end{array}$ \\
\hline R07 & 268.00 & 30.50 & 280 & 335 & 834 & 6051.7 & 0.7 & $\mathrm{~N}$ & \\
\hline R08 & 269.50 & 30.75 & 232 & 60 & 218 & 6052.2 & 1.2 & $\mathrm{~N}$ & \\
\hline R09 & 272.25 & 27.25 & 230 & 75 & 162 & 6052.5 & 1.5 & $\mathrm{~N}$ & \\
\hline R10 & 272.00 & 32.00 & 226 & 40 & 117 & 6052.1 & 1.1 & $\mathrm{~N}$ & \\
\hline R11 & 268.25 & 30.75 & 221 & 95 & 237 & 6052.3 & 1.3 & $\mathrm{~N}$ & \\
\hline R12 & 261.75 & 27.50 & 213 & 50 & 136 & 6052.8 & 1.8 & $Y$ & $\begin{array}{c}\text { Kulimina } \\
\text { Corona }\end{array}$ \\
\hline R13 & 262.50 & 28.00 & 203 & 90 & 172 & 6052.5 & 1.5 & $Y$ & $\begin{array}{c}\text { Kulimina } \\
\text { Corona }\end{array}$ \\
\hline R14 & 271.25 & 28.00 & 203 & $65 / 10 / 5$ & 112 & 6053.6 & 2.6 & $\mathrm{~N}$ & \\
\hline R15 & 268.25 & 30.50 & 197 & 60 & 106 & 6052.3 & 1.3 & $\mathrm{~N}$ & \\
\hline R16 & 265.50 & 28.25 & 196 & $85 / 70 / 25$ & 309 & 6052.4 & 1.4 & $\mathrm{~N}$ & \\
\hline R17 & 266.00 & 24.50 & 186 & 330 & 391 & 6051.7 & 0.7 & $Y$ & $\begin{array}{l}\text { Chuku } \\
\text { Corona }\end{array}$ \\
\hline R18 & 275.75 & 31.50 & 175 & 80 & 302 & 6052.6 & 1.6 & $Y$ & $\begin{array}{l}\text { Obiemi } \\
\text { Corona }\end{array}$ \\
\hline R19 & 269.50 & 29.00 & 154 & 55 & 122 & 6051.9 & 0.9 & $\mathrm{~N}$ & \\
\hline R20 & 273.25 & 27.25 & 152 & 85 & 75 & 6053.2 & 2.2 & $\mathrm{~N}$ & \\
\hline R21 & 269.50 & 29.75 & 148 & 60 & 132 & 6052.2 & 1.2 & $\mathrm{~N}$ & \\
\hline $\mathrm{R} 22$ & 263.00 & 28.00 & 114 & 65 & 63 & 6052.3 & 1.3 & $Y$ & $\begin{array}{l}\text { Kulimina } \\
\text { Corona }\end{array}$ \\
\hline R23 & 268.00 & 23.00 & 111 & $60 / 35$ & 110 & 6051.7 & 0.7 & $\mathrm{~N}$ & \\
\hline R24 & 267.00 & 30.00 & 107 & 90 & 74 & 6052.8 & 1.8 & $\mathrm{~N}$ & \\
\hline R25 & 267.75 & 31.50 & 99 & 60 & 104 & 6051.7 & 0.7 & $\mathrm{~N}$ & $\begin{array}{l}\text { Otohime } \\
\text { Tholus }\end{array}$ \\
\hline R26 & 266.25 & 27.00 & 99 & 35 & 85 & 6051.5 & 0.5 & $\mathrm{~N}$ & \\
\hline R27 & 266.75 & 29.00 & 57 & 40 & 38 & 6051.9 & 0.9 & $\mathrm{~N}$ & \\
\hline R28 & 267.00 & 23.00 & 46 & 70 & 38 & 6051.9 & 0.9 & $\mathrm{~N}$ & \\
\hline
\end{tabular}


Table 4.2. Properties of the linear graben-fissure systems mapped in the study area. See text for details on column headings.

\begin{tabular}{|c|c|c|c|c|c|c|c|c|}
\hline System & $\begin{array}{c}\text { Longitude } \\
\left.\text { ( }{ }^{\circ} \mathrm{E}\right)\end{array}$ & $\begin{array}{l}\text { Latitude } \\
\left({ }^{\circ} \mathrm{S}\right)\end{array}$ & $\begin{array}{l}\text { Length } x \\
\text { width } \\
(\mathrm{km})\end{array}$ & $\begin{array}{c}\text { \# of } \\
\text { mapped } \\
\text { lineaments }\end{array}$ & $\begin{array}{c}\text { Central } \\
\text { elevation } \\
(\mathrm{km})\end{array}$ & $\begin{array}{l}\text { Elevation } \\
\text { above } \\
\text { MPR (km) }\end{array}$ & $\begin{array}{c}\text { Within } \\
\text { corona? }\end{array}$ & $\begin{array}{l}\text { Associated } \\
\text { structure }\end{array}$ \\
\hline L01 & 266.00 & 26.50 & $393 \times 148$ & 248 & 6052.7 & 1.7 & $\mathrm{~N}$ & \\
\hline L02 & 264.50 & 29.00 & $343 \times 134$ & 87 & 6052.4 & 1.4 & $\mathrm{~N}$ & \\
\hline L03 & 263.00 & 29.75 & $341 \times 104$ & 133 & 6052.5 & 1.5 & $\mathrm{~N}$ & \\
\hline L04 & 273.75 & 27.75 & $195 \times 43$ & 79 & 6052.3 & 1.3 & $\mathrm{~N}$ & \\
\hline L05 & 274.00 & 31.50 & $187 \times 73$ & 122 & 6052.0 & 1.0 & $Y$ & $\begin{array}{l}\text { Obiemi } \\
\text { Corona }\end{array}$ \\
\hline L06 & 260.25 & 25.25 & $164 \times 56$ & 119 & 6052.9 & 1.9 & $\mathrm{~N}$ & \\
\hline L07 & 275.50 & 30.50 & $152 \times 54$ & 194 & 6052.2 & 1.2 & $Y$ & $\begin{array}{l}\text { Gertjon } \\
\text { Corona }\end{array}$ \\
\hline L08 & 262.25 & 27.00 & $150 \times 54$ & 84 & 6052.6 & 1.6 & $\mathrm{Y}$ & $\begin{array}{c}\text { Kulimina } \\
\text { Corona }\end{array}$ \\
\hline L09 & 266.25 & 30.50 & $143 \times 58$ & 236 & 6051.6 & 0.6 & $\mathrm{~N}$ & \\
\hline L10 & 264.25 & 26.75 & $108 \times 54$ & 82 & 6051.8 & 0.8 & $\mathrm{~N}$ & \\
\hline L11 & 266.25 & 30.75 & $92 \times 40$ & 49 & 6051.7 & 0.7 & $\mathrm{~N}$ & \\
\hline L12 & 271.25 & 31.00 & $88 \times 107$ & 157 & 6052.5 & 1.5 & $\mathrm{~N}$ & \\
\hline
\end{tabular}

Table 4.3. Properties of the circumferential graben-fissure systems mapped in the study area. See text for details on column headings.

\begin{tabular}{|c|c|c|c|c|c|c|c|c|c|}
\hline System & $\begin{array}{c}\text { Longitude } \\
\left.\text { ( }{ }^{\circ} \mathrm{E}\right)\end{array}$ & $\begin{array}{c}\text { Latitude } \\
\left({ }^{\circ} \mathrm{S}\right)\end{array}$ & $\begin{array}{c}\text { Max } \\
\text { radius } \\
(\mathrm{km})\end{array}$ & $\begin{array}{l}\text { Arc } \\
\left({ }^{\circ}\right)\end{array}$ & $\begin{array}{c}\text { \# of } \\
\text { mapped } \\
\text { lineaments }\end{array}$ & $\begin{array}{c}\text { Central } \\
\text { elevation } \\
(\mathrm{km})\end{array}$ & $\begin{array}{c}\text { Elevation } \\
\text { above } \\
\text { MPR } \\
\text { (km) }\end{array}$ & $\begin{array}{l}\text { Within } \\
\text { corona? }\end{array}$ & $\begin{array}{c}\text { Associated } \\
\text { structure }\end{array}$ \\
\hline C01 & 269.00 & 25.25 & 138 & 360 & 273 & 6052.1 & 1.1 & $Y$ & $\begin{array}{l}\text { Hervor } \\
\text { Corona }\end{array}$ \\
\hline $\mathrm{CO2}$ & 262.25 & 27.50 & 121 & $130 / 90$ & 89 & 6052.6 & 1.6 & $Y$ & $\begin{array}{c}\text { Kulimina } \\
\text { Corona }\end{array}$ \\
\hline $\mathrm{CO3}$ & 265.75 & 24.50 & 75 & 320 & 119 & 6051.7 & 0.7 & $Y$ & $\begin{array}{l}\text { Chuku } \\
\text { Corona }\end{array}$ \\
\hline $\mathrm{CO4}$ & 275.75 & 31.75 & 74 & 280 & 45 & 6052.6 & 1.6 & $\mathrm{Y}$ & $\begin{array}{l}\text { Obiemi } \\
\text { Corona }\end{array}$ \\
\hline $\mathrm{CO5}$ & 273.00 & 27.50 & 70 & 300 & 30 & 6053.3 & 2.3 & $\mathrm{~N}$ & $\begin{array}{c}\text { Ts'an Nu } \\
\text { Mons }\end{array}$ \\
\hline $\mathrm{C06}$ & 269.50 & 25.25 & 52 & 330 & 97 & 6051.3 & 0.3 & $Y$ & $\begin{array}{l}\text { Hervor } \\
\text { Corona }\end{array}$ \\
\hline $\mathrm{CO7}$ & 269.75 & 28.00 & 39 & 340 & 34 & 6052.9 & 1.9 & $Y$ & $\begin{array}{c}\text { Xmukane } \\
\text { Corona }\end{array}$ \\
\hline
\end{tabular}


All grouped graben-fissure systems were catalogued using a code-designated numbering system: R\# for radiating systems (Table 4.1); L\# for linear systems (Table 4.2); and $\mathrm{C \#}$ for circumferential systems (Table 4.3). Physical characteristics for all systems were also obtained, including: maximum radius (for radiating and circumferential systems) or length and width (for linear systems); system arc angle (for radiating and circumferential systems); number of mapped lineaments; and the central elevation. Also indicated for each system is whether or not it is located within a corona, or associated with an IAU catalogued geologic structure (i.e. corona, large volcano, etc.). Maximum radius is measured from the centre of a radiating or circumferential system to its farthest identified lineament; while the maximum length and width of a linear system are measured across the entire set of mapped lineaments. The arc of radiating and circumferential systems captures the overall amount of angular spread created by the collection of mapped lineaments (Figure 4.2). The central elevation was obtained from the Magellan topography data, which provided the planetary radius at the interpreted system centre. This elevation value was also calculated as an elevation above Mean Planetary Radius (MPR) by subtracting $6051 \mathrm{~km}$ (Venus' MPR value - analogous to Earth's sea level).
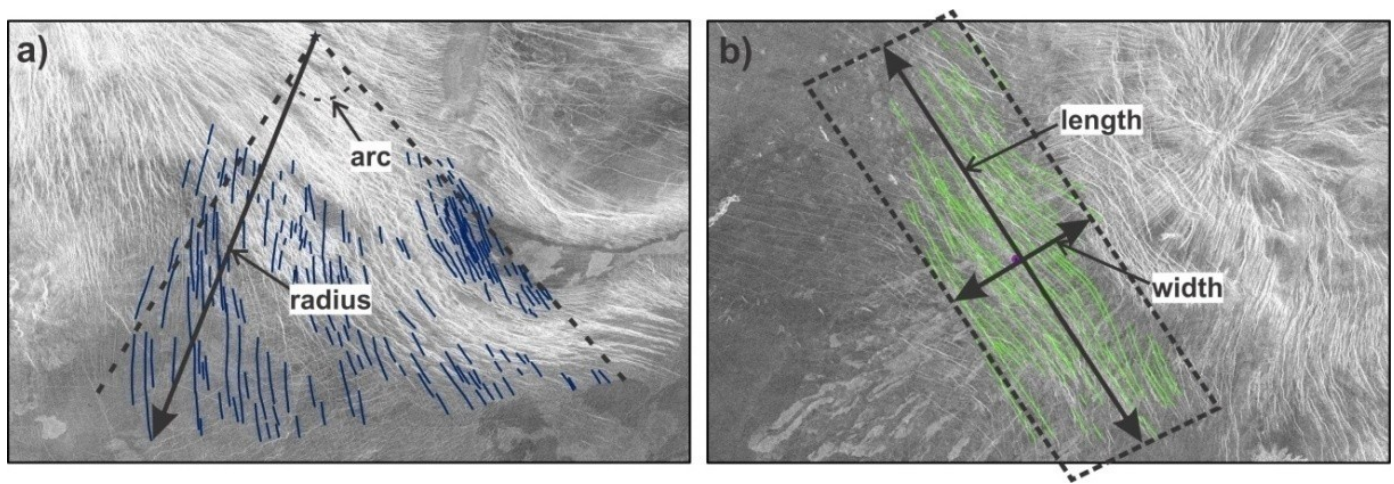

Figure 4.2. Process of measuring (a) the maximum radius and arc of a radiating system, and (b) the length and width of a linear system. Examples shown for systems R08 (Table 4.1) and L05 (Table 4.2). 


\subsubsection{Extensional Lineaments Interpreted as Rift Faults}

Extensional lineaments associated with rifting along Parga Chasma were also mapped. Regional rift faults are situated in a NW-SE orientation and are associated with the overall regional NE-SW extension of Parga Chasma (catalogued as RF01). Local rift faults are distinguished from regional when they are observed as separate rift segments extending from individual magmatic centres. In the study area there are 11 local rift segments (catalogued as $R F 02-R F 12$ ). However, as both of these lineament groups (regional and local) are interpreted to be rift-related, they exhibit similar morphologies on SAR images, including high radar-brightness, thickness, and sinuosity (Section 3.4). Within the study area over 1,500 rift-related lineaments were systematically mapped, corresponding to 1,016 local rift faults and 633 regional rift faults (Figure 4.3).

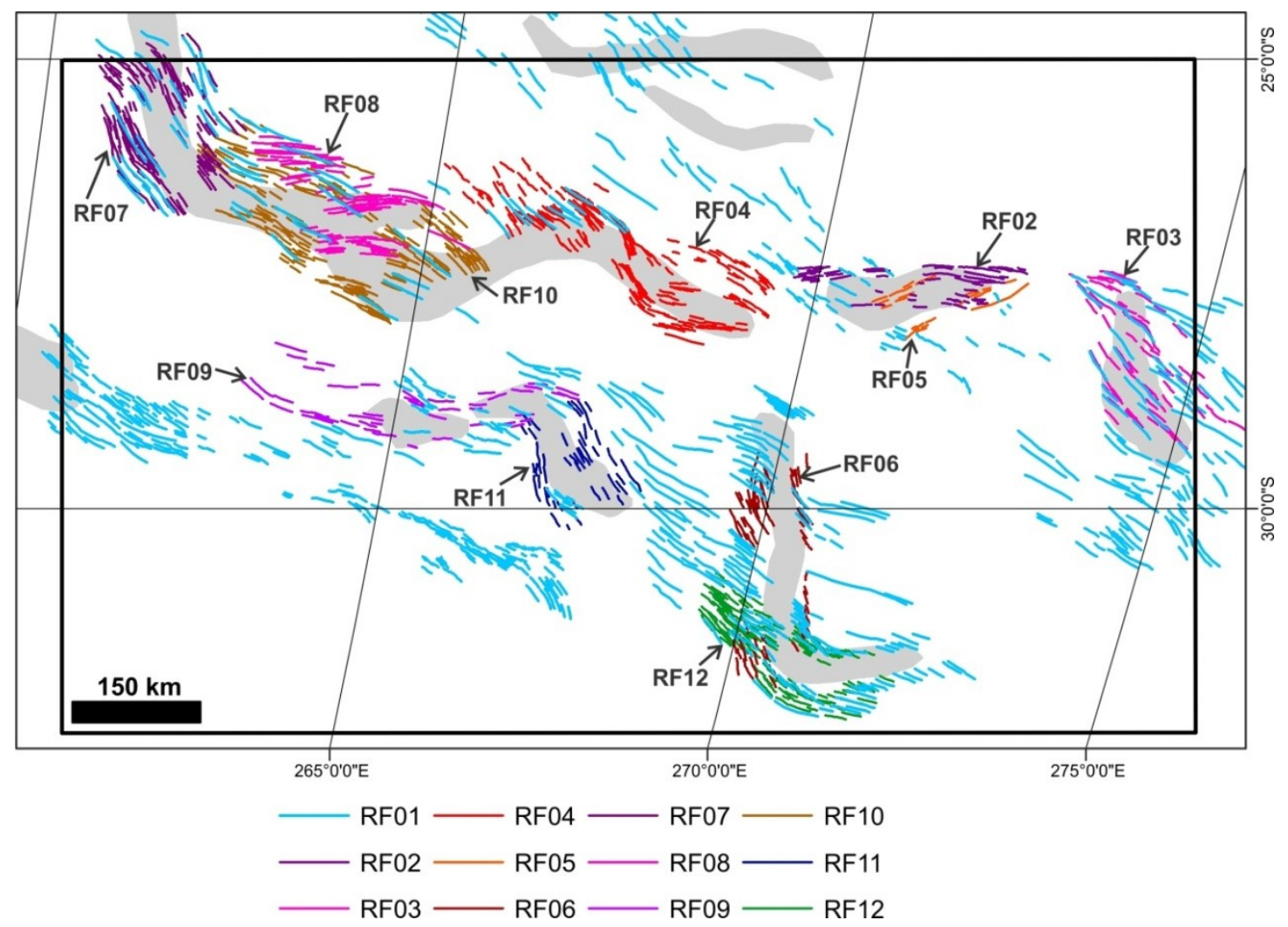

Figure 4.3. Distribution of rift-related lineaments within the study area. Topographic troughs are indicated in grey (Section 3.4). 


\subsubsection{Descriptions of Most Significant Graben-Fissure Systems}

Within the study area, there are notable locations that are host to multiple grabenfissure systems and/or contain major geologic structures (i.e. coronae, large volcanoes, etc.). Specifically, ten of these notable locations have been selected (Figure 4.4) as representations of either the largest or most densely populated graben-fissure systems in the study area, or as locations of major geologic structures that often host a dense clustering of rift faults and/or multiple graben-fissure systems. These locations will herein be discussed in greater detail describing the physical characteristics, morphologies, and tectonic setting (where possible) of these notable graben-fissure systems and geologic structures. Also discussed will be cross-cutting relationships between interacting graben-fissure systems - later used to produce a relative chronology timeline (Section 4.3) and summary map (Section 4.4).

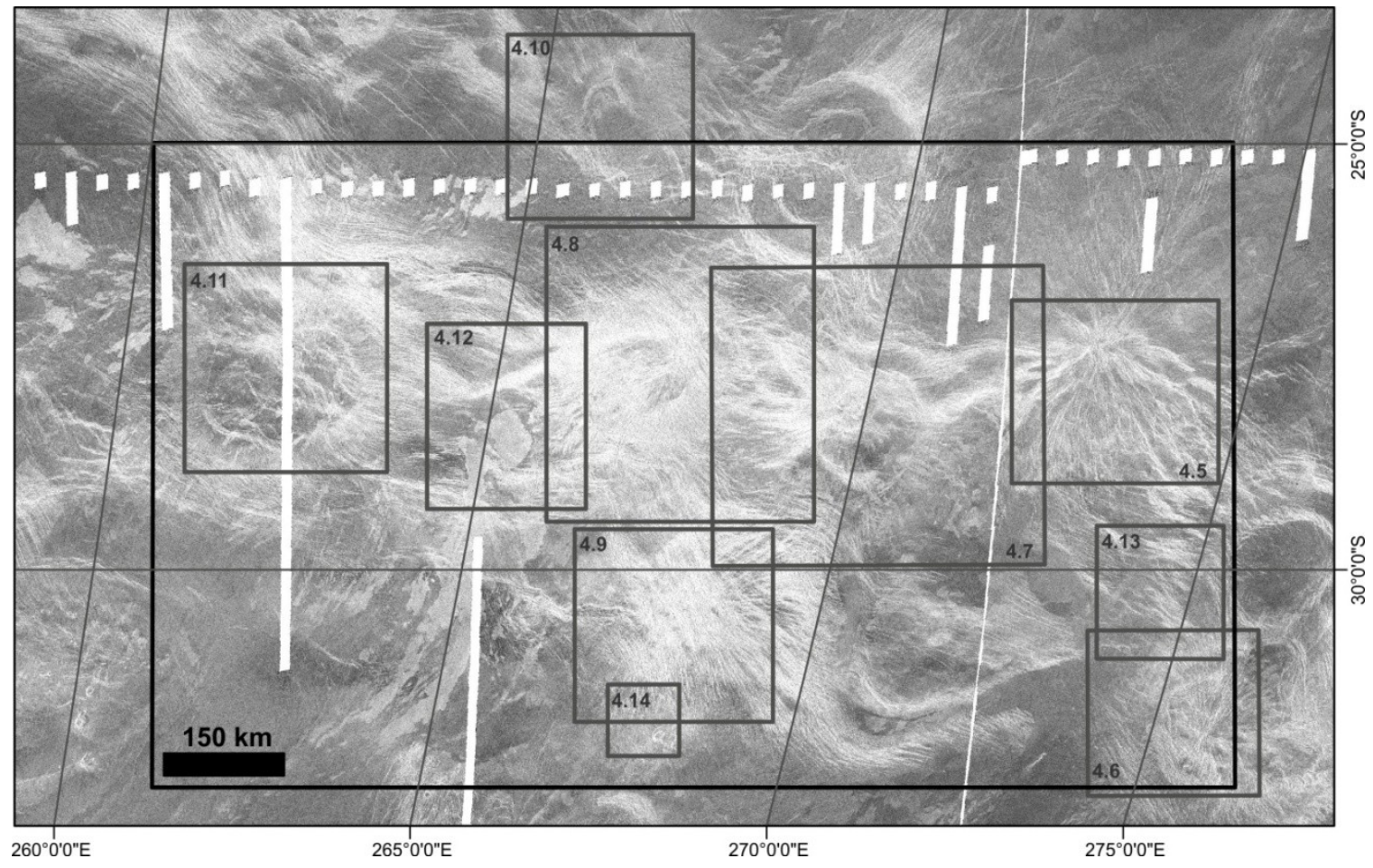

Figure 4.4. Designated locations for subsequent figures $(4.5-4.14)$. 


\subsubsection{Systems R04, R09, R20: Ts'an Nu Mons}

Ts'an Nu Mons $\left(272.75^{\circ} \mathrm{E}, 27.25^{\circ} \mathrm{S}\right)$ is a large volcano, $310 \mathrm{~km}$ in diameter (Figure 4.5), in the northwestern corner of the V-53 Themis Regio quadrangle $\left(270^{\circ}-300^{\circ} \mathrm{E}, 25^{\circ}\right.$ $-50^{\circ} \mathrm{S}$ ). It reaches an elevation of $2.8 \mathrm{~km}$ above Mean Planetary Radius (MPR) and 1.6 $\mathrm{km}$ above the surrounding volcanic plains material composed of intermediate radar backscatter flow units, likely formed from the volcanic edifice itself (Stofan and Brian, 2012). Assuming that this large volcano is associated with a mantle plume, then domal uplift is expected and could result in local triple-junction rifting, creating two rift arms one trending west (RF02) towards Xmukane Corona (and system R01); the other trending south-southeast (RF03) towards Gertjon Corona (and system L07) (Figure 4.3). These rift arms are associated with topographic troughs that also contain dense clusters of thick and sinuous radar-bright lineaments trending from $\mathrm{Ts}$ 'an $\mathrm{Nu}$ Mons. The rift faults comprising the south-southeast trending rift arm towards Gertjon Corona are observed to be following previously established regional rift faults (RF01), produced from the largescale regional NE-SW extension of Parga Chasma (Martin et al., 2007; Lopez and Hansen, 2008; Stofan and Brian, 2012). Both the regional and local rift fault lineaments (Section 4.2.2) are interpreted to be rift-related (associated with the overall formation of Parga Chasma). However, cross-cutting is observed between these prominent rift faults (local and regional) at the detailed scale of this mapping, resulting in the observation that the local rifting events - interpreted to be linked to separate magmatic centres (e.g. Ts'an $\mathrm{Nu}$ Mons) - are distinct from the older rifting associated with regional extension. Within the areal extent of Ts'an Nu Mons lie the radiating graben-fissure systems R04, R09, and R20. 

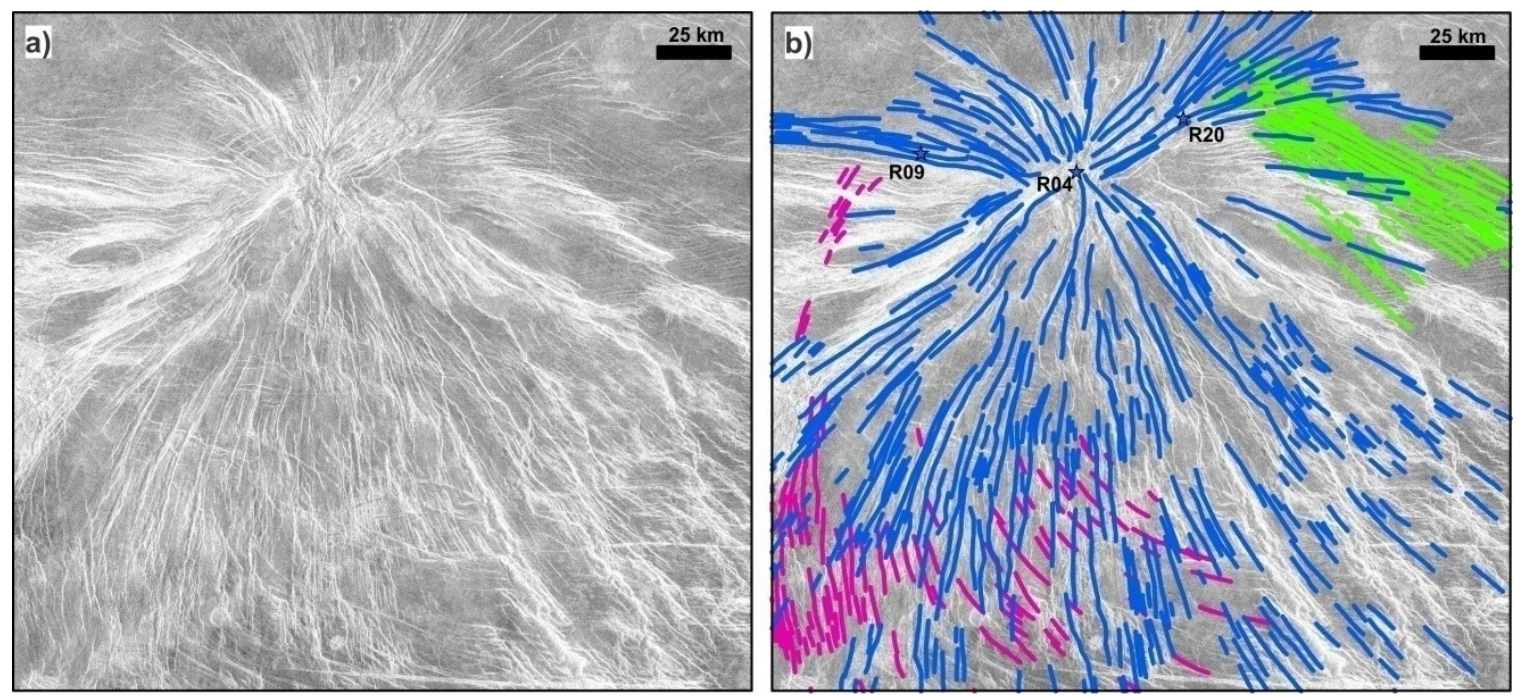

Figure 4.5. Graben-fissure systems R04 (blue), R09 (pink), and R20 (light green); Ts'an Nu Mons is situated surrounding the centre of R04. (a) Magellan SAR image. (b) SAR image superimposed with mapped systems. Graben-fissures from system R04 cut across those of R09 and R20, and are interpreted as being younger. See Figure 4.4 for image location.

\subsection{System R04}

System R04 is a radiating graben-fissure system centred at $273^{\circ} \mathrm{E}, 27.25^{\circ} \mathrm{S}$, and situated roughly $30-50 \mathrm{~km}$ southwest from the central high point of Ts'an $\mathrm{Nu}$ Mons (Figure 4.5). Due to its spatial proximity to the centre of Ts'an $\mathrm{Nu}$ Mons it is likely a product of the same underlying mantle source. It is interpreted to have been emplaced after the main constructional phase of the volcano and subsequent lava flow units, due to the graben and fissures that cross-cut the surrounding plains. This system contains 634 mapped lineaments of graben-fissures, with a maximum observed radius of $471 \mathrm{~km}$, a near-perfect $\operatorname{arc}$ of $320^{\circ}$, and is elevated $2.2 \mathrm{~km}$ above MPR.

Systems directly interacting with R04 include: R01 (Xmukane Corona), R03 (Obiemi Corona), R09, R18, R20, L04, and L07, in addition to lineaments from both local (RF02, RF03) and regional (RF01) rifting (Figure 4.3). Age relationships are inferred between systems R04 and R14, as only indirect interactions are observed. Analysis of cross-cutting relationships between interacting graben-fissure systems reveals 
R04 to be among the youngest based on well defined cross-cutting by many grabenfissure lineaments belonging to R04. However, ambiguous cross-cutting is observed between some interacting graben-fissures of systems R04 and R01, and so a degree of synchroneity between these systems is inferred.

Graben-fissures from R04 extend to within the radial extent of system R14, but direct cross-cutting between the lineaments is not observed, therefore relative age relationships can only be inferred from indirect interactions. The formation of Ts'an $\mathrm{Nu}$ Mons and subsequently system R04 itself is interpreted as the source point for local triple-junction rifting. System R14 is observed to cross-cut some of the surrounding plains material and the local rift faults, and is therefore inferred to be younger or partially synchronous to R04.

Due to its genetic link to the formation of Ts'an $\mathrm{Nu}$ Mons, system R04 is interpreted as coeval with the local rift faulting (RF02, RF03), but is observed to crosscut the older regional NW-SE rift fault pattern (RF01) (Figure 4.3). Some cross-cutting is observed between the graben-fissures from R04 and the rift faults comprising the local south-southeast trending rift segment (RF03), however, this local rift segment follows the same orientation as the regional rift fault pattern (RF01), resulting in some ambiguity in the observed interactions.

\subsection{System R09}

System R09 is also a radiating system, centred at $272.25^{\circ} \mathrm{E}, 27.25^{\circ} \mathrm{S}$, on the western

flank of Ts'an Nu Mons, $53 \mathrm{~km}$ west of the centre of system R04. System R09 is elevated $1.5 \mathrm{~km}$ above MPR, consists of 162 mapped lineaments, has a maximum observed radius 
of $230 \mathrm{~km}$, and an $\operatorname{arc}$ of $75^{\circ}$ opening to the south. R09 is observed as an older system that is cross-cut by graben-fissures of R04, as well as both local (RF02, RF05) and regional (RF01) rift faulting. R09 displays a slightly arcuate geometry and may instead represent a small annular portion of an old or possibly cryptic circumferential grabenfissure system, unrelated to the formation of Ts'an Nu Mons.

\subsection{System R20}

System R20 is a radiating system located on the eastern flank of Ts'an Nu Mons, centred at $273.25^{\circ} \mathrm{E}, 27.25^{\circ} \mathrm{S}$, and $40 \mathrm{~km}$ northeast of system R04. System R20 is $2.2 \mathrm{~km}$ above MPR, consists of 75 mapped lineaments, and forms a maximum observed radius of $152 \mathrm{~km}$ with an arc of $85^{\circ}$ opening to the southeast. System R20 interacts with grabenfissures from systems R04 and L04, and is observed to be cross-cut by both. Crosscutting relationships reveal R20 to predate both the adjacent rift faulting (RF01, RF03) and the surrounding flooded plains material, within which the radar brightness of the lineaments diminish as they are covered by lava flows.

\subsubsection{Systems R03, R18, L05: Obiemi Corona}

Obiemi corona (Figure 4.6) is an obliquely shaped ellipsoidal corona in the southeast corner of the study area. It is situated in the northwest of Themis Regio and centred at approximately $276^{\circ} \mathrm{E}, 31.75^{\circ} \mathrm{S}$. It features a maximum and minimum diameter of $276 \mathrm{~km}$ and $182 \mathrm{~km}$, respectively. Obiemi corona has experienced a high amount of deformation, resulting in a heavily fractured interior rim with very sinuous and obliquely oriented circumscribing fractures; the observed exterior rim lacks well defined circumscribing fractures. This corona is spatially associated with graben-fissure systems R03, R18, and L05. System R03 is interpreted to be genetically related to the corona 
formation, but is centred $21 \mathrm{~km}$ west of the Obiemi corona centre. Additionally, a smaller subcentre is located $12 \mathrm{~km}$ south of the R03 centre, containing prominent graben-fissures with possible genetic association to the formation of either or both system R03 and Obiemi Corona.

\subsection{System R03}

System R03 is a radiating system centred at $275.75^{\circ} \mathrm{E}, 31.75^{\circ} \mathrm{S}$, approximately 21 $\mathrm{km}$ west of the centre of Obiemi Corona. A total of 751 lineaments have been mapped, exhibiting a maximum radius of $475 \mathrm{~km}$ and an arc of at least $330^{\circ}$; the remaining portion is outside the study area to the east and was not mapped (Figure 4.6). System R03 is elevated $1.5 \mathrm{~km}$ above MPR and interacts with many other mapped systems, including: R04, R08, R10, R18, L05, L07, L12, and a number of lineaments associated with both local (RF12) and regional (RF01) rifting of Parga Chasma (Figure 4.3). Observed to be cross-cut by most of the aforementioned systems, R03 is interpreted to be an older system that is also cut by regional (RF01) rifting. System R18 is observed as older or partially synchronous to R03, and is likely a precursor event to the corona-forming event and to the larger system R03. R03 is also observed to be either younger or partially synchronous to linear system L07. 

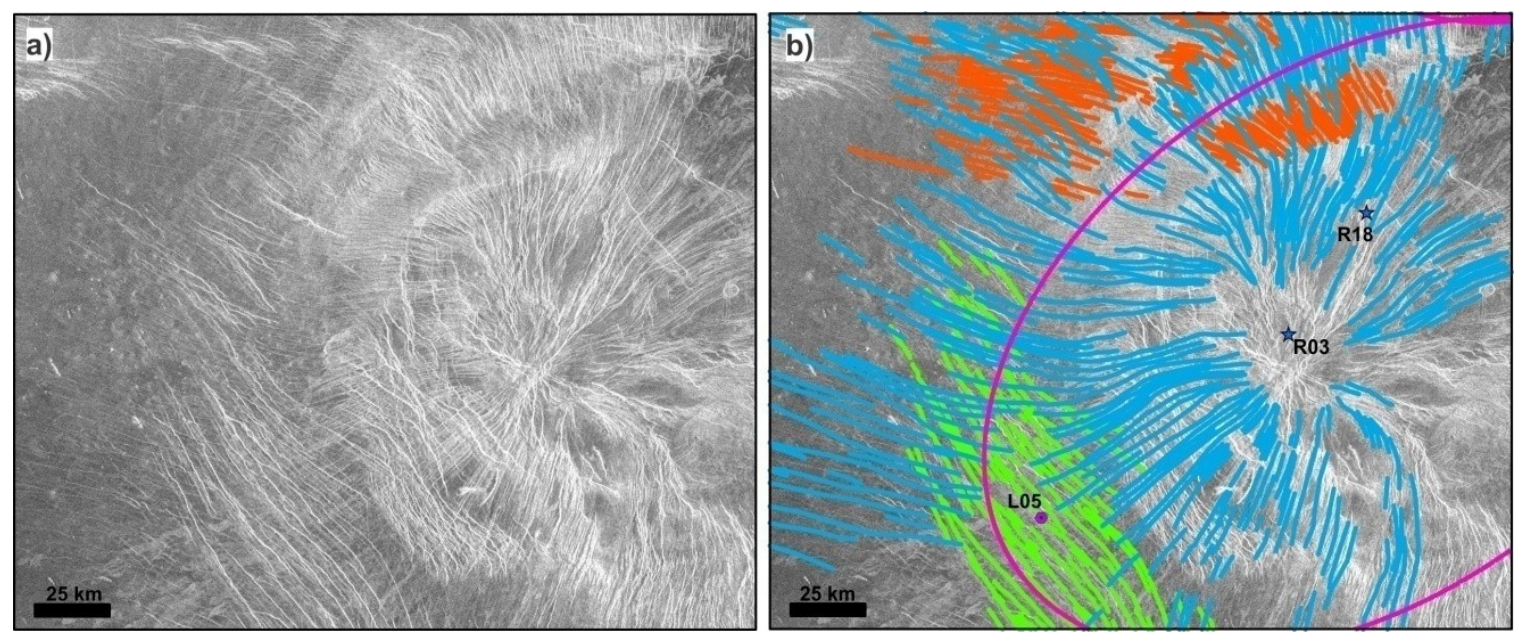

Figure 4.6. Graben-fissure systems R03 (light blue), R18 (orange), and L05 (light green); the rim of Obiemi Corona is outlined in magenta. (a) Magellan SAR image. (b) Image superimposed with mapped systems. Graben-fissures from R03 display a younger to synchronous cross-cutting relationship with R18, but are clearly cut by L05, interpreted as the youngest of the three. See Figure 4.4 for image location.

\subsection{System R18}

System R18 is a small radiating system centred at $275.75^{\circ} \mathrm{E}, 31.5^{\circ} \mathrm{S}$, near system R03. It extends outward to the northwest, but becomes completely flooded within the western plains after extending $175 \mathrm{~km}$ from its centre. System R18 consists of 302 mapped lineaments, with an arc of $80^{\circ}$ opening towards the northwest, and is elevated 1.6 km above MPR - likely a result of being situated near the raised rim of Obiemi Corona. System R18 directly interacts with systems R03, R04, and L07, and indirectly with L05. Cross-cutting relationships reveal R18 to be older than systems R03, R04, and L07. It is interpreted to also be older than system L05 as the observed cross-cutting relationships reveal that the development of Obiemi Corona preceded the formation of L05, but occurred after the formation of R18. System R18 is also covered extensively by lava flows interpreted to have originated from Obiemi Corona, providing further evidence of its earlier formation. 


\subsection{System L05}

System L05 is a small linear system that passes through the southwestern flank of Obiemi Corona. System L05 may also be an extended portion of a larger graben-fissure system associated with Rigatona Corona, located to the southeast of Obiemi Corona and outside of the study area. System L05 contains 122 mapped lineaments, a maximum length of $187 \mathrm{~km}$, and a width of $73 \mathrm{~km}$. System L05 interacts only directly with system R03 and indirectly with system R18. Cross-cutting relationships reveal it to be younger than Obiemi Corona, and therefore younger than both systems R03 and R18. Grabenfissures of system L05 are also observed to clearly cross-cut the lineaments of these other systems, as well as the majority of the flooded plains and corona annulus material, indicating later formation.

\subsubsection{System R01 and Xmukane Corona}

Centred almost exactly on the borders between the V-52 and V-53 quadrangles of Helen Planitia and Themis Regio, respectively $\left(270^{\circ} \mathrm{E}, 28.25^{\circ} \mathrm{S}\right)$, Xmukane Corona displays a near perfect circular geometry with a diameter of $140 \mathrm{~km}$ (Figure 4.7). It is located at the centre of a flooded rift valley and interpreted to be the locus of triplejunction rifting, producing individual rift segments extending in three directions: northwest (RF04), east-northeast (RF05), and south (RF06) (Figure 4.3).

The northwest rift segment (RF04) propagates sinuously towards system R02, and displays the characteristic normal faulting expected with rifting, but also displays transtensional characteristics by exhibiting a component of strike-slip faulting $250 \mathrm{~km}$ away from Xmukane Corona. This strike-slip component (observed as right-lateral or dextral) can be seen in the deformational offset pattern within the linear swarm of system 
L01, to the northwest of system R02 (Figure 4.8). The trend of this rift segment is also interpreted to have been deformed around the eastern flank of system R02 due to local compressional stresses associated with the crustal relaxation (e.g. see model shown in Figure 8 in Lopez et al., 2008) beneath R02. This is observed in the rift fault pattern (RF04) as it exhibits different local trends along the length of the single rift segment, notably when observed to veer around the structure of system R02 (Figures 4.3 and 4.8).
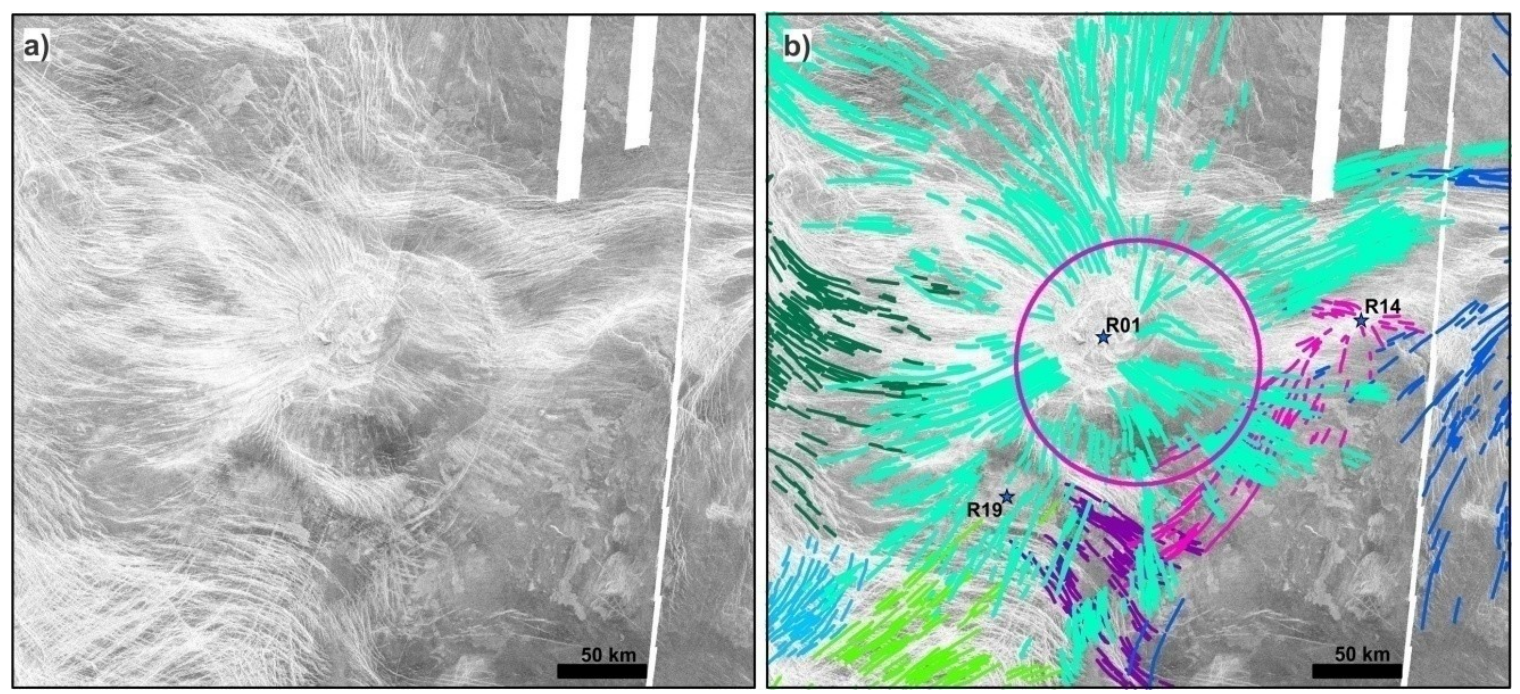

Figure 4.7. Graben-fissure systems R01 (turquoise), R02 (dark green), R04 (blue), R07 (light green), R14 (pink), R19 (purple), and R23 (light blue); the rim of Xmukane Corona is outlined in magenta. (a) Magellan SAR image. (b) SAR image superimposed with mapped systems. Graben-fissures from R01 cut across those from systems R02, R07, and R23, but are cut by graben-fissures from R04, R14, and R19. Some overlap in timing is observed to exist between systems R01, R02, R04, and R07. See Figure 4.4 for image location.

The valley to the northeast of Xmukane Corona consists of a combination of the east-northeast rift segment (RF05) from Xmukane Corona, and the western rift segment (RF02) from Ts'an $\mathrm{Nu}$ Mons $300 \mathrm{~km}$ to the northeast (Figures 4.3 and 5.3). This interpretation comes from the detailed mapping of the rift fault lineament pattern and the appearance of two distinct trends contained within a single rift valley. The orientation of this rift valley is also oblique to the regional rift fault pattern associated with the regional extension of Parga Chasma. 
The southern rift segment (RF06) contains a complex set of fault lineament orientations that is interpreted to consist of a combination of both the local and regional rift fault patterns (Figure 4.3). The formation of the local rift segment is likely a younger event compared to the regional rifting of Parga Chasma, because this local rift valley is almost completely flooded, obscuring the traces of nearly all radar-bright lineaments within, including local and regional rift faults, and graben-fissures.

\subsection{System R01}

Radiating system R01 (Figure 4.7) is centred at $269.75^{\circ} \mathrm{E}, 28^{\circ} \mathrm{S}, 24 \mathrm{~km}$ northwest of the centre of Xmukane Corona, and elevated $1.9 \mathrm{~km}$ above MPR. R01 consists of 733 mapped lineaments, extending as far as $747 \mathrm{~km}$ from their source centre, with a complete radial arc of $360^{\circ}$. There is also a small and confined system of circumscribing fractures surrounding the centre of R01, but offset from the corona centre - possibly associated with an interior rim of Xmukane Corona. R01 interacts directly with systems R02, R04, R07, R14, R17, R19, R23, L01, and indirectly with R21. Cross-cutting relationships reveal R01 to be younger than systems R02, R07, R23, L01, and regional rifting (RF01), but older than systems R04, R14, R17, R19. Graben-fissures from R01 and R21 both extend through the flooded southern rift valley, however, the graben-fissures from R21 are observed to be completely flooded, while the graben-fissures from R01 are only partially flooded. These lava flows are interpreted to be associated with Xmukane Corona, following the formation of the southern rift segment, which is also observed to cut across system R21, further leading to the interpretation of an earlier emplacement of R21. Graben-fissures from system R01 are also interpreted to be younger than the formation of Hervor Corona to the north (Figure 4.1), as many lineaments extend nearly 
uninterrupted across the corona, in addition to cross-cutting a series of fractures circumscribing multiple annuli locations within Hervor Corona. Additionally, some graben-fissures from R01 are observed to be propagating within some circumferential fractures of Hervor Corona when their respective trends match up, providing further evidence of younger graben-fissures following previously established fracture zones.

\subsubsection{System R02}

System R02 is centred at $267.5^{\circ} \mathrm{E}, 27.5^{\circ} \mathrm{S}$ and elevated at $0.8 \mathrm{~km}$ above MPR. R02 contains 730 mapped lineaments, a maximum radius of $560 \mathrm{~km}$, and an $\operatorname{arc}$ of $260^{\circ}$. Its arc may extend further towards the east, but the lineament trace becomes obscured by early lava flooding, graben-fissures from R01, and the local rift faults from the adjacent rift segment (RF04). R02 (Figure 4.8) interacts directly with systems R01, R06, R16, R26, L01, local (RF04, RF07 - RF10) and regional (RF01) rifting (Figure 4.3), and indirectly with system R17. The structure associated with R02 was likely in the gravitational relaxation stage producing local compressional stresses during local rift formation (e.g. see model shown in Figure 8 in Lopez et al., 2008), thereby causing the northwestward propagating rift segment from Xmukane Corona to veer around the structure of R02, and also leading to a right-lateral (dextral) strike-slip component within system L01 to the north of R02. Cross-cutting relationships reveal system R02 to be older than R01, R06, and RF04. Synchroneity is observed between R02 and the remaining local rift faults (RF07 - RF10). Graben-fissures from system R02 are observed to cross-cut those from systems R26 and L01, with synchroneity observed between R02 and R16 based on ambiguous cross-cutting relationships. Despite a lack of direct cross-cutting between R02 and R17, age relationships are inferred based on the age relationship 
between R01 and R17. R01 is observed to cross-cut R02, but gets cross-cut by R17, and therefore, R02 is inferred to be older than R17.
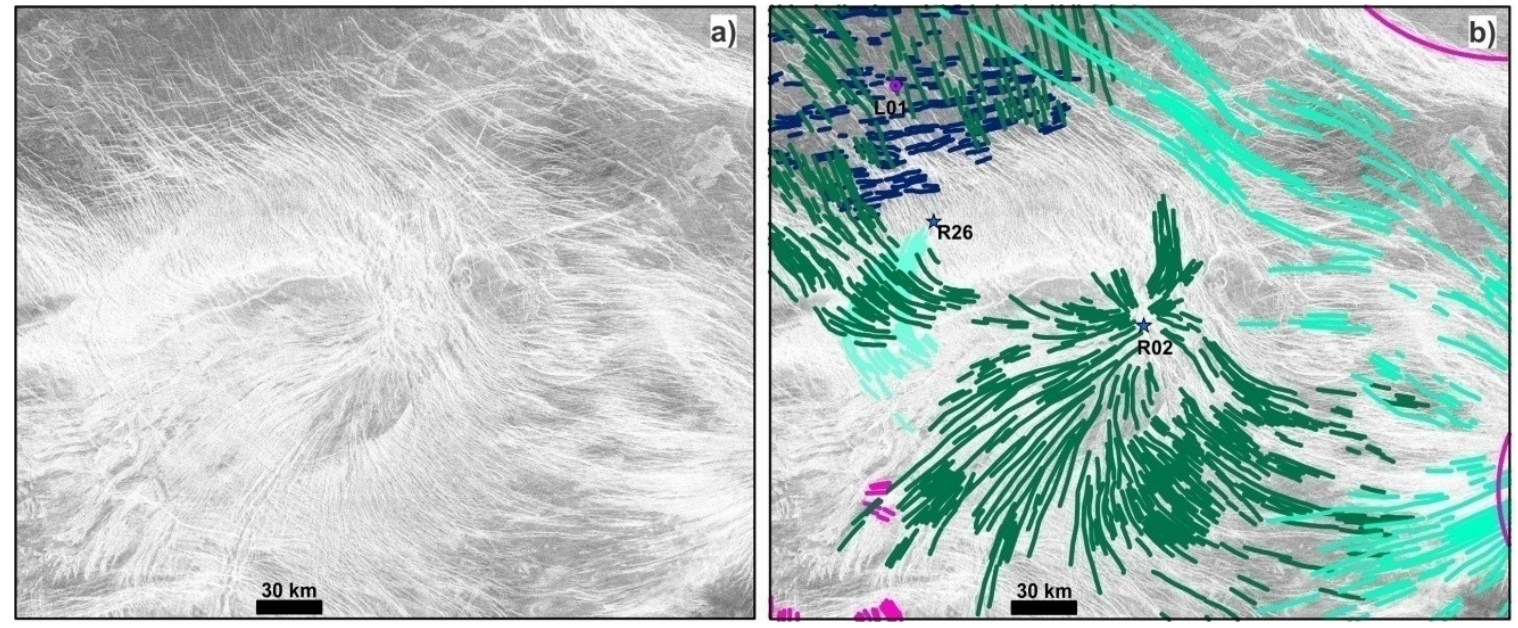

Figure 4.8. Graben-fissure systems R01 (turquoise), R02 (dark green), R16 (pink), R26 (aqua), and L01 (dark blue). (a) Magellan SAR image. (b) SAR image superimposed with mapped systems. Graben-fissures from R02 cross-cut those of R26 and L01, are synchronous with R16, and are cut by R01; R26 is observed to be the oldest of the five. See Figure 4.4 for image location.

\subsubsection{Systems R07, R11, R15, R23, R24, L09, L11}

Collectively, the centres of graben-fissure systems R07, R11, R15, and R23 all fall within the spatial proximity of a hypothesized major mantle upwelling zone, providing a magma source for these multiple systems (Figure 4.9). There are also two interpreted rift segments (based on the local rift fault pattern) located to the northwest (RF11) and southeast (RF12) (Figure 4.3) of these graben-fissure systems - all of which are interpreted to have been formed from this underlying mantle upwelling. Within this broad zone of magmatism, there is a very dense clustering of radar-bright lineaments and an overall high radar backscatter signal throughout, indicating a high amount of tectonomagmatic activity. Some of these interpreted rift faults may also be linked to the magmatic centre of system R16, or could be linked to the regional extension of Parga Chasma, as they follow the NW-SE orientation of the regional rifting pattern (RF01). 

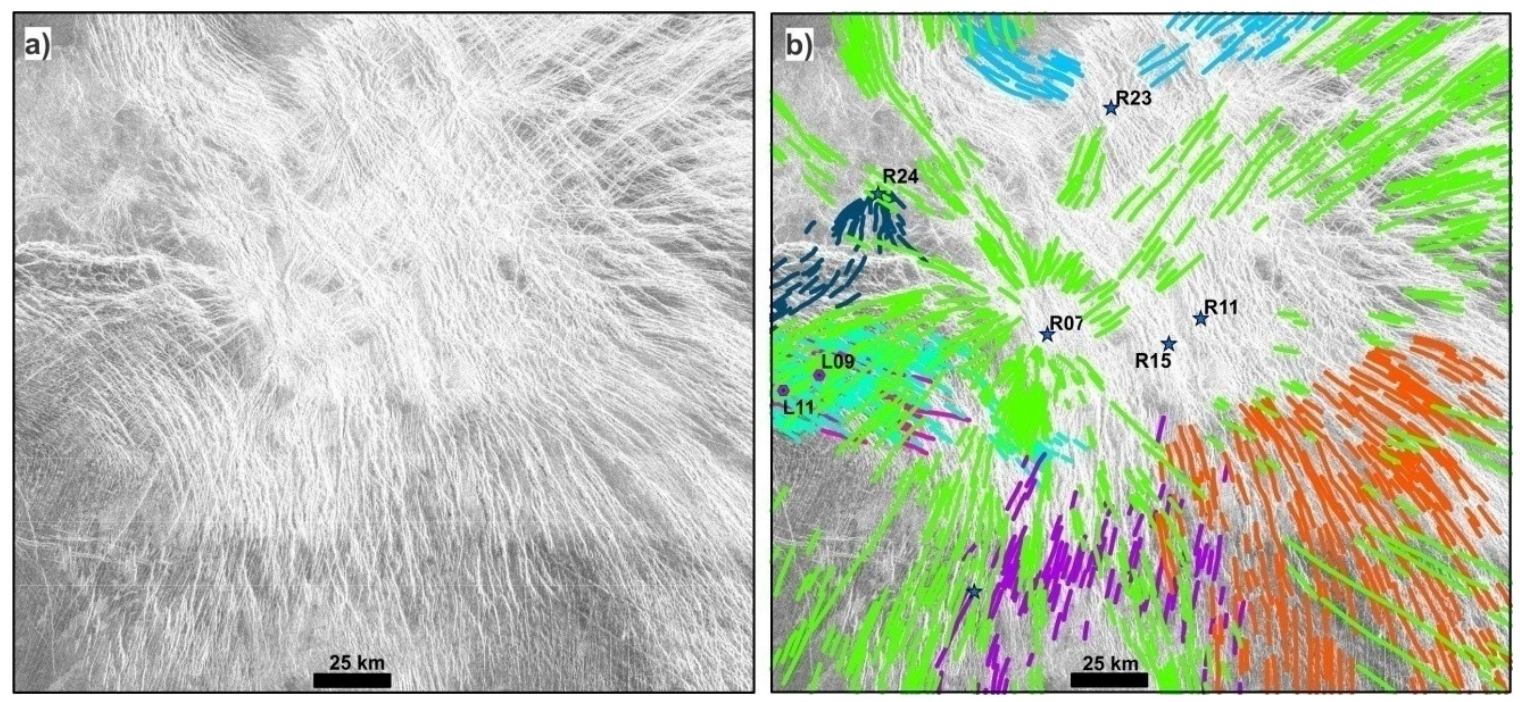

Figure 4.9. Graben-fissure systems R07 (light green), R11 (orange), R15 (purple), R23 (light blue), R24 (dark blue), L09 (turquoise), and L11 (pink). (a) Magellan SAR image. (b) SAR image superimposed with mapped systems. The dense clustering and abundance of radar-bright lineaments lead to the interpretation of a large mantle source underlying these graben-fissure systems. R07 cross-cuts systems R15, L09, and L11, and exhibits synchroneity with systems R23 and R24. R11 cross-cuts R07, thus is interpreted as the youngest. See Figure 4.4 for image location.

\subsection{System R07}

System R07 is centred at $268^{\circ} \mathrm{E}, 30.5^{\circ} \mathrm{S}, 78 \mathrm{~km}$ south-southwest of R23 and similarly elevated at $0.7 \mathrm{~km}$ above MPR. R07 is much larger than R23, featuring a maximum radius of $280 \mathrm{~km}$, with an $\operatorname{arc}$ of $335^{\circ}$. R07 also contains the highest number of mapped lineaments of all mapped systems in the study area at 834. This system is observed to be the largest magmatic pulse from the underlying mantle source beneath systems R07, R11, R15, R23, R24, R28, L09, and L11 (Figure 4.9). R07 interacts directly with neighbouring systems R01, R03, R08, R10, R11, R15, R23, R24, L09, L11, L12, and indirectly with R19 to the northeast. R07 is observed to be older than R07 and R11, and younger than systems R03, R10, R15, R23, R24, R28, L09, L11, and L12, with some partial synchroneity observed with R08 and R01. Despite a lack of directly observed cross-cutting relationships, R07 is inferred to be partially synchronous with R19 based on the age relationship between R01 and R19 (Section 4.2.3.3.1). 


\subsection{System R11}

Centred at $268.25^{\circ} \mathrm{E}, 30.75^{\circ} \mathrm{S}$, system R11 is only $40 \mathrm{~km}$ northeast of R15, and is interpreted to be the youngest pulse from the underlying mantle source. Likely due to its proximity to $\mathrm{R} 15$, it is also elevated $1.3 \mathrm{~km}$ above MPR, but displays a larger radius of $221 \mathrm{~km}$ and arc of $95^{\circ}$, consisting of 237 mapped lineaments. Many of its grouped lineaments also follow the trend direction of the NW-SE regional rift fault pattern (RF01) and so it is likely that many of the graben-fissures from this source had followed the already weakened and fractured crust. Within the vicinity of R11 is an abundance of densely clustered radar-bright lineaments with large thicknesses and sinuosity (likely riftrelated). This clustering is interpreted to consist mostly of regional rift faults (RF01), with a lesser amount of local rift faults (RF12) (Figures 4.3 and 4.9). This provides further evidence in support of system R11 graben-fissures following the previously established zones of weakness associated with the older phase of regional rifting. R11 interacts with graben-fissures from systems R07, R08, R10, R15, and L09. Cross-cutting relationships reveal R11 to be the youngest of all interacting systems, coinciding with the interpretation of $\mathrm{R} 11$ representing the youngest magmatic pulse from the underlying source.

\subsection{System R15}

System R15, centred at $268.25^{\circ} \mathrm{E}, 30.5^{\circ} \mathrm{S}$, is located $40 \mathrm{~km}$ east of system R07 and $14 \mathrm{~km}$ southwest of system R11. It is elevated $1.3 \mathrm{~km}$ above MPR, and is interpreted to be one of the major centres (along with systems R07, R11, and R23) produced by the hypothesized underlying mantle source - also interpreted as the focal point of local triplejunction rifting. R15 features a maximum radius of $197 \mathrm{~km}$, extending southward with an 
arc of $60^{\circ}$ and consisting of 106 mapped lineaments. R15 interacts with systems R07, R11, and L09. Cross-cutting relationships reveal it to be older than systems R07 and R11, but younger than L09. System R15 is interpreted as the oldest pulse from the hypothesized mantle source feeding the centres of systems R07, R11, R15, and R23.

\subsection{System R23}

System R23 is centred at $268^{\circ} \mathrm{E}, 30.5^{\circ} \mathrm{S}$, with its radial geometry split into two separate arc segments - one with an angle of $35^{\circ}$ opening to the northwest, and the other opening $60^{\circ}$ to the northeast. R23 is centred at an elevation of $0.7 \mathrm{~km}$ above MPR, consists of 110 mapped lineaments, and exhibits a maximum radius of $111 \mathrm{~km}$. R23 interacts with systems R01, R07, R27, and the local rift faults from the interpreted northwest trending rift segment (RF11). Cross-cutting relationships reveal system R23 to be older than systems R01, R07, and the local rift faults. It is also inferred to be younger than R27, based on a lesser degree of partial flooding observed within the valley to the northwest of R23. The proposed local rift faults (RF11) and the regional rifting pattern (RF01) are both observed to cross-cut the graben-fissures of R23, thus making R23 older than both the local rifting and regional extension of Parga Chasma.

\subsection{System R24}

System R24 is a small and sinuous radiating system $73 \mathrm{~km}$ northwest of system R07. It is centred at $267^{\circ} \mathrm{E}, 30^{\circ} \mathrm{S}$, and elevated at $1.8 \mathrm{~km}$ above MPR, which is significantly higher than R07. R24 features a maximum radius of $107 \mathrm{~km}$ and consists of 74 mapped lineaments with an arc of $90^{\circ}$. Graben-fissures from R24 trend south then southwest across an interpreted escarpment zone where topography drops sharply in elevation toward the south-southwest $(\sim 1 \mathrm{~km}$ over a lateral distance of $80 \mathrm{~km})$. The top 
"cliff edge" is densely clustered with thick and very sinuous radar-bright lineaments correlated to the regional rifting pattern (RF01) from the extension of Parga Chasma. Graben-fissures of R24 extend across zones of regional rift faulting and are observed to exhibit a degree of synchroneity with the regional rifting; however, some locations do exist where graben-fissures from system R24 are clearly overprinted by regional rift faults. R24 also interacts with lineaments from systems R07, L09, and L11. R24 exhibits well defined cross-cutting relationships with graben-fissures from L09 and L11, but is observed to be cut by graben-fissures of system R07.

\subsection{Systems L09 and L11}

Systems L09 and L11 are linear graben-fissure systems centred close together$266.25^{\circ} \mathrm{E}, 30.5^{\circ} \mathrm{S}$ and $30.75^{\circ} \mathrm{S}$, and elevated only 0.6 and $0.7 \mathrm{~km}$ above MPR, respectively. L09 is the larger of the two, with a maximum length of $143 \mathrm{~km}$, a width of $58 \mathrm{~km}$, and consisting of a total of 236 mapped lineaments. System L11 exhibits a maximum length of $92 \mathrm{~km}$, a width of $40 \mathrm{~km}$, and consists of only 49 mapped lineaments. L11 displays interactions with graben-fissures from systems R07, R24, and L09, and is interpreted to be older than all three systems, and is one of the oldest systems within the study area. L09 interacts with systems R07, R11, R15, R24, and L11. Cross-cutting relationships reveal it to also be older than all interacting systems, except for L11, as previously stated. Aside from being younger than L11, L09 is also observed to be one of the oldest systems in the study area. Both systems are interpreted to predate the regional extension of Parga Chasma (RF01). 


\subsubsection{System R17 and Chuku Corona}

The interpreted centre of Chuku Corona is located approximately $100 \mathrm{~km}$ north of the system R17 centre (Figure 4.10). Chuku Corona displays a deformed morphology represented by an oblique orientation of circumscribing fractures, most notably observed along its northern flank. It is catalogued as having a diameter of $380 \mathrm{~km}$, but due to its deformed morphology, establishing its exact boundaries is difficult. The corona itself does not contain a central radiating system (only R17 which is offset by $\sim 100 \mathrm{~km}$ from the corona centre), or any well defined circumscribing annular fractures. It is observed to be cut by regional rift faults, indicating an early formation that predates the regional extension of Parga Chasma. Additionally, gravitational relaxation has reduced its central topography, with observable flooding within many parts of its centre region.

R17 is centred at $266^{\circ} \mathrm{E}, 24.5^{\circ} \mathrm{S}$ and located $100 \mathrm{~km}$ south of the centre of Chuku Corona (Figure 4.10). Containing a well-established circumferential system of its own, R17 is interpreted to represent a younger magmatic pulse from the same or a nearby mantle source. Magmatism here has produced a radiating system with a maximum observed radius of $186 \mathrm{~km}$, and 391 mapped lineaments creating an arc of a nearlycomplete $330^{\circ}$. Similar to the depressed centre of Chuku Corona, R17 is elevated only 0.7 $\mathrm{km}$ above MPR, despite being situated within the rim of Chuku Corona, along the southern flank. R17 displays interactions with graben-fissures from systems R01, R02, and the regional rift faulting of Parga Chasma north of the study area. R17 is observed to cross-cut the graben-fissures from both $\mathrm{R} 01$ and $\mathrm{R} 02$, as well as the regional rift faulting (RF01), and is consequently interpreted as one of the youngest mapped systems during this study. 

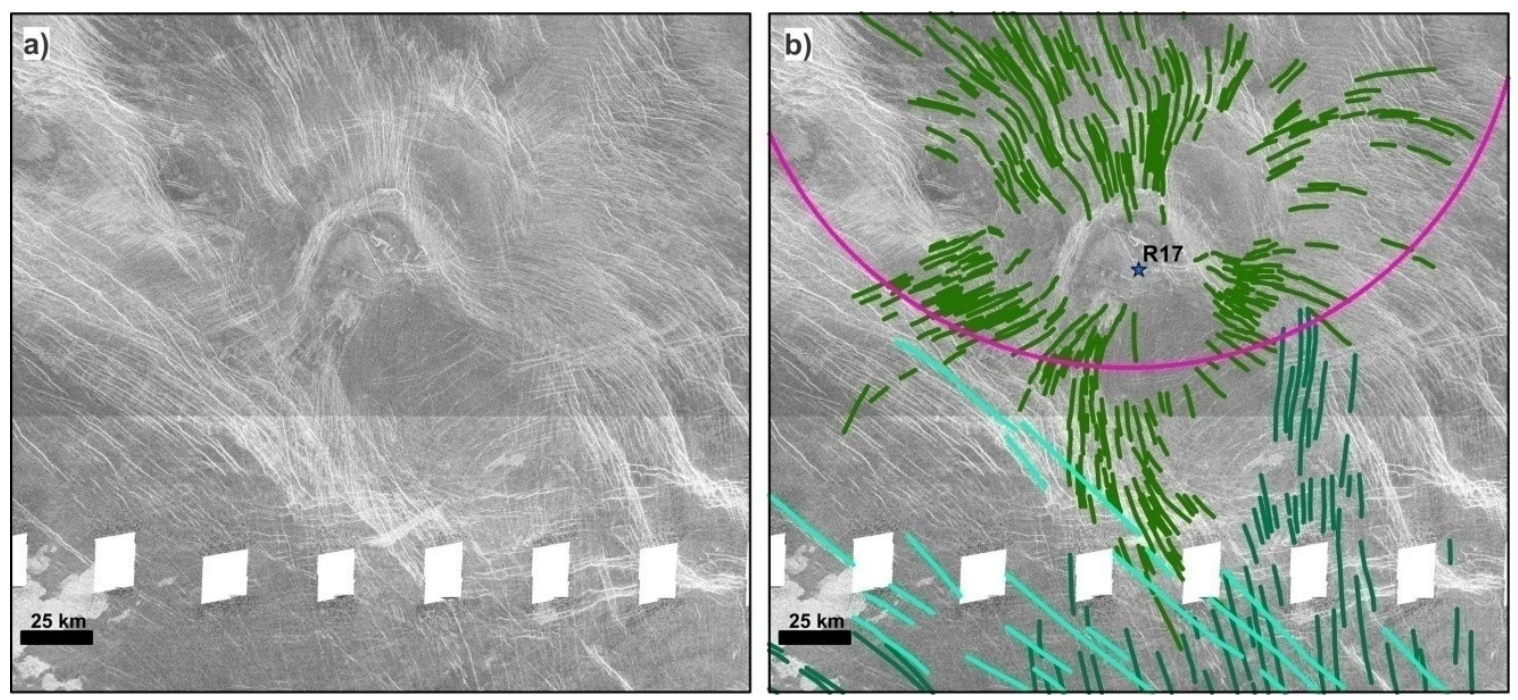

Figure 4.10. Graben-fissure systems R01 (turquoise), R02 (dark green), and R17 (green); the rim of Chuku Corona is outlined in magenta. (a) Magellan SAR image. (b) SAR image superimposed with mapped systems. Graben-fissures from R17 cross-cut both R01 and R02, and R17 is interpreted as the youngest. See Figure 4.4 for image location.

\subsubsection{Systems R05, R06, R12, R13, R22, L08: Kulimina Corona}

Kulimina Corona is a deformed ellipsoidal corona with a minimum and maximum diameter of $160 \mathrm{~km}$ and $215 \mathrm{~km}$, respectively. It is located in the northwestern corner of the study area and centred approximately at $262^{\circ} \mathrm{E}, 27.5^{\circ} \mathrm{S}$ (Figure 4.11 ). Within the boundaries of its deformed and ellipsoidal annulus lie the centres of systems R05, R06, R12, and R13, with system R22 situated just outside its eastern flank. Linear system L08 passes across its northwestern border. Kulimina Corona is interpreted to be the source of triple-junction style rifting, forming three separate rift segments, extending to the northnorthwest (RF07), east (RF08), and southeast (RF09) (Figures 4.3 and 4.11). The rift valley to the east (RF08) contains rift faults in an east-west orientation, but also displays rift faults in a northwest-southeast orientation. This indicates the possibility of multiple local rifting events, with the NW-SE trending segment (RF10) having formed from either the hypothesized magmatic centre to the southeast underlying systems R07, R11, R15, $\mathrm{R} 23$, or from a cryptic centre interpreted to underlie radiating system R16, $323 \mathrm{~km}$ east of 
Kulimina Corona. These NW-SE trending rift faults may also comprise part of the regional rifting (RF01) from Parga Chasma extension. Systems R05, R06, R12, and R13 are linked to the main building stage of Kulimina Corona (Figure 4.11), and all three are interpreted to postdate the regional extension of Parga Chasma (with some synchroneity observed in R05 and R12 in comparison with the regional rifting). Additionally, R06 cross-cuts all of these systems and its associated graben-fissures are observed to follow the weakened crustal zones from established local and regional rift faulting, and so R06 is interpreted as the youngest and largest magmatic pulse from the mantle source underlying Kulimina Corona.
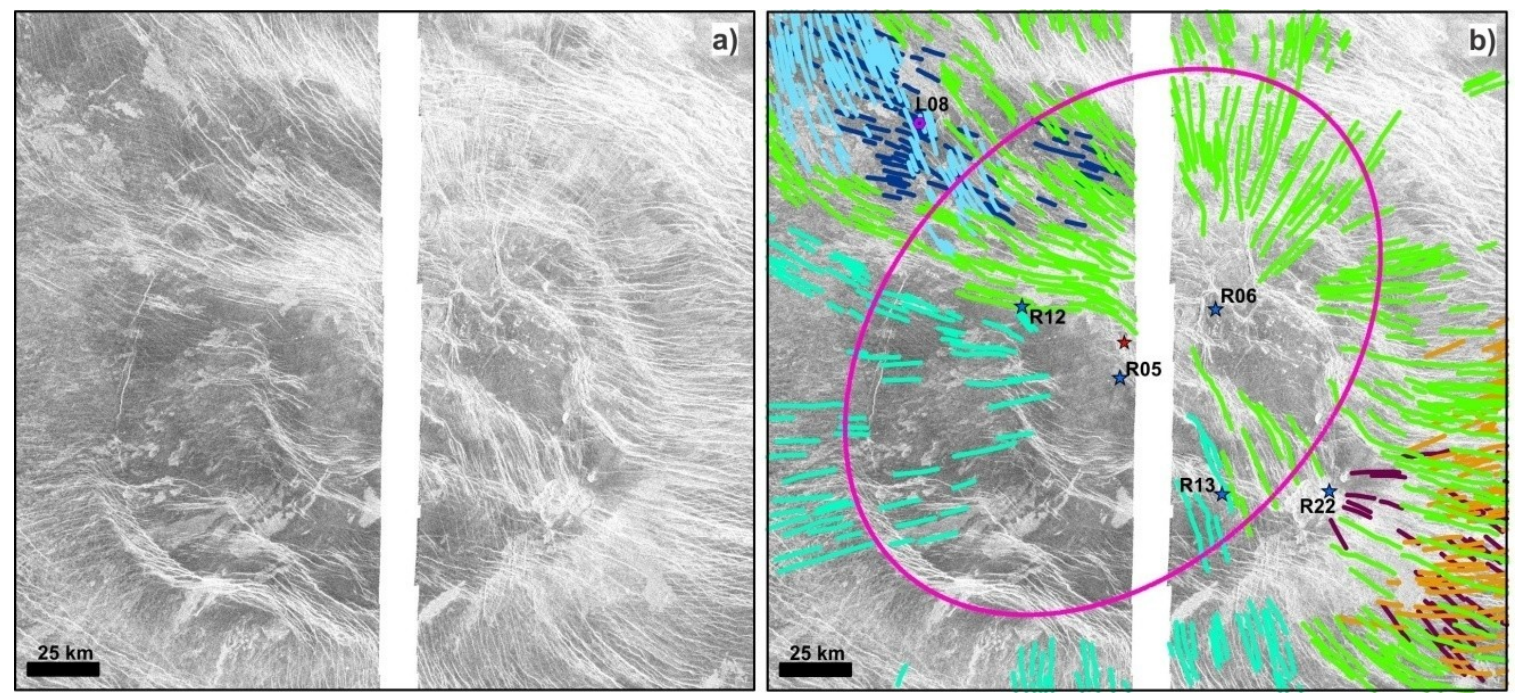

Figure 4.11. Graben-fissure systems R05 (turquoise), R06 (light green), R12 (light blue), R13 (orange), R22 (purple), and L08 (dark blue); the rim of Kulimina Corona is outlined in magenta. (a) Magellan SAR image. (b) SAR image superimposed with mapped systems. R06 cross-cuts all interacting systems and is interpreted as the youngest. See Figure 4.4 for image location.

\subsection{System R05}

R05 is centred at $262^{\circ} \mathrm{E}, 28^{\circ} \mathrm{S}$, only $42 \mathrm{~km}$ southwest of R06. It is elevated $1.5 \mathrm{~km}$ above MPR, features a maximum radius of $448 \mathrm{~km}$ from 344 mapped lineaments, and an arc split into two separate directions - west-southwest and southeast at $50^{\circ}$ and $45^{\circ}$ angles, respectively (Figure 4.11). R05 is located only $12 \mathrm{~km}$ south of the Kulimina 
Corona centre, but interacts only with graben-fissures from R06. However, some grabenfissures from system R12 may belong to the centre of R05 - based on the spatial proximity of R12 and the orientation of its graben-fissures - which in turn would imply interactions with system L08. If this is the case, then R05 would be observed to postdate L08. Cross-cutting relationships reveal R05 to be older than R06.

\subsection{System R06}

Centred within Kulimina Corona at $262.5^{\circ} \mathrm{E}, 27.5^{\circ} \mathrm{S}$, system R06 is a large radiating system elevated $1.2 \mathrm{~km}$ above MPR with 711 mapped lineaments and features a maximum observed radius of $352 \mathrm{~km}$, with a $250^{\circ}$ arc (Figure 4.11). R06 interacts with graben-fissures from systems R05, R12, R13, R16, R22, L06, L08, and L10. It is also interpreted to postdate local and regional rifting (RF01, RF07 - RF10) and its associated graben-fissures are observed to follow the trend of established local and regional rift faults from the formation of Parga Chasma. R06 is observed to cross-cut all systems interacting with it, and is therefore interpreted to be the youngest event within the immediate vicinity.

\subsection{Systems R12 and L08}

$\mathrm{R} 12$ is a radiating system centred at $262.75^{\circ} \mathrm{E}, 27.5^{\circ} \mathrm{S}$, and $38 \mathrm{~km}$ west-northwest from the centre of Kulimina Corona (Figure 4.11). R12 consists of 136 mapped lineaments, a maximum observed radius of $213 \mathrm{~km}$, and an arc of $50^{\circ}$ opening towards the north. L08 is a linear system centred at $262.25^{\circ} \mathrm{E}, 27^{\circ} \mathrm{S}$, extending across the northern flank of Kulimina Corona. L08 features a maximum length measured at $150 \mathrm{~km}$, a width of $54 \mathrm{~km}$, and consists of 84 mapped lineaments. Both systems, R12 and L08, have similar elevations of $1.6 \mathrm{~km}$ and $1.8 \mathrm{~km}$ above MPR, respectively. R12 interacts with 
graben-fissures from R06 and L08. R12 is observed to cross-cut graben-fissures from L08, and be cross-cut by those from R06. L08 interacts with graben-fissures from R06 and R12, and is observed to be cross-cut by both. Additionally, the graben-fissures from L08 are observed to be partially flooded by lava flows from Kulimina Corona - both within and outside the corona centre - and therefore, L08 is interpreted to be older.

\subsection{Systems R13 and R22}

Systems R13 and R22 are only $38 \mathrm{~km}$ apart and centred at $262.5^{\circ} \mathrm{E}$ and $263^{\circ} \mathrm{E}$, $28^{\circ} \mathrm{S}$, respectively (Figure 4.11). Each system is situated at similar elevations of $1.5 \mathrm{~km}$ and $1.3 \mathrm{~km}$ above MPR, respectively. System R13 is the larger and younger of the two, consisting of 172 mapped lineaments, a maximum radius of $203 \mathrm{~km}$, and an arc of $90^{\circ}$; R22 consists of 63 mapped lineaments, a maximum radius of $114 \mathrm{~km}$, and an arc of $65^{\circ}$. R22 is observed to be cross-cut by graben-fissures from R13, and local rift faults (RF09). R22 is also observed to be partially flooded by lava flows from Kulimina Corona, further indicating an early formation. Both systems interact with the large system R06, while R13 also interacts with R16 and L10. Cross-cutting relationships reveal R13 to be younger than R22, L10 and regional rift faulting (RF01); synchronous with R16; and older than R06.

\subsubsection{System R16}

$\mathrm{R} 16$ is located at $265.5^{\circ} \mathrm{E}, 27.5^{\circ} \mathrm{S}$, features a maximum radius of $196 \mathrm{~km}$, three separate arcs of $85^{\circ} \mathrm{S}, 70^{\circ} \mathrm{NW}$, and $25^{\circ} \mathrm{E}$, and consists of 309 mapped lineaments (Figure 4.12). R16 is interpreted as the source for graben-fissures propagating primarily to the northwest, and a lesser amount propagating to the south and to the east. The location of R16 as a magmatic centre suggests a link to local rift faults trending to the northwest 
(RF10) and southeast (RF11) of R16 (Figure 4.3), as well as explaining the presence of adjacent and surrounding lava flows to the southwest.

R16 interacts with systems R02, R06, R13, L02, and L10 (Figure 4.12). Crosscutting relationships reveal R16 to be younger than L02 and L10; synchronous with R02 and R13; and either older or partially synchronous with R06. Cross-cutting relationships are difficult to resolve between R16 and the regional rifting (RF01), but lava flows associated with R16 are observed to both cross-cut and be cross-cut by regional rift faults, and so some degree of synchroneity is inferred.
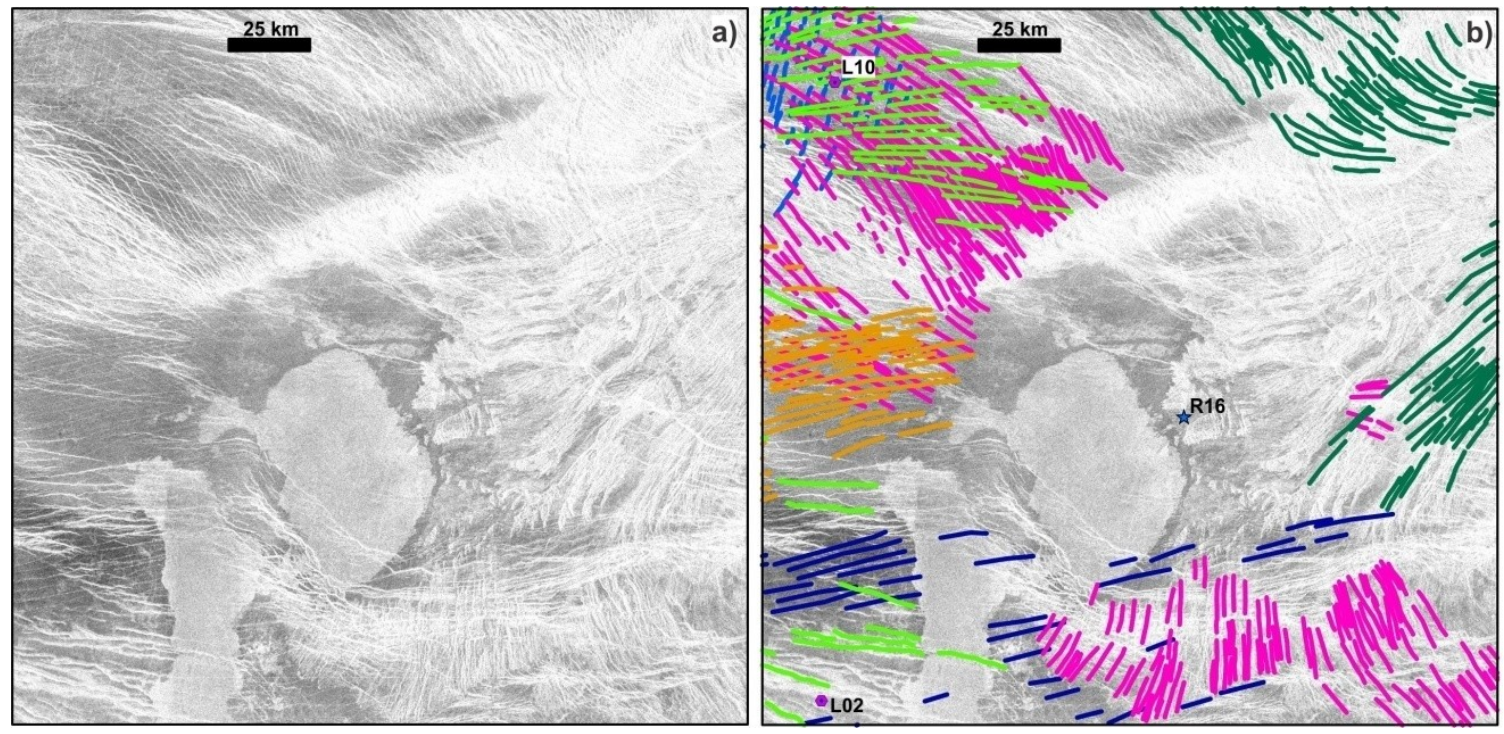

Figure 4.12. Graben-fissure systems R02 (dark green), R06 (light green), R13 (orange), R16 (pink), L02 (dark blue), and L10 (blue). (a) Magellan SAR image. (b) SAR image superimposed with mapped systems. Graben-fissures from R16 cross-cut those from L02 and L10; are relatively synchronous with those from R02 and R13; and are cut by R06 - indicating R06 as the youngest system. See Figure 4.4 for image location. 


\subsubsection{System L07 and Gertjon Corona}

Gertjon Corona is an ellipsoidal corona situated at $266^{\circ} \mathrm{E}, 30^{\circ} \mathrm{S}$ along the eastern border of the study area. It has a maximum diameter of $210 \mathrm{~km}$ and a minimum diameter of $165 \mathrm{~km}$ (Figure 4.13). Gertjon Corona contains heavily deformed annulus of circumscribing fractures and lacks a radiating system focussed on its centre. It is located at a possible junction point for the local southeast trending rift segment (RF03) from Ts'an Nu Mons (Figure 4.3).

L07 is a small linear system that extends from the southwestern flank of Gertjon Corona to the western plains. L07 is situated at $275.5^{\circ} \mathrm{E}, 30.5^{\circ} \mathrm{S}$, and consists of 194 mapped lineaments with a length of $152 \mathrm{~km}$ and width of $54 \mathrm{~km}$ (Figure 4.13). The central area is located at an elevation of $1.2 \mathrm{~km}$ above MPR. L07 interacts with grabenfissures from R03, R04, R18, and the regional rifting of Parga Chasma. Graben-fissures from L07 are observed to be cross-cut by the regional rift faults (RF01), and so are interpreted to predate Parga Chasma extension. Ambiguous cross-cutting relationships are observed between the graben-fissures of L07 with those from R03 and R18 - which are also cut by regional rift faults - and so synchroneity between these systems is inferred. Cross-cutting relationships between L07 and R04 are difficult to resolve; however, graben-fissures from R04 postdate the regional rifting. Therefore, L07 is interpreted to be older than R04. 

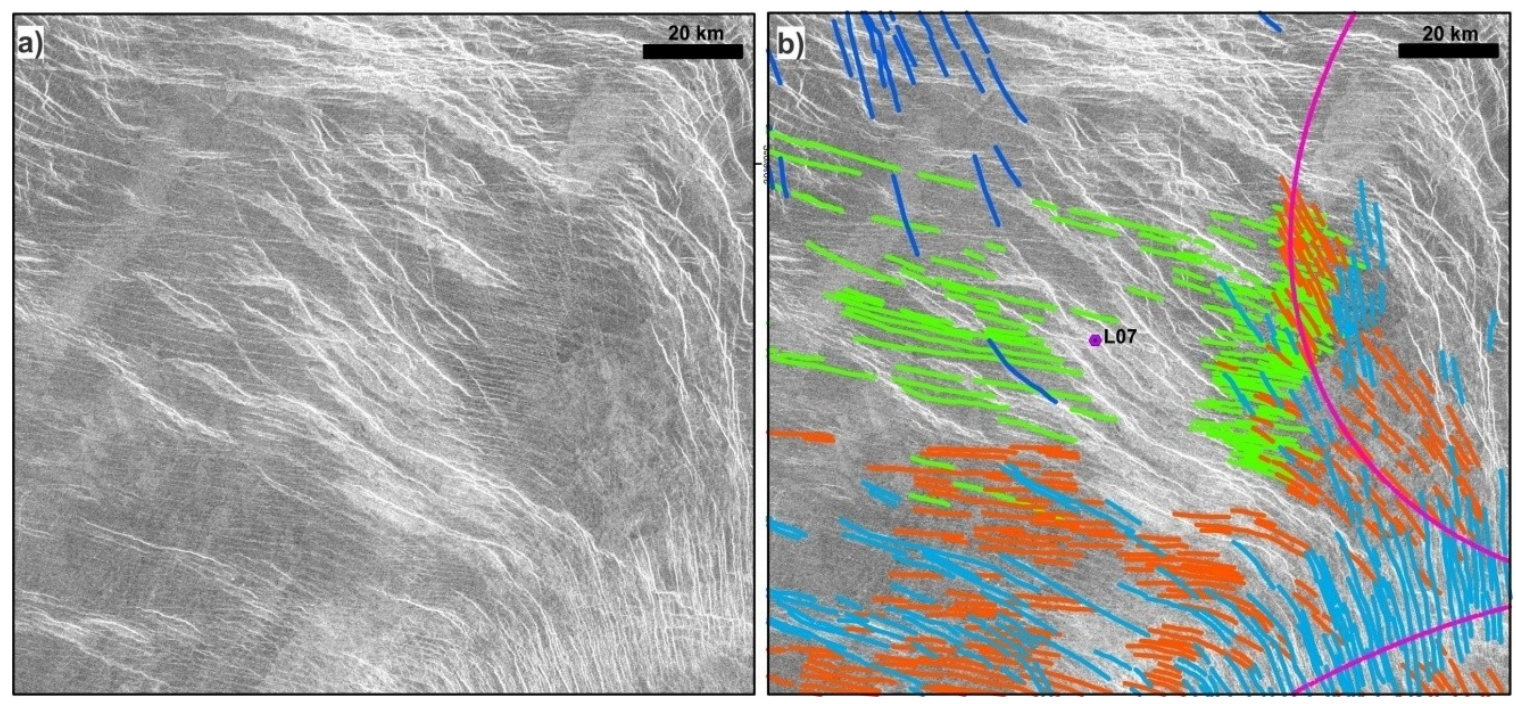

Figure 4.13. Graben-fissure systems R03 (light blue), R04 (blue), R18 (orange), and L07 (light green); the western rim of Gertjon Corona is outlined in magenta. (a) Magellan SAR image. (b) SAR image superimposed with mapped systems. Cross-cutting reveals L07 to be older than R04, and synchronous with R03 and R18. See Figure 4.4 for image location.

\subsubsection{System R25 and Otohime Tholus}

Otohime Tholus is a small circular domal structure, roughly $20 \mathrm{~km}$ in diameter, located at $268.25^{\circ} \mathrm{E}, 32^{\circ} \mathrm{S}$ (Figure 4.14). Graben-fissures belonging to systems R07, R15, and R25 all extend towards and past Otohime Tholus but cannot be tracked across the structure. Because of this observation the formation of Otohime Tholus is interpreted to postdate systems R07, R15, and R25.

R25 is a small radiating system that propagates southeast towards Otohime Tholus, centred at $267.75^{\circ} \mathrm{E}, 31.5^{\circ} \mathrm{S}$ (Figure 4.14), and situated at an elevation of $0.7 \mathrm{~km}$ above MPR. R25 consists of 104 mapped lineaments, spreading over an arc of $60^{\circ}$ opening towards the southeast, and extending to a maximum radius of $99 \mathrm{~km}$. R25 (Figure 4.14) interacts only with graben-fissures from systems R07 and R15, with cross-cutting relationships revealing it to be the oldest of these systems. 

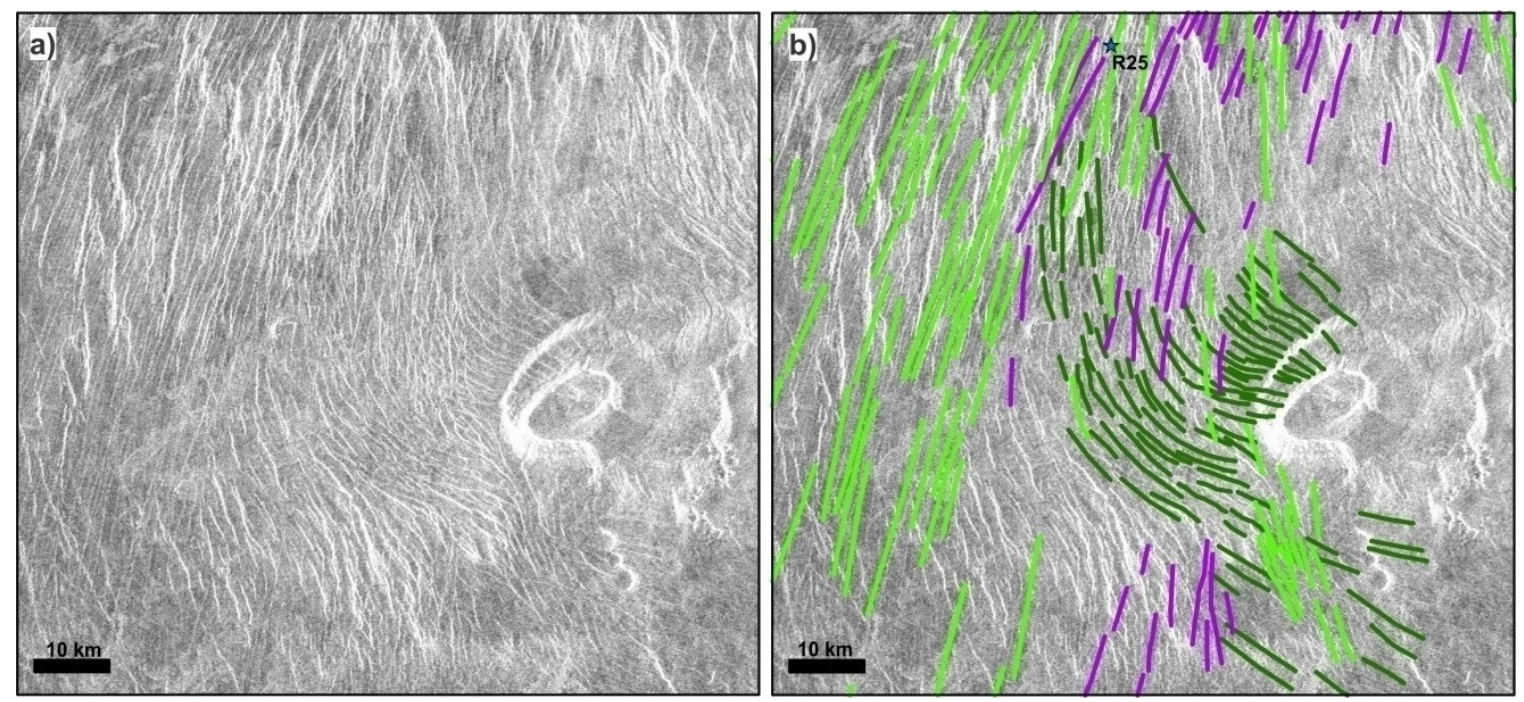

Figure 4.14. Graben-fissure systems R07 (light green), R15 (purple), and R25 (green); Otohime Tholus is the circular structure to the east lacking graben-fissures. (a) Magellan SAR image. (b) SAR image superimposed with mapped systems. Graben-fissures from R25 are observed to be cut by those of R07 and R15, and R25 is interpreted as the oldest. See Figure 4.4 for image location.

\subsubsection{System Size Distribution throughout the Study Area}

Of the 47 grouped systems, the majority (37) have maximum radii/lengths less than $250 \mathrm{~km}$, while the remaining systems (10) extend to greater distances (Figure 4.15). Two systems (R01 and R02) extend more than $550 \mathrm{~km}$ from their source. The smaller sizes of most observed graben-fissure systems $(<500 \mathrm{~km})-$ compared to previous mapping work (e.g. Ernst et al., 2003; Studd et al., 2011) in which multiple radiating systems had been observed with maximum radii exceeding $1,000 \mathrm{~km}$ - could be attributed to the detailed mapping of a larger number of separate systems within a smaller study area (1.5 million $\mathrm{km}^{2}$ compared to $>10$ million $\mathrm{km}^{2}$ study areas in Ernst et al., 2003 and Studd et al., 2011). There is also the possibility that some linear graben-fissure systems could actually be distal parts of larger radiating and/or circumferential systems (e.g. Ernst et al., 2003). 


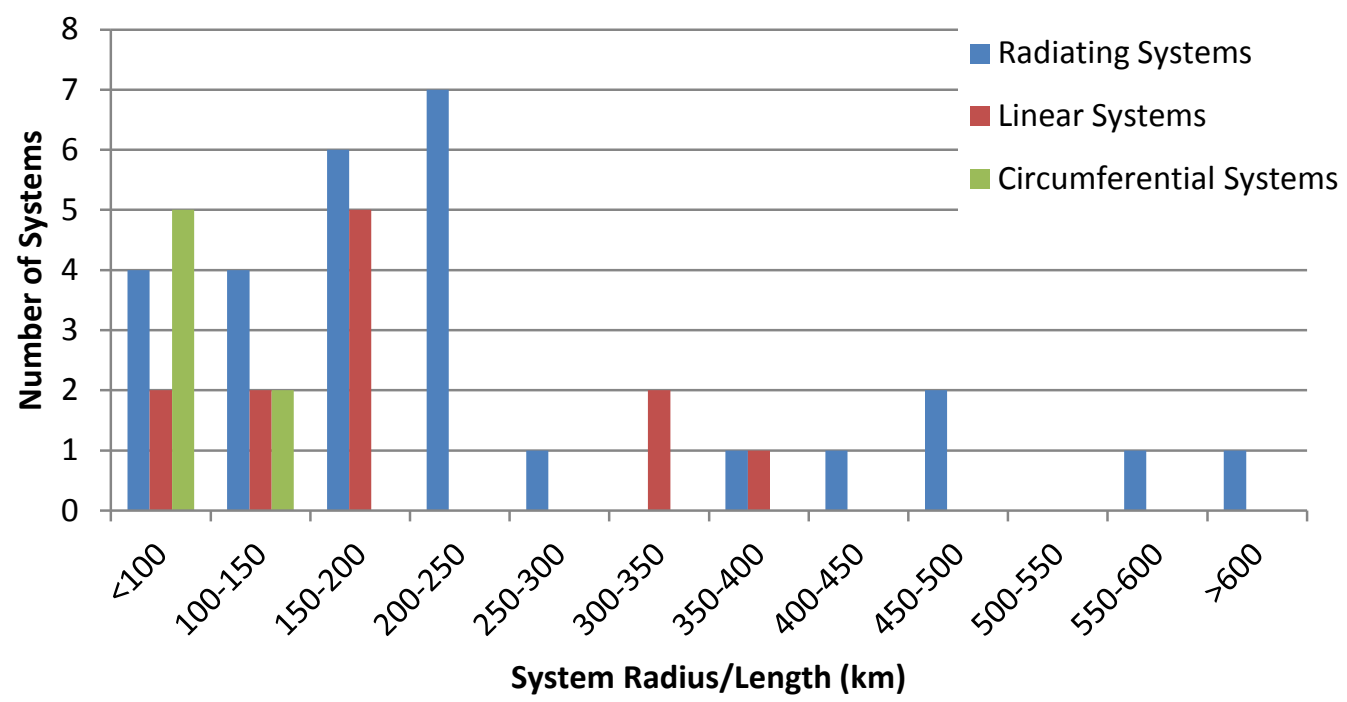

Figure 4.15. Histogram of the maximum radius (radiating/circumferential systems) or length (linear systems) of all mapped graben-fissure systems. Values come from the data catalogued in Tables 4.1 - 4.3.

\subsubsection{Topographic Variations throughout the Study Area}

The relationship between system size and central elevation was also obtained for all systems (Figure 4.16). Within the study area, all systems are situated at elevations above MPR. This result coincides with the tectonic setting of the study area as part of the uplifted volcanic plateau that largely defines Themis Regio. The southern boundaries of this plateau are present within the study area - marked by the southwestern regional rift faults (RF01) (Figure 4.3) and an escarpment - which exhibits a $\sim 1 \mathrm{~km}$ drop in a southsouthwest direction across a lateral distance of $\sim 80 \mathrm{~km}$.

A cluster of variable system elevations $(0.5-2.5 \mathrm{~km}$ above MPR) is observed for the majority of systems with maximum sizes $<300 \mathrm{~km}$. The largest systems $(>400 \mathrm{~km})$ are observed to reach elevations no higher than $1.5 \mathrm{~km}$ above MPR. Many systems associated with major geologic structures - notably coronae and large volcanoes - are situated at higher elevations. Additionally, graben-fissure systems that are centred within a single corona often exhibit distinct central elevations for their respective centres. This 
could imply an unequal distribution of topography variation during the early constructional uplift and later gravitational relaxation stages of corona formation, or a time-transgressive formation of graben-fissure systems from a singular mantle source.

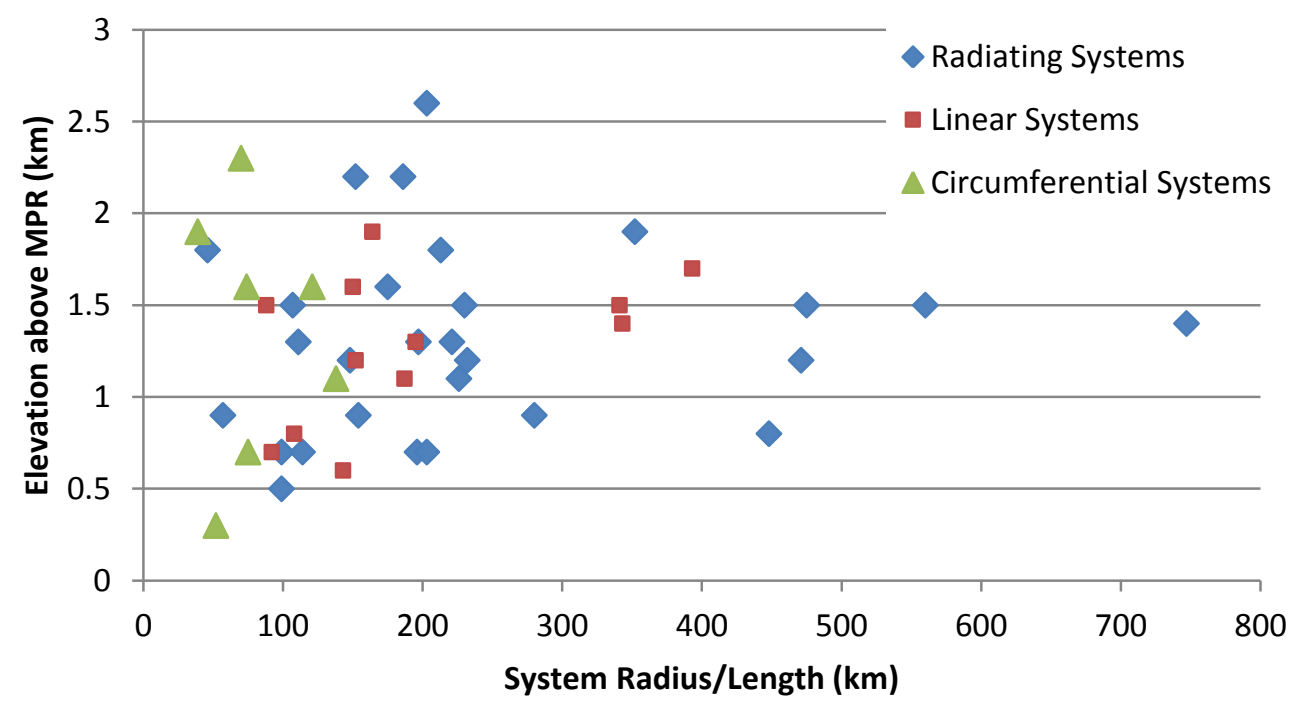

Figure 4.16. Relationship between the elevation above MPR and the maximum sizes of associated grabenfissure systems. Values come from data catalogued in Tables 4.1-4.3.

\subsection{Relative Chronology of Tectono-Magmatic Events}

Using similar methods employed by Studd et al. (2010), a relative chronology of the tectono-magmatic events within the study area has been created (Figure 4.17). This method utilized the analysis of cross-cutting relationships to interpret the temporal emplacement of graben-fissure systems with respect to rifting. For this study it has also been assumed that the time period of emplacement for each graben-fissure system was short ( a few Myr), based on terrestrial studies of dyke swarm emplacement (e.g. Ernst et al., 2001; Ernst, 2014). The initial regional extension and rifting of Parga Chasma is interpreted to have occurred over a relatively short time span of $10-50 \mathrm{Myr}$, based on the terrestrial rift review and catalogue by Sengör and Natal'in (2001), and is placed in the centre of the produced timeline. For the purposes of this study, the regional rifting of 
Parga Chasma is assumed to have temporal synchroneity. However, the timing of local triple-junction rifting events have variable timing and are linked to the localized magmatic centres from which they are interpreted to be focussed on.

To build this chronology, the relationships between neighbouring radiating and linear graben-fissure systems and/or the local/regional rifting of Parga Chasma (Table 4.4) were integrated to produce a timeline of tectono-magmatic events in the study area (Figure 4.17). The criteria used for determining the relative age relationships were presented in Section 4.1, and is summarized herein.

Graben-fissure lineaments that clearly cross-cut rift-related lineaments are interpreted to have been emplaced after rifting, whereas graben-fissure lineaments that are clearly cross-cut by rifting are interpreted to have been emplaced prior to rifting. When there is ambiguity between interacting graben-fissure and/or rift-related lineaments, or contradictory cross-cutting is observed, synchronous emplacement is interpreted to have occurred. Age relationships were further constrained when the presence of lava flooding (partially or completely) obscures the radar signal of grabenfissures and/or rift faults. In this timeline, horizontal lines are used to schematically represent the time span of possible age ranges of each system, with time moving from left to right (older to younger). When graben-fissures interacted with regional rift faults from Parga Chasma, age relationships relative to rifting could be determined and the system was provisionally placed on the left, centre, or right side of the timeline. When the graben-fissures from different systems were observed to intersect, age relationships between neighbouring systems could be obtained and the relative positioning of these systems on the timeline could be refined. 
Older

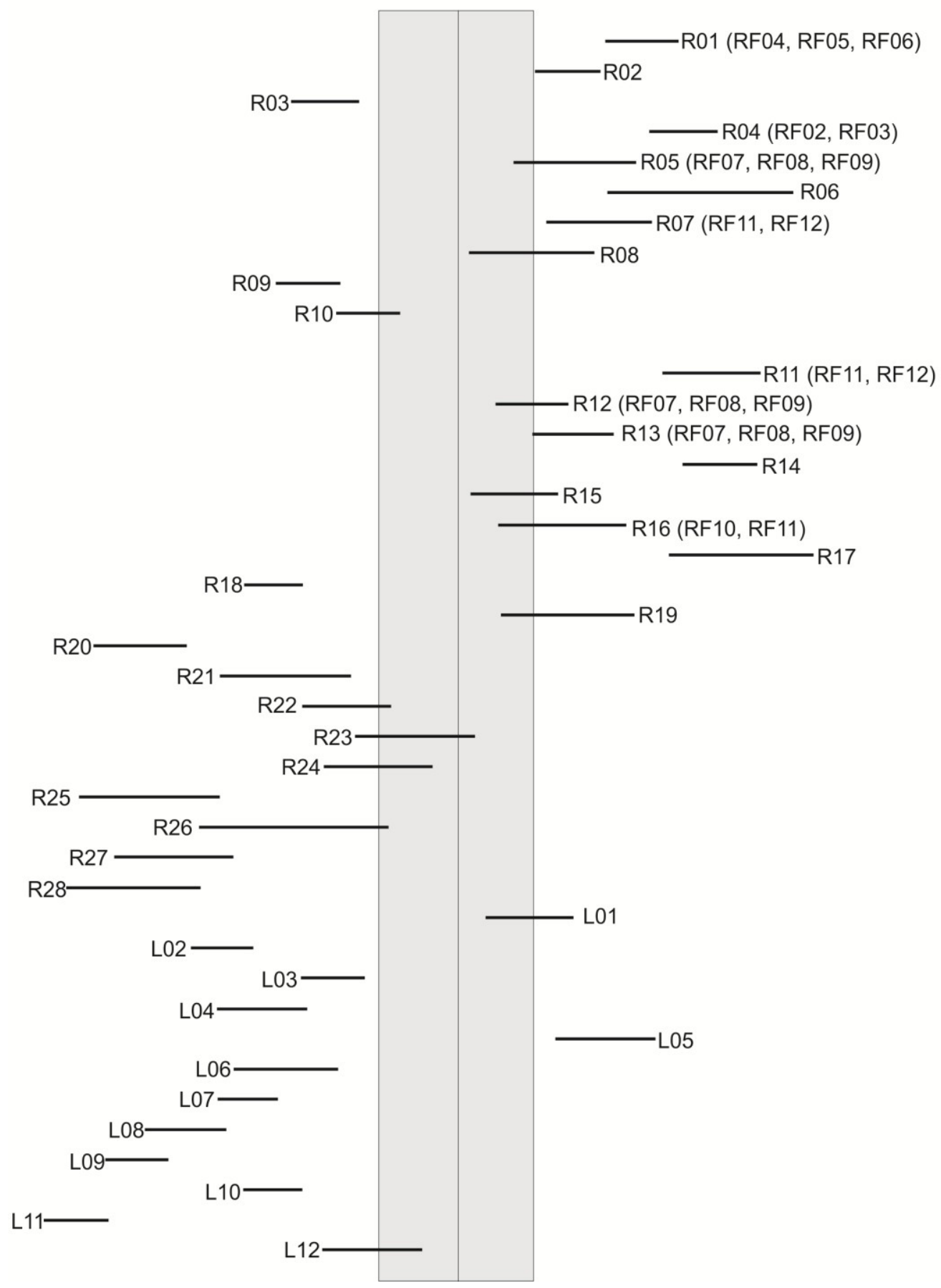

Figure 4.17. Timeline of the tectono-magmatic events within the study area. The regional rifting of Parga Chasma is taken as the baseline, with the interpreted temporal formation of each graben-fissure system relative to regional rifting (RF01). Older systems are placed towards the left side; younger towards the right. Systems interpreted to be synchronous with regional rifting intersect the baseline. Systems are numbered from top to bottom with horizontal lines representing their interpreted age ranges relative to each other and to the regional extension (Table 4.4). Local rift fault segments are listed in parentheses next to the system(s) they are genetically linked to. 
Table 4.4. Summary of cross-cutting relationships between radiating and linear graben-fissure systems catalogued in the study area. Systems in the first column are compared to all interacting systems or regional rift faults in subsequent columns as younger $(<)$, coeval $(=)$, older $(>)$, or a combination thereof. Types of cross-cutting observed are colour-coded based on either direct (blue) or indirect (green) interactions.

\begin{tabular}{|c|c|c|c|c|c|c|c|c|c|c|c|c|c|c|}
\hline & R01 & R02 & R03 & R04 & R05 & R06 & R07 & R08 & R09 & R10 & R11 & R12 & R13 & R14 \\
\hline R01 & & $<$ & & $>/=$ & & & $<$ & & & & & & & $>$ \\
\hline R02 & $>$ & & & & & $>$ & & & & & & & & \\
\hline R03 & & & & $>$ & & & & $>$ & & $>$ & & & & \\
\hline R04 & $</=$ & & $<$ & & & & & & $<$ & & & & & $>$ \\
\hline R05 & & & & & & $>/=$ & & & & & & $=$ & & \\
\hline R06 & & $<$ & & & $</=$ & & & & & & & $<$ & $</=$ & \\
\hline R07 & $>$ & & $<$ & & & & & $>$ & & $<$ & $<$ & & & \\
\hline R08 & & & $<$ & & & & $>/=$ & & & $<$ & $>$ & & & \\
\hline R09 & & & & $>$ & & & . & & & & 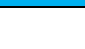 & & & \\
\hline R10 & & & $</=$ & & & & $>$ & $>$ & & 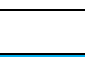 & $>$ & & & \\
\hline R11 & & & & & & & $<$ & $<$ & & $<$ & & & & \\
\hline R12 & & & & & & $>$ & & & & & & & & \\
\hline R13 & & & & & & $>/=$ & & & & & & & & \\
\hline R14 & $</=$ & & & $=$ & & & & & & & & & & \\
\hline R15 & & & & & & & $>$ & & & & $>$ & & 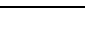 & \\
\hline R16 & & $=$ & & & & $>/=$ & & & & & & & $=$ & \\
\hline R17 & $</=$ & $<$ & & & & & & & & & & & & \\
\hline R18 & & & $>/=$ & $>$ & & & & & & & & & & \\
\hline R19 & $>/=$ & & & & & & $=$ & & & & & & & $>$ \\
\hline R20 & & & & $>$ & & & & & & & & & & \\
\hline R21 & & & & & & & & & & & & & 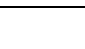 & \\
\hline R22 & & & & & & $>$ & - & & & & & & $>$ & \\
\hline R23 & $>$ & & & & & & $>$ & & & & & & & \\
\hline R24 & & & & & & & $>$ & & & & & & & \\
\hline R25 & & & & & & & $>$ & & & & & & & \\
\hline R26 & & $>$ & & & & & 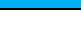 & & & & & & & \\
\hline R27 & & & & & & & $>$ & & & & & & & \\
\hline R28 & & $>$ & & & & & $>$ & & & & & & & \\
\hline L01 & $>$ & $>$ & & & & & & & & & & & & \\
\hline L02 & & & & & $>$ & & & & & & & & & \\
\hline L03 & & & & & $>$ & & & & & & & & & \\
\hline L04 & & & & $>$ & & & & & & & & & & \\
\hline L05 & & & $<$ & & & & & & & & & & & \\
\hline L06 & & & & & & $>$ & & & & & & & & \\
\hline L07 & & & $>/=$ & $>$ & & & & & & & & & & \\
\hline L08 & & & & & & $>$ & & & & & & $>$ & & \\
\hline L09 & & & & & & & $>$ & & & & $>$ & & & \\
\hline L10 & & & & & & $>$ & 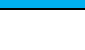 & & & & & & $>$ & \\
\hline L11 & & & & & & & $>$ & & & & & & & \\
\hline L12 & & & $</=$ & & & & $>$ & $>$ & & & & & & \\
\hline
\end{tabular}


Table 4.4. continued.

\begin{tabular}{|c|c|c|c|c|c|c|c|c|c|c|c|c|c|c|}
\hline & R15 & R16 & R17 & R18 & R19 & R20 & R21 & R22 & R23 & R24 & R25 & R26 & R27 & R28 \\
\hline R01 & & & $>$ & & $>$ & & $<$ & & $<$ & & & & & \\
\hline R02 & & $<$ & $>$ & & & & & & & & & $<$ & & \\
\hline R03 & & & & $</=$ & & & & & & & & & & \\
\hline R04 & & & & $<$ & & $<$ & & & & & & & & \\
\hline \multicolumn{15}{|l|}{ R05 } \\
\hline R06 & & $</=$ & & & & & & $<$ & & & & & & \\
\hline R07 & $<$ & & & & $>$ & & & & $<$ & $<$ & & & & $<$ \\
\hline \multicolumn{15}{|l|}{ R08 } \\
\hline \multicolumn{15}{|l|}{ R09 } \\
\hline \multicolumn{15}{|l|}{ R10 } \\
\hline R11 & $<$ & & & & & & & & & & & & & \\
\hline \multicolumn{15}{|l|}{ R12 } \\
\hline R13 & & $\overline{=}$ & & & & & & $<$ & & & & & & \\
\hline R14 & & & & & $<$ & & & & & & & & & \\
\hline \multicolumn{15}{|l|}{ R15 } \\
\hline R16 & & & & & & & & $<$ & & & & & $<$ & \\
\hline \multicolumn{15}{|l|}{ R17 } \\
\hline \multicolumn{15}{|l|}{ R18 } \\
\hline \multicolumn{15}{|l|}{ R19 } \\
\hline \multicolumn{15}{|l|}{ R20 } \\
\hline \multicolumn{15}{|l|}{ R21 } \\
\hline R22 & & $>$ & & & & & & & & & & & . & \\
\hline R23 & & & & & & & & & & & & & $<$ & \\
\hline \multicolumn{15}{|l|}{ R24 } \\
\hline \multicolumn{15}{|l|}{ R25 } \\
\hline \multicolumn{15}{|l|}{ R26 } \\
\hline R27 & & $>$ & & & & & & & $>$ & & & & & $</=$ \\
\hline \multicolumn{15}{|l|}{ R28 } \\
\hline \multicolumn{15}{|l|}{ L01 } \\
\hline L02 & & $>$ & & & & & & & & & & & & \\
\hline \multicolumn{15}{|l|}{ L03 } \\
\hline L04 & & & & & & $<$ & & & & & & & & \\
\hline L05 & & & & $<$ & & & & & & & & & & \\
\hline \multicolumn{15}{|l|}{ L06 } \\
\hline L07 & & & & $>/=$ & & & & & & & & & & \\
\hline \multicolumn{15}{|l|}{ L08 } \\
\hline L09 & $>$ & & & & & & & & & $>$ & & & & \\
\hline L10 & & $>$ & & & & & & & & & & & & \\
\hline L11 & & & & & & & & & & $>$ & & & & \\
\hline L12 & & & & & & & & & & & & & & \\
\hline
\end{tabular}


Table 4.4. continued.

\begin{tabular}{|c|c|c|c|c|c|c|c|c|c|c|c|c|c|}
\hline & L01 & L02 & L03 & L04 & L05 & L06 & L07 & L08 & L09 & L10 & L11 & L12 & RF01 \\
\hline R01 & $<$ & & & & & & & & & & & & $<$ \\
\hline R02 & $</=$ & & & & & & & & & & & & $<$ \\
\hline R03 & & & & & $>$ & & $<$ & & & & & $>$ & $>$ \\
\hline R04 & & & & $<$ & & & $<$ & & & & & & $<$ \\
\hline R05 & & & $<$ & & & & & $<$ & & & & & $</=$ \\
\hline R06 & & $<$ & & & & $<$ & & & & $<$ & & & $<$ \\
\hline R07 & & & & & & & & & $<$ & & $<$ & $>$ & $<$ \\
\hline R08 & & & & & & & & & & & & $<$ & $</=$ \\
\hline R09 & & & & & & & & & & & & & $>$ \\
\hline R10 & & & & & & & & & & & & & $>/=$ \\
\hline R11 & & & & & & & & & $<$ & & & & $<$ \\
\hline R12 & & & & & & & & $<$ & & & & & $</=$ \\
\hline R13 & & & & & & & & & & $<$ & & & . \\
\hline R14 & & & & & & & & & & & & & $<$ \\
\hline R15 & & & & & & & & & $<$ & & & & $</=$ \\
\hline R16 & & $<$ & & & & & & & & $<$ & & & $</=$ \\
\hline R17 & & & & & & & & & & & & & $<$ \\
\hline R18 & & & & & $>$ & & $</=$ & & & & & & $>$ \\
\hline R19 & & & & & & & & & & & & & $</=$ \\
\hline R20 & & & & $>$ & & & & & & & & & $>$ \\
\hline R21 & & & & & & & & & & & & $>1=$ & $>$ \\
\hline R22 & & & & & & & & & & & & & \\
\hline R23 & & & & & & & & & & & & & $>1=$ \\
\hline R24 & & & & & & & & & $<$ & & $<$ & & $>/=$ \\
\hline R25 & & & & & & & & & & & & & \\
\hline R26 & & & & & & & & & & & & & $>/=$ \\
\hline R27 & & & & & & & & & & & & & \\
\hline R28 & & & & & & & & & & & & & $>$ \\
\hline L01 & & & & & & & & & & & & & $</=$ \\
\hline L02 & & & $>$ & & & & & & & & & & $>$ \\
\hline L03 & & $<$ & & & & & & & & & & & $>$ \\
\hline L04 & & & & & & & & & & & & & $>$ \\
\hline L05 & & & & & & & & & & & & & \\
\hline L06 & & & & & & & & & & & & & $>$ \\
\hline L07 & & & & & & & & & & & & & $>$ \\
\hline L08 & & & & & & & & & & & & & \\
\hline L09 & & & & & & & & & & & $<$ & & $>$ \\
\hline L10 & & & & & & & & & & & & & $>$ \\
\hline L11 & & & & & & & & & $>$ & & & & $>$ \\
\hline L12 & & & & & & & & & & & & & $>/=$ \\
\hline
\end{tabular}


Results derived from this timeline (Figure 4.17) are: 17 / 40 (42.5\%) of systems are observed to directly predate regional rifting; 13 / 40 (32.5\%) exhibit synchroneity with regional rifting, and $10 / 40(25 \%)$ of all systems directly postdate regional rifting. Of the 13 systems that exhibit synchroneity to regional rifting, 7 / 13 (54 \%) exhibit a combination of younger and synchronous relationships, while the remaining 6 / 13 (46\%) exhibit a combination of older and synchronous relationships.

\subsection{Implications of the Relative Chronology}

The main results from this relative chronology (Figure 4.17) have been superimposed onto a SAR image of the study area, with detailed linework mapping (Figure 4.18). From this figure it can be seen that graben-fissure systems of all sizes are evenly distributed throughout the study area, but the largest ones - notably systems R01R05 - are situated within the centres of coronae (R01-R03, R05) or large volcanoes (R04). There are also some locations, such as within the areal extent of Kulimina Corona (e.g. systems R05 and R06) and in the vicinity of the hypothesized centre that likely underlies system R07 that contain dense clusters of (mostly) smaller systems. These aforementioned locations also host the majority of young systems interpreted to postdate regional rifting. Many of the largest radiating systems are also among the youngest systems (with R03 as a notable exception) in the study area. Additionally, all local magmatic centres that are interpreted as the focal points for local triple-junction rifting contain graben-fissure systems that are observed to cross-cut regional rift faults. These age relationships provide further evidence in support of multiple stages of Parga Chasma rifting - beginning from regional NE-SW extension between Atla and Themis Regiones and following with local rifting events from isolated magmatic centres. 


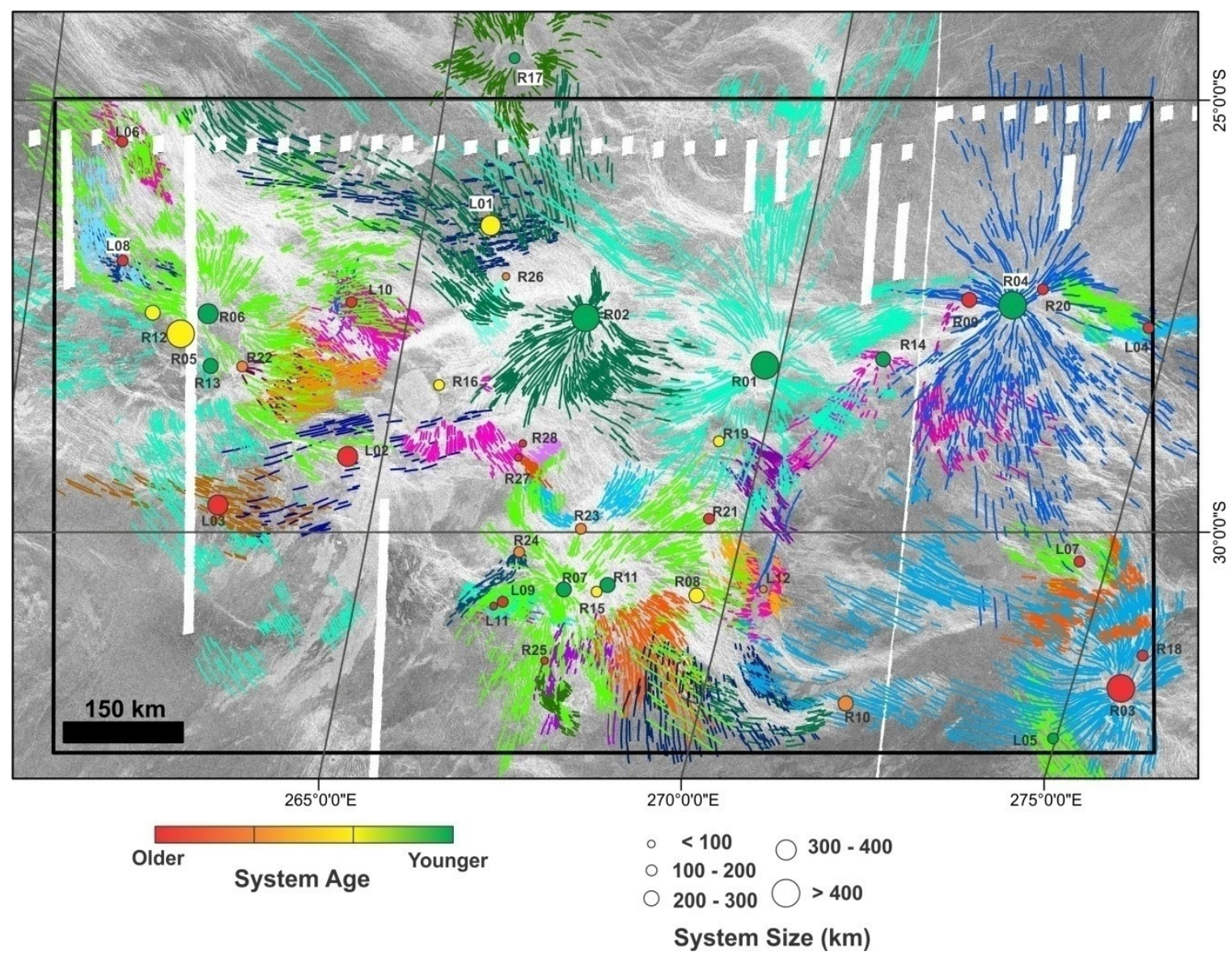

Figure 4.18. Magellan SAR image of the study area, superimposed with detailed linework of all radiating and linear graben-fissure systems. All system centres are identified by circles which are sized and coloured according to maximum system radius/length and relative age, respectively. 


\section{Chapter: Relationship between Rifting and Magmatic Centres}

\subsection{Regional and Local Rifting within the Study Area}

Prominent rifting has taken place throughout the study area (Figure 4.3), interpreted to be associated with both regional and local rifting of the Parga Chasma rift system. The regional rifting is observed as a pattern of NW-SE trending rift faults extending across the study area (Figure 5.1), while local rifting is observed as individual segments (also marked by topographic troughs) extending from isolated magmatic centres (Figure 5.2). Lineaments associated with both the regional and local rifting of Parga Chasma are rift-related and thus exhibit the same morphological characteristics that distinguish them from graben-fissures (Section 3.4). Detailed mapping in the study area has revealed over 1,500 rift-related lineaments, grouped into 1,016 local and 633 regional rift faults, respectively (Figure 4.3).

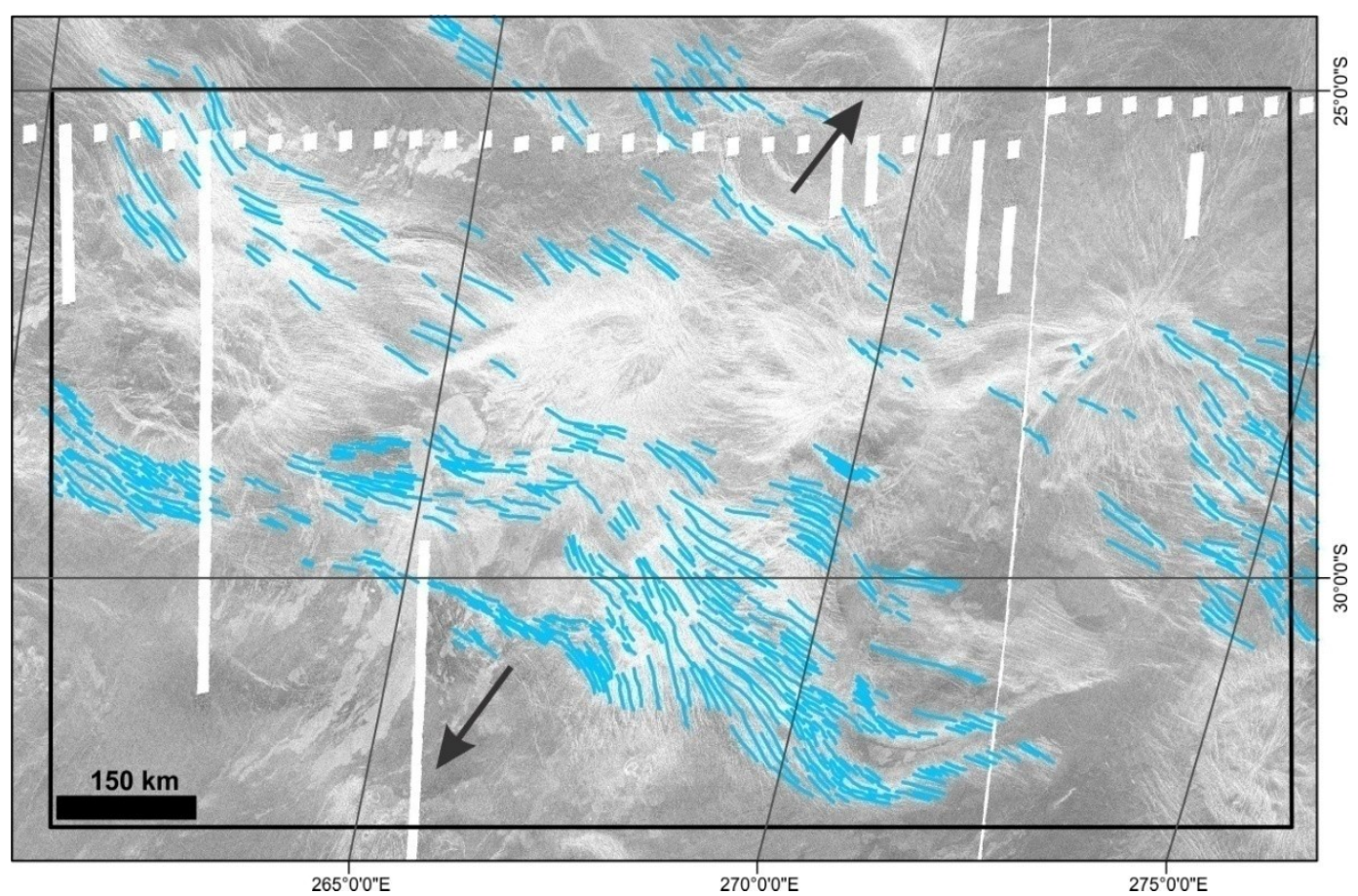

Figure 5.1. Magellan SAR image of the study area superimposed with mapping of the regional rift fault pattern (light blue). The arrows denote the regional NE-SW extension of Parga Chasma. 


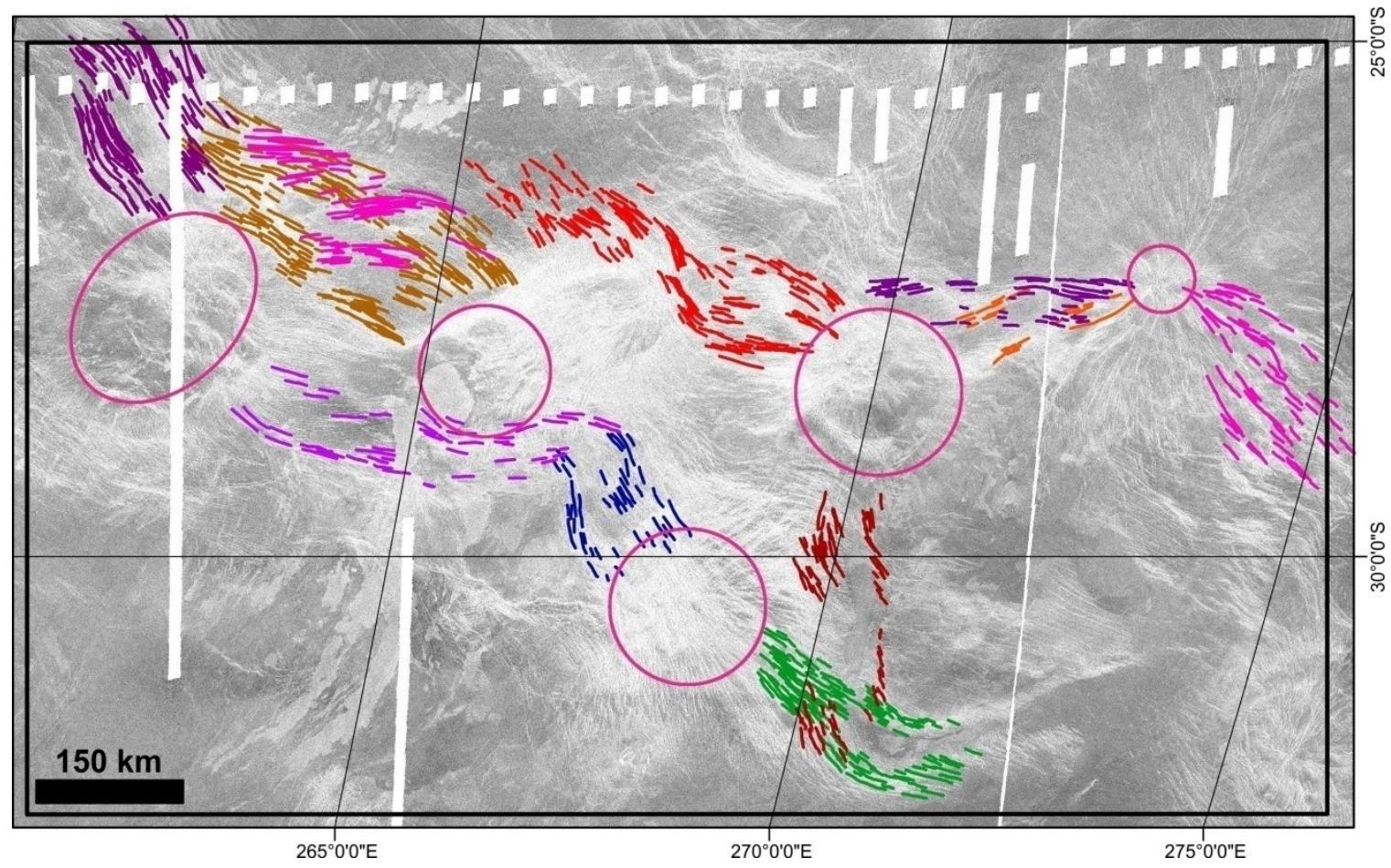

Figure 5.2. Magellan SAR image of the study area superimposed with mapping of local rift faults. The various orientations of these lineaments have been grouped into individual rift segments (cf. Figure 4.3), each of which has been linked to a specific magmatic centre (pink circles) as a focal point.

Within the study area, all of the interpreted local rift segments can be linked to individual magmatic centres acting as the focal points of local triple-junction rifting. Some of these centres are coronae, while the rest are linked to large volcanoes or cryptic centres only recognized as the locus of radiating graben-fissure systems - each of which are understood to be formed from mantle upwellings (Ernst and Buchan, 1997a; Herrick, 1999; Ernst et al., 2001). These upwellings may be linked to rising mantle plumes or from lithospheric delamination (e.g. Sengör, 2001; Sengör and Natal'in, 2001; Ernst, 2014) - with plume-generated triple-junction rifting well observed in terrestrial settings (Burke and Dewey, 1973) 
From detailed mapping, 11 local rift segments have been identified and are interpreted to extend directly from 5 individual magmatic centres (Table 5.1; Figure 5.3). These centres include 1 large volcano - Ts'an Nu Mons, 2 coronae - Xmukane Corona and Kulimina Corona, and 2 unnamed magmatic centres, interpreted as the sources of radiating graben-fissures systems. These two magmatic centres are associated with system R16 (Figure 4.12) and system R07 (Figure 4.9).

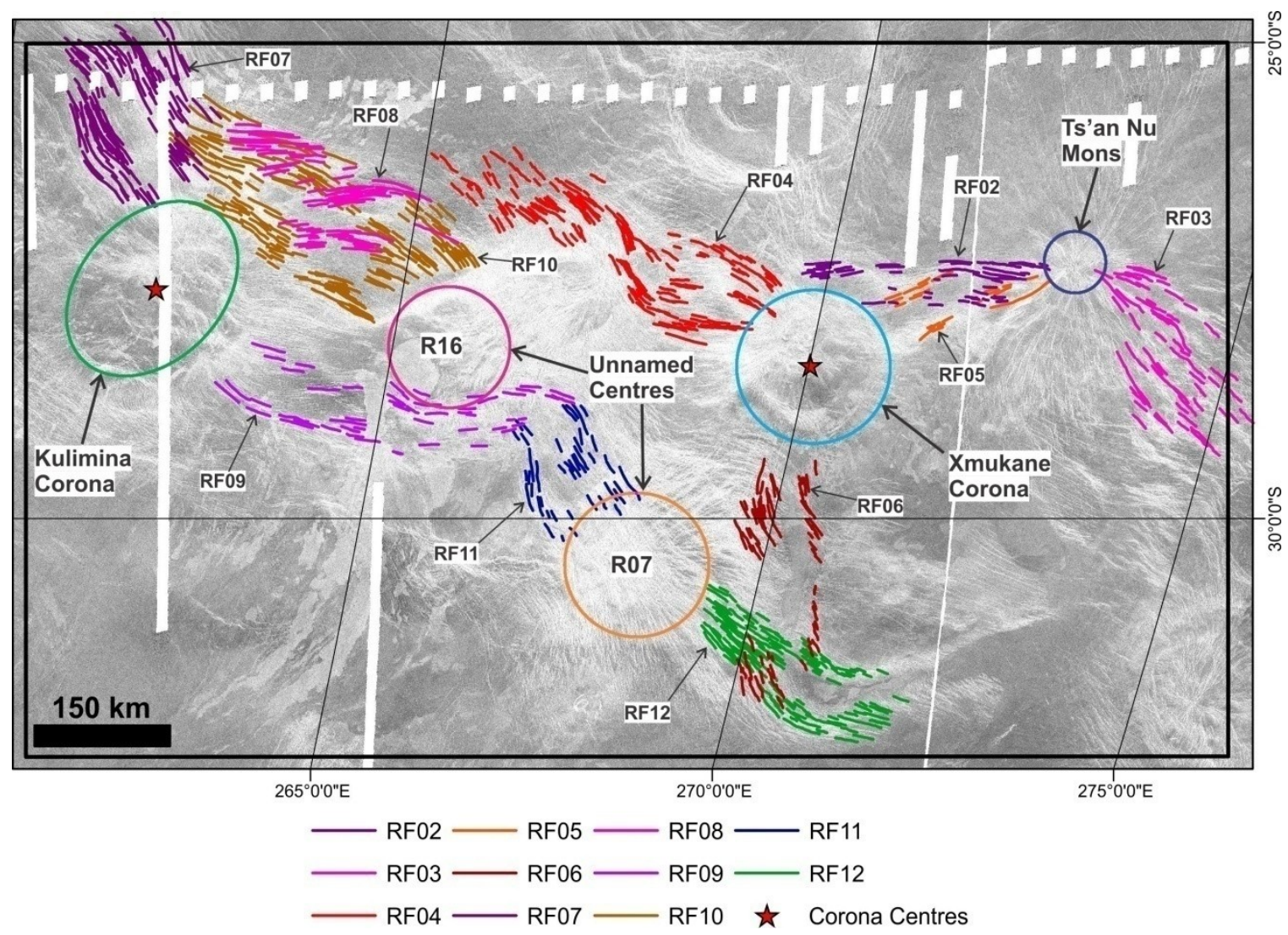

Figure 5.3. Magellan SAR image of the study area superimposed by mapping of the local rift faults which are further grouped into separate rift segments based on lineament orientation. These local rift segments are colour-coded to refer to the specific magmatic centre they are linked with. Corona centres are denoted by red stars. Local rift segments are labelled based on the data catalogued in Table 5.1. 
Table 5.1. Local rift segments catalogued in the study area.

\begin{tabular}{|c|c|c|c|c|}
\hline Rift Segment & $\begin{array}{c}\text { Number of } \\
\text { Rift Faults }\end{array}$ & $\begin{array}{c}\text { Associated Magmatic } \\
\text { Centre }\end{array}$ & $\begin{array}{c}\text { Extension } \\
\text { Direction }\end{array}$ & $\begin{array}{c}\text { Colour-Coded } \\
\text { Association }\end{array}$ \\
\hline RF02 & 52 & Ts'an Nu Mons & West & Dark Blue \\
\hline RF03 & 64 & Ts'an Nu Mons & Southeast & Dark Blue \\
\hline RF04 & 202 & Xmukane Corona & Northwest & Turquoise \\
\hline RF05 & 23 & Xmukane Corona & Northeast & Turquoise \\
\hline RF06 & 75 & Xmukane Corona & South & Turquoise \\
\hline RF07 & 136 & Kulimina Corona & Northwest & Green \\
\hline RF08 & 67 & Kulimina Corona & East & Green \\
\hline RF09 & 51 & Kulimina Corona & East-southeast & Green \\
\hline RF10 & 174 & System R16 & Northwest & Pink \\
\hline RF11 & 43 & System R16 / R07 & $\begin{array}{c}\text { Southeast / } \\
\text { northwest }\end{array}$ & Pink / Orange \\
\hline RF12 & 129 & System R07 & Southeast & Orange \\
\hline
\end{tabular}

Ts'an $\mathrm{Nu}$ Mons (Figure 5.4) is the source of two separate rift segments, propagating to the west (RF02) and to the southeast (RF03) of the volcano. Xmukane Corona (Figure 5.5) contains 3 separate rift segments - propagating to the northeast (RF04), northwest (RF05), and to the south (RF06) of the corona. Kulimina Corona (Figure 5.6) also contains 3 rift segments - propagating to the northwest (RF07), east (RF08), and east-southeast (RF09) of the corona. The unnamed magmatic centres are interpreted based on the local rift fault pattern, coupled with the presence of multiple graben-fissure systems. System R16 (Figure 5.7) is centred on a northwest trending rift segment (RF10), in addition to a segment trending to the southeast (RF11) - this latter segment also connects with the other magmatic centre at system R07. The magmatic centre at system R07 (Figure 5.7) is also interpreted to be the source of a rift segment trending to the southeast (RF12), in addition to having a connection with the rift segment (RF11) in between the magmatic centres at systems R16 and R07 (Figure 5.7). Combining these observations yields a summary map of the study area that displays the distribution of the 5 major magmatic centres interpreted to each be the locus for 
associated local triple-junction rifting (Figure 5.8) - distinct from the regional NW-SE rift pattern (Figure 5.1).
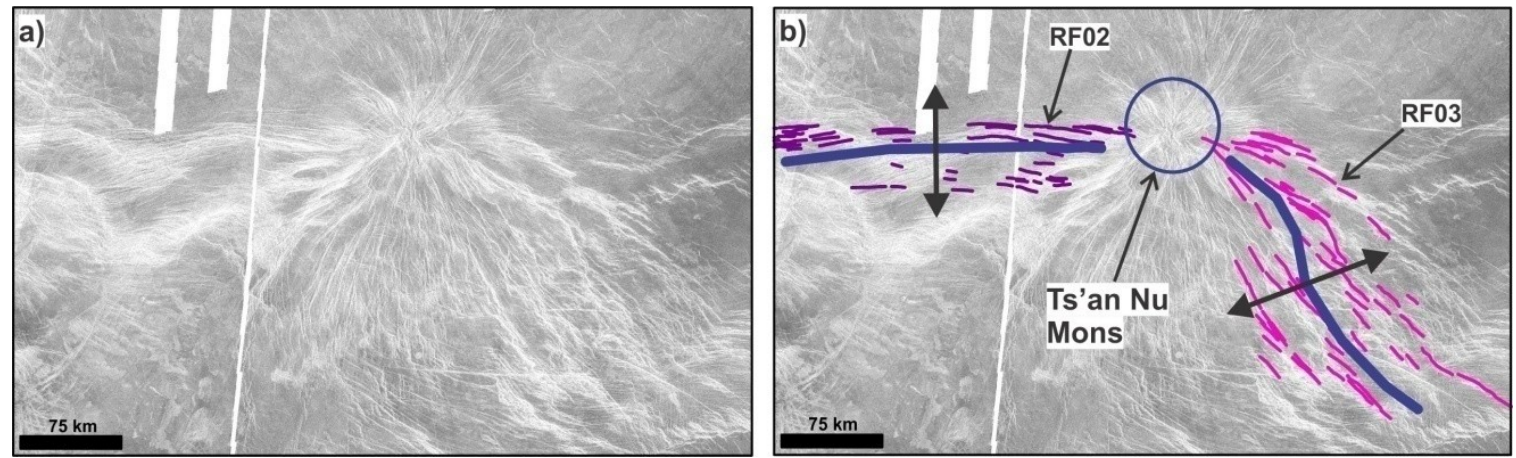

Figure 5.4. Local rifting associated with Ts'an Nu Mons. (a) Magellan SAR image. (b) Image overlain with mapping of local rift faults and segment lines (RF02, RF03) extending from Ts'an Nu Mons (dark blue). Arrows denote direction of opening.
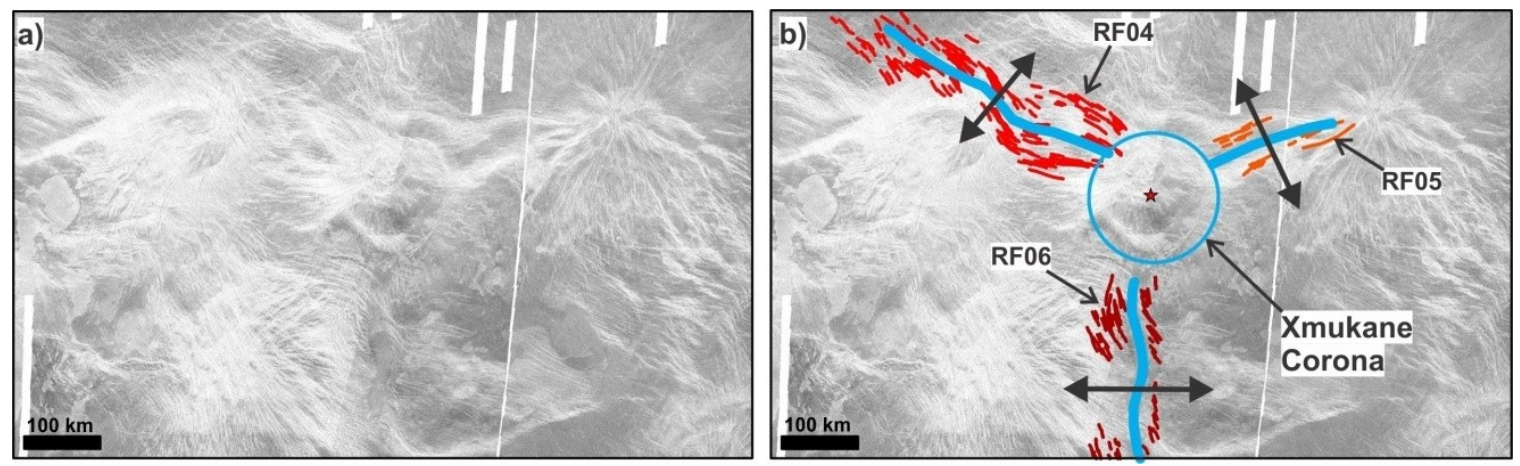

Figure 5.5. Local rifting associated with Xmukane Corona. (a) Magellan SAR image. (b) Image overlain with mapping of local rift faults and segment lines extending from Xmukane Corona (turquoise). Arrows denote direction of opening.
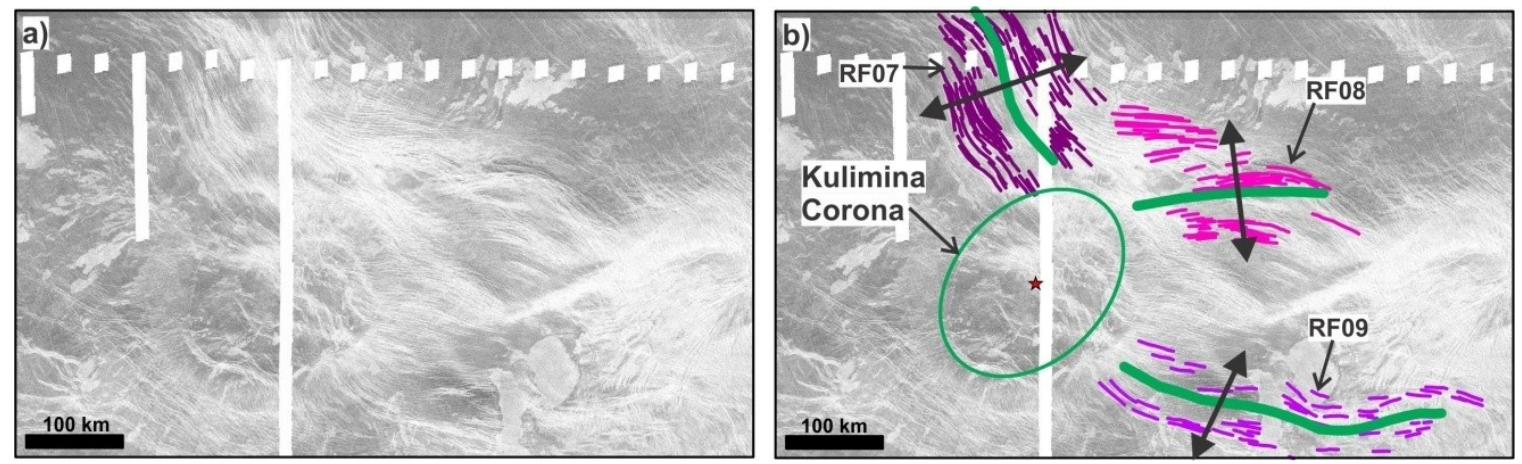

Figure 5.6. Local rifting associated with Kulimina Corona. (a) Magellan SAR image. (b) Image overlain with mapping of local rift faults and segment lines extending from Kulimina Corona (green). Arrows denote direction of opening. 

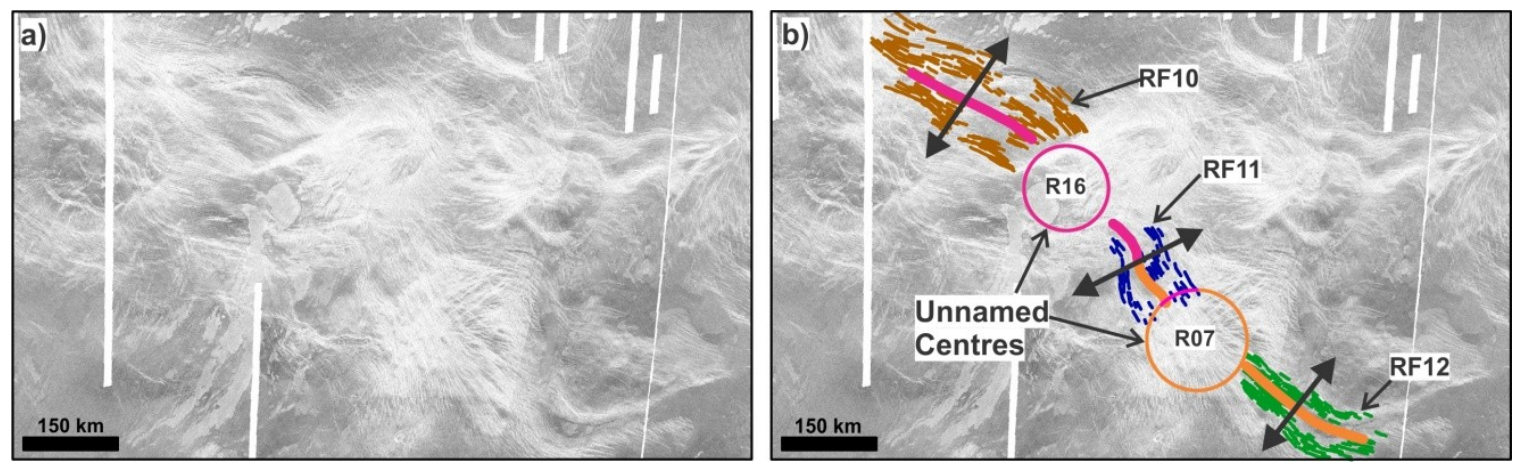

Figure 5.7. Local rifting associated with the two unnamed magmatic centres. (a) Magellan SAR image. (b) Image overlain with mapping of local rift faults segment lines extending from R16 (magenta) and R07 (orange). The rift segment RF11 is observed connecting the two centres and is coloured in both magenta and orange. Arrows denote direction of opening.

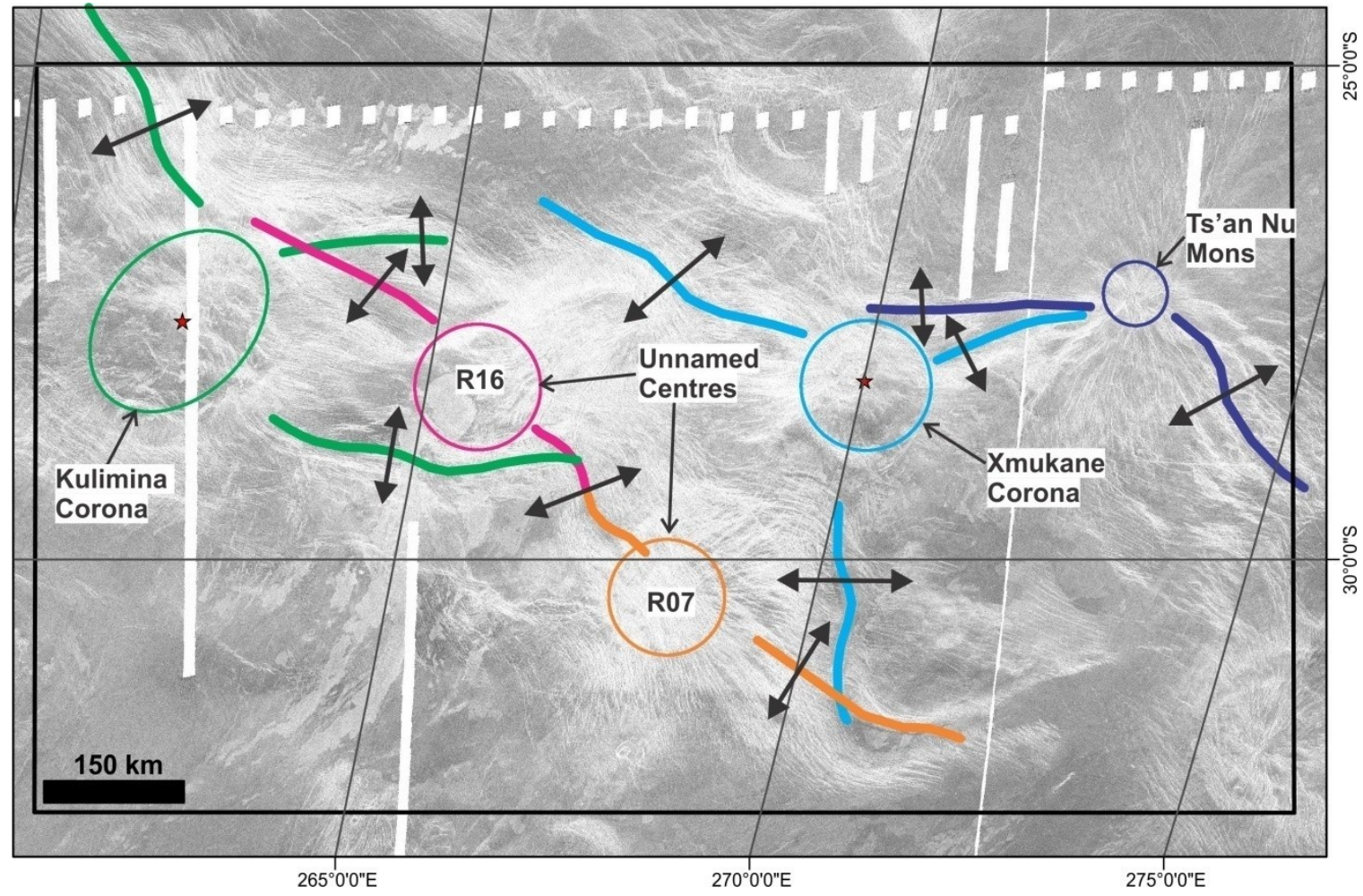

Figure 5.8. Magellan SAR image of the study area superimposed by a summary of all magmatic centres interpreted to be the locus of an individual triple-junction rifting event; rift segments and centres are coloured-coded based on this interpreted association. Arrows denote direction of local opening.

In summary, the detailed mapping and analysis of the local rift fault pattern throughout the study area has revealed numerous local trends and provided the necessary information to group these rift faults into individual rift segments. Grouping these local rift segments allowed them to be linked to specific magmatic centres from which they 
extend. The magmatic centres are typically marked by coronae, large volcanoes, or radiating and/or circumferential graben-fissure system. When enough of these mantle upwellings occur in a zone of regional extension and crustal thinning, these isolated magmatic centres can collectively produce the appearance of a large, but often discontinuous rift system. Examining the relative age relationships between the grabenfissure systems focussed at these isolated magmatic centres (Section 4.3; Figures 4.17 and 4.18) reveals a temporal link between local triple-junction rifting and graben-fissure system formation - different from (and postdating) the timing of regional extension.

\subsection{BAT Region Rift Systems as Collections of Local Rifting}

From the previous section it was observed that a major section of Parga Chasma can be interpreted as a collection of separate local rift segments, formed via triplejunction rifting from isolated magmatic centres. This section explores the possibility that isolated magmatic centres (coronae, volcanoes, centres of graben-fissure systems) can act as similar loci of triple-junction rifting along other parts of Parga Chasma and along the other major rift systems of the BAT region. This hypothesis is applied to explain the observed discontinuities in the rift zone morphologies throughout Hecate and Parga Chasmata (Figures 2.8 and 2.10). By contrast, Devana Chasma can most easily be explained as the result of triple-junction rifting extending from only the two major volcanic rises of Beta and Phoebe Regiones at the ends of the rift system (Figures 2.7b- $f$ and 2.9). The southern rift segment from Beta Regio extends to the south, where it is met by a segment from Phoebe that extends to the north. 
Hecate and Parga Chasmata (Figures 2.8 and 2.10) extend from major volcanic rises located at the ends of each respective rift system and are responsible for zones of regional extension. However, both Hecate and Parga contain numerous additional local rift segments. Applying the results from detailed mapping in the study area, I interpret that Hecate Chasma is composed of 13 local rift segments (Figure 5.9), including those extending directly from the main triple-junction rifting of Atla and Beta Regiones. For Parga Chasma, I interpret to contain as many as 45 local rift segments throughout its full length (Figure 5.10). Most of these local rift segments are linked to a corona or large volcano, but some segments are observed to be isolated from any corona of volcano. However, in such cases, graben-fissure systems (often radiating and/or circumferential geometries) are observed which mark a cryptic magmatic centre. On the following figures of Hecate and Parga Chasmata (Figures 5.9 and 5.10), the interpreted local rift segments and associated magmatic centres are grouped together and numbered as rift segment groups (RGS), and are catalogued with respect to each rift system (Tables 5.2 and 5.3). 

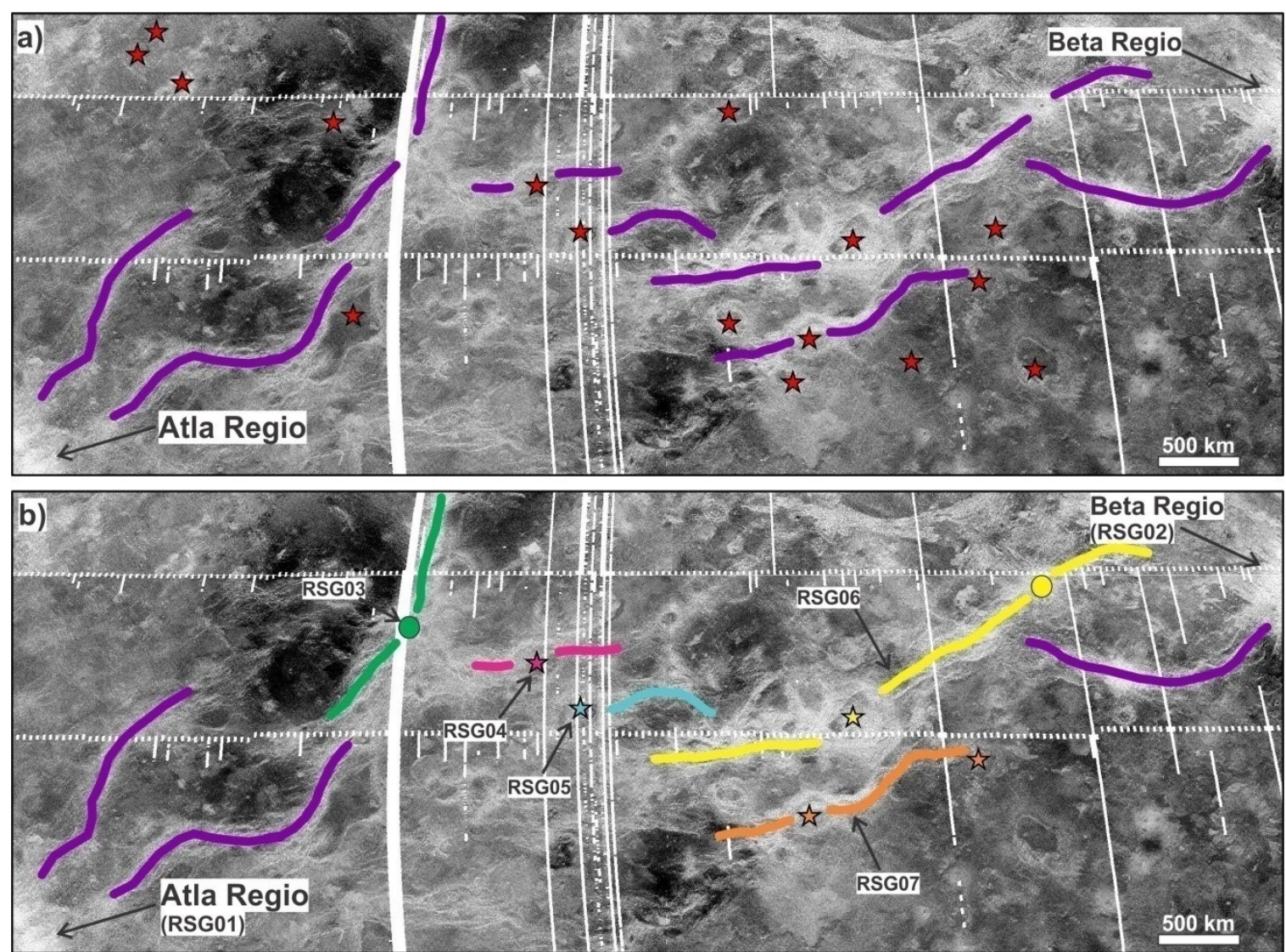

Figure 5.9. Magellan SAR images of Hecate Chasma (centred at $240^{\circ} \mathrm{E}, 16^{\circ} \mathrm{N}$ ). (a) Image overlain by ungrouped local rift segments (purple lines) and corona locations (red stars). (b) Local rift segments and magmatic centres organized into rift segment groups (RGS) and colour-coded to represent genetic association. Stars represent coronae, while circles denote radiating and/or circumferential graben-fissure systems as either volcanoes or cryptic centres. Rift segment groups are catalogued in Table 5.2. 

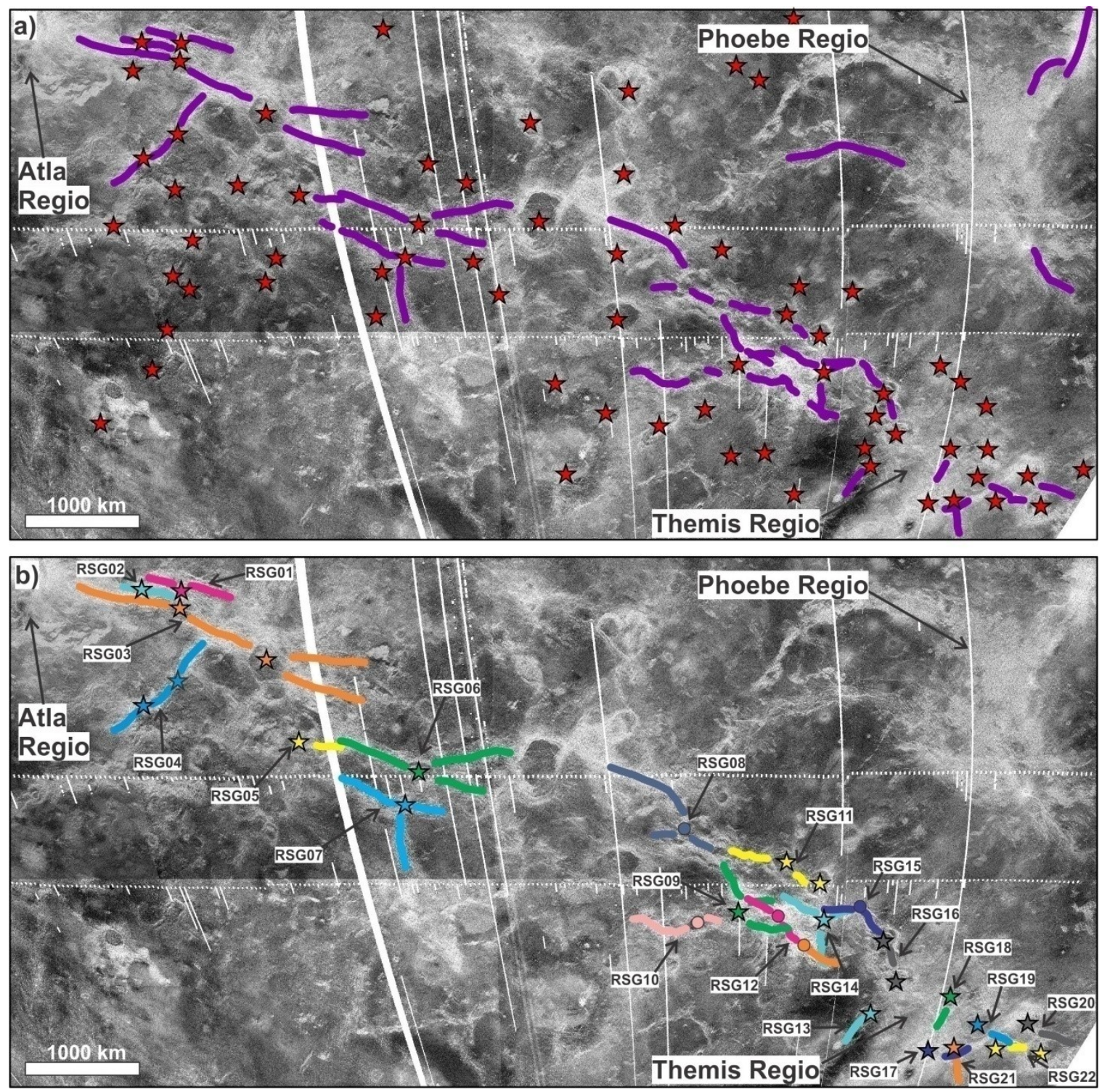

Figure 5.10. Magellan SAR images of Parga Chasma (centred at $245^{\circ} \mathrm{E}, 20^{\circ} \mathrm{S}$ ). (a) Image overlain by ungrouped local rift segments (purple lines) and corona locations (red stars). (b) Local rift segments and magmatic centres organized into rift segment groups (RGS) and colour-coded to represent genetic association. Stars represent coronae, while circles denote radiating and/or circumferential graben-fissure systems as either volcanoes or cryptic centres. Rift segment groups are catalogued in Table 5.3. 
Table 5.2. Rift segment groups catalogued along Hecate Chasma. Volcanic rises of Atla and Beta Regiones are labelled as such in the first column.

\begin{tabular}{|c|c|c|c|}
\hline $\begin{array}{c}\text { Rift Segment } \\
\text { Group }\end{array}$ & \# of Local Segments & $\begin{array}{c}\text { \# of Associated } \\
\text { Magmatic Centres }\end{array}$ & Type(s) of Centre(s) \\
\hline $\begin{array}{c}\text { RGS01 } \\
\text { (Atla Regio) }\end{array}$ & 2 & 1 & Volcanic rise \\
\hline $\begin{array}{c}\text { RGS02 } \\
\text { (Beta Regio) }\end{array}$ & 1 & 1 & Volcanic rise \\
\hline RGS03 & 2 & 1 & Graben-fissure system \\
\hline RGS04 & 2 & 1 & Corona \\
\hline RGS05 & 1 & 1 & Corona \\
\hline RGS06 & 3 & 2 & $\begin{array}{c}\text { Corona \& graben-fissure } \\
\text { system }\end{array}$ \\
\hline RGS07 & 2 & 2 & Corona \\
\hline
\end{tabular}

Table 5.3. Rift segment groups catalogued along Parga Chasma. RGS09, RGS12, RGS14, and RGS15 are the groups associated with the local centres mapped in the study area, and are labelled as such in the first column. Atla Regio is similarly labelled under RGS03.

\begin{tabular}{|c|c|c|c|}
\hline $\begin{array}{l}\text { Rift Segment } \\
\text { Group }\end{array}$ & \# of Local Segments & $\begin{array}{c}\text { \# of Associated } \\
\text { Magmatic Centres }\end{array}$ & Type(s) of Centre(s) \\
\hline RGS01 & 2 & 1 & Corona \\
\hline RGS02 & 2 & 1 & Corona \\
\hline $\begin{array}{c}\text { RGS03 } \\
\text { (Atla Regio) }\end{array}$ & 4 & 3 & Corona \& volcanic rise \\
\hline RGS04 & 3 & 2 & Corona \\
\hline RGS05 & 1 & 1 & Corona \\
\hline RGS06 & 3 & 1 & Corona \\
\hline RGS07 & 3 & 1 & Corona \\
\hline RGS08 & 3 & 1 & Graben-fissure system \\
\hline $\begin{array}{c}\text { RGS09 } \\
\text { (Kulimina) }\end{array}$ & 3 & 1 & Corona \\
\hline RGS10 & 2 & 1 & Graben-fissure system \\
\hline RGS11 & 2 & 2 & Corona \\
\hline $\begin{array}{c}\text { RGS12 } \\
\text { (R16 and R07) }\end{array}$ & 3 & 2 & Graben-fissure system \\
\hline RGS13 & 1 & 1 & Corona \\
\hline $\begin{array}{c}\text { RGS14 } \\
\text { (Xmukane) }\end{array}$ & 3 & 1 & Corona \\
\hline $\begin{array}{c}\text { RGS15 } \\
\text { (Ts'an Nu Mons) }\end{array}$ & 2 & 1 & Volcano \\
\hline RGS16 & 2 & 2 & Corona \\
\hline RGS17 & 1 & 1 & Corona \\
\hline RGS18 & 1 & 1 & Corona \\
\hline RGS19 & 1 & 1 & Corona \\
\hline RGS20 & 1 & 1 & Corona \\
\hline RGS21 & 1 & 1 & Corona \\
\hline RGS22 & 1 & 2 & Corona \\
\hline
\end{tabular}




\subsection{Terrestrial Analogue to Hecate and Parga Chasmata}

The discontinuous morphology of rift systems, coupled with the interpretation of regional formation via a combination of local rifting from multiple magmatic centres, is not confined only to Venus. On Earth, the pre-spreading orientation of the Atlantic Rift System (Figure 5.11) exhibits discontinuities along its full extent, that are similar to those observed along both Hecate and Parga Chasmata. In addition, the rifting and subsequent opening of the Atlantic Ocean is linked to the arrival of three large mantle plumes, each of which resulted in the formation of a Large Igneous Province (LIP) (Ernst, 2014). Many similarities between the terrestrial rifting of the Atlantic Rift System and the Venusian rifting of Hecate and Parga Chasmata can be observed. Specifically, each rift system: (1) exhibits similar discontinuous morphology; (2) contains major plume-related magmatic centres, likely acting as a primary cause of rifting; and (3) contain smaller centres that display localized triple-junction rifting.

It is interesting to note that Hecate Chasma is observed to exhibit a more continuous morphology with a lesser number of local rift segments than the Atlantic Rift System (Figure 5.12). Parga Chasma, however, remains as a very complex and discontinuous rift system, and exhibits many similarities in morphology to the Atlantic Rift System (Figure 5.13). Both of these rift systems are observed to extend between major primary centres and similarly contain an abundance of local triple-junction rifting events from smaller magmatic centres along their full extent. 


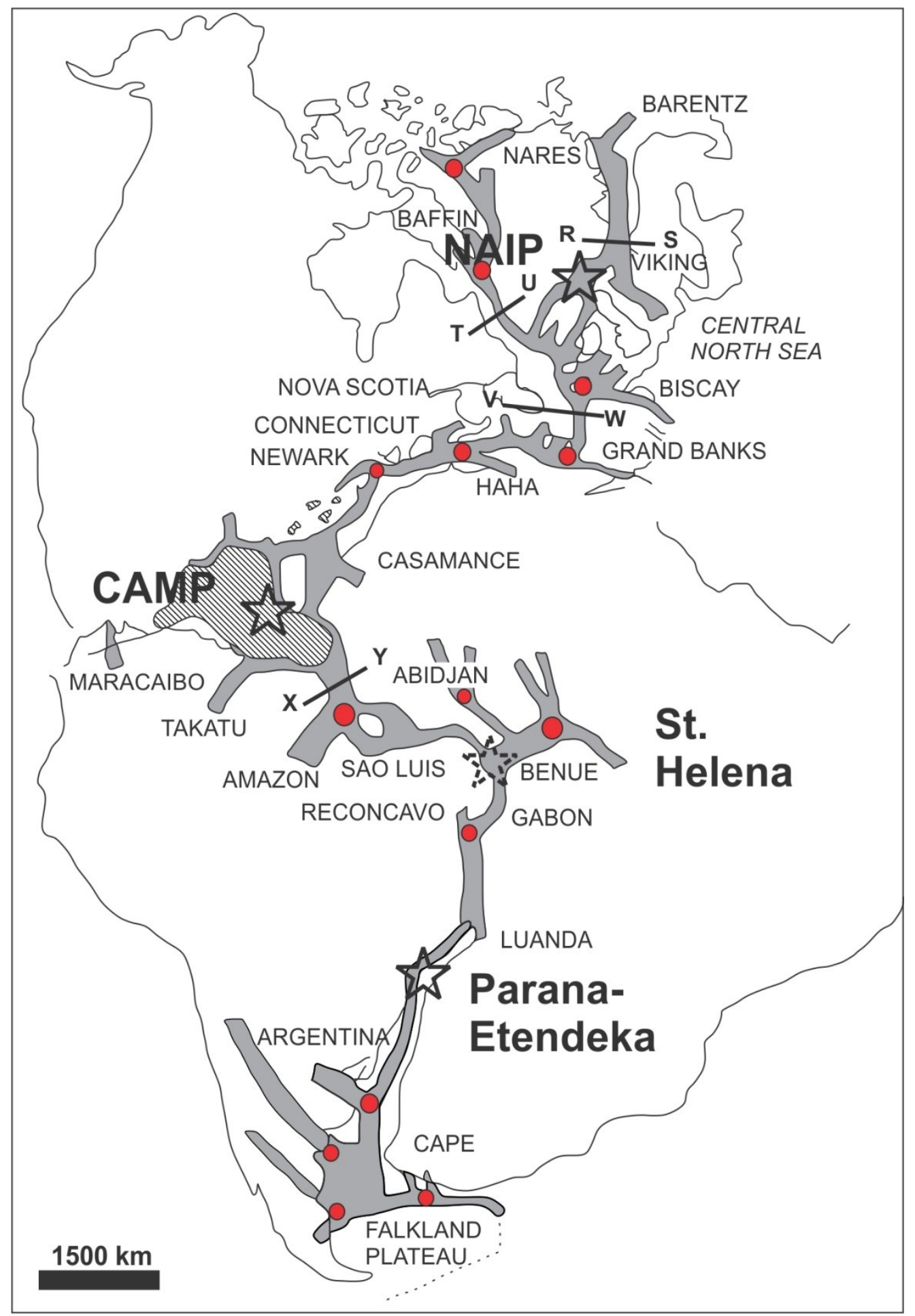

Figure 5.11. Rifting associated with the opening of the Atlantic Ocean and relationship to plumes and LIPs. See text for details. Interpreted centres of local triple-junction rifting superimposed (red circles). Background rift diagram is from Sengör (1995) with the mantle plume centres (stars) superimposed (from Figure 11.2 in Ernst, 2014). 

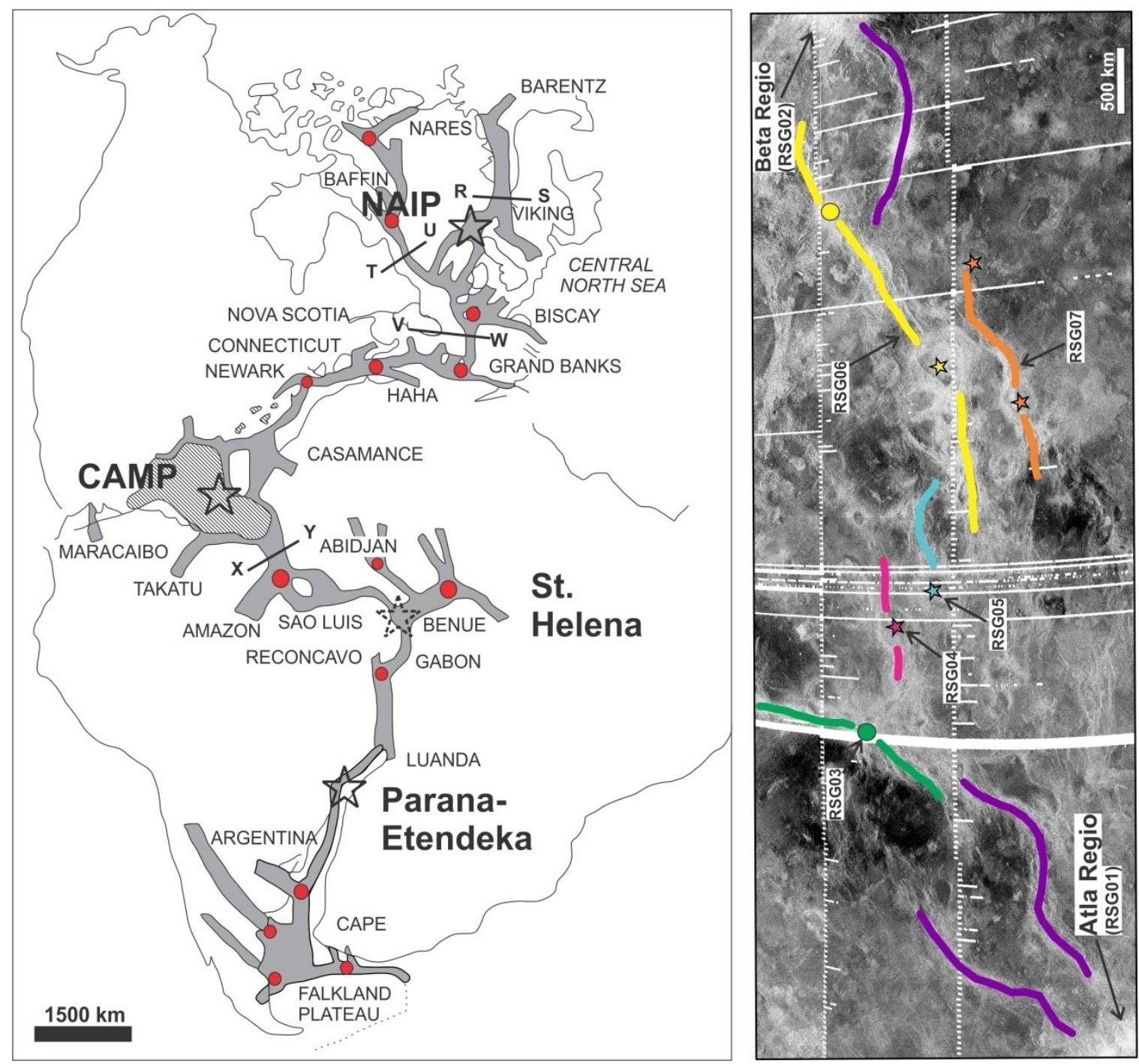

Figure 5.12. Comparison between the rifting along the Atlantic Rift System on Earth with the rifting of Hecate Chasma on Venus, rotated $90^{\circ}$. Note the difference in scale. 

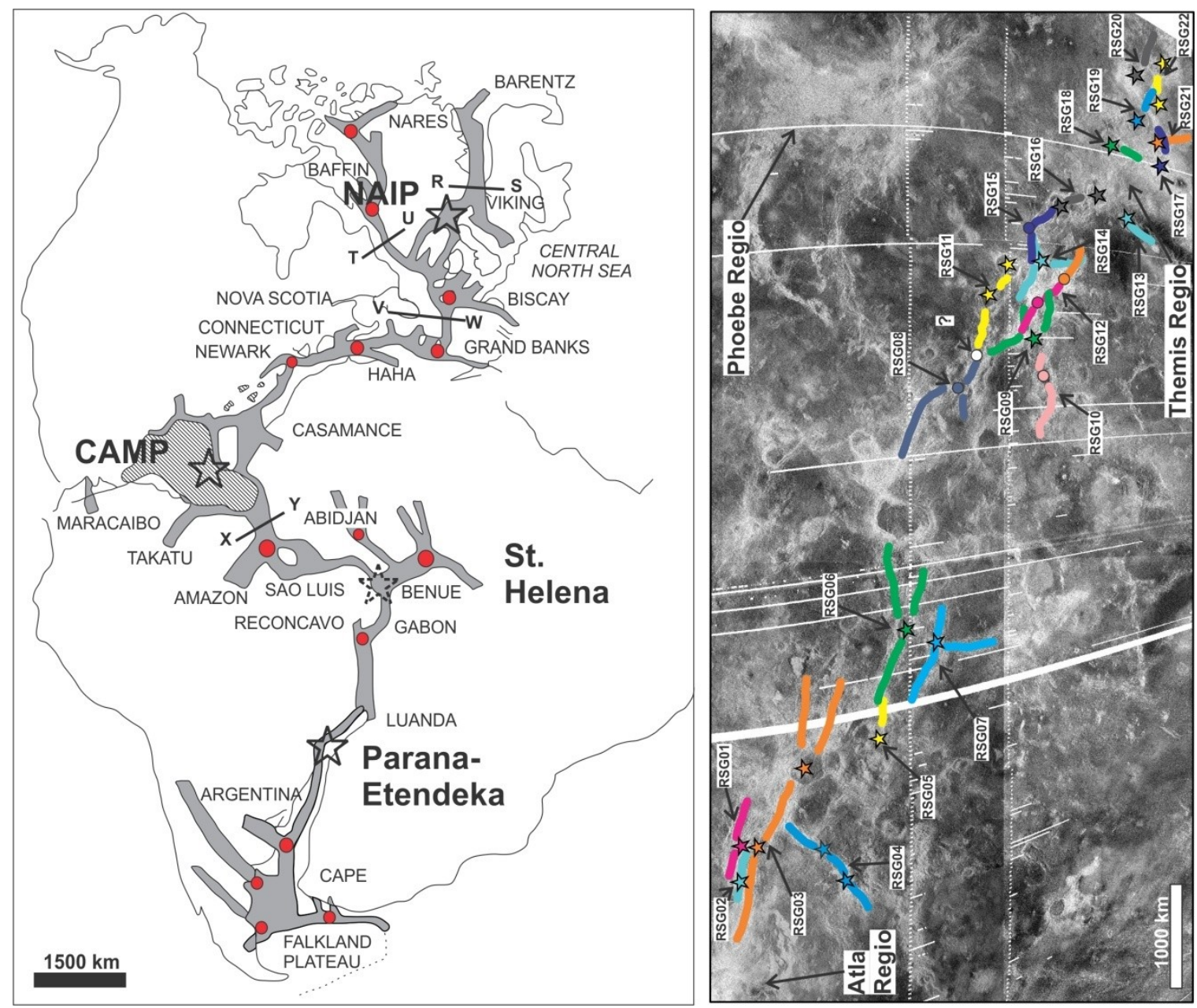

Figure 5.13. Comparison between the rifting along the Atlantic Rift System on Earth with the rifting of Parga Chasma on Venus, rotated $90^{\circ}$. Note the difference in scale.

Drawing further comparisons between terrestrial and Venusian rifting involves the age relationships between the rifting events and their interpreted magmatic centres. In the case of the Atlantic Rift System, while the main plume centres were emplaced at different times over a range of $\sim 140$ million years $(200,135$, and $62 \mathrm{Ma}$; see Figure 11.2 in Ernst, 2014 for details), the individual rifts are interpreted to have formed synchronously $(+/-$ $\sim 10-20 \mathrm{Ma}$ ) with their associated plume centre (Ernst, 2014). With respect to Venusian rifting, the relative chronology of magmatic events within the study area (Chapter 4) reveals a comparable result. Specifically, the magmatic centres (and associated grabenfissure systems) that have been linked to local rift segments are as follows: Ts'an $\mathrm{Nu}$ 
Mons (R04); Xmukane Corona (R01); Kulimina Corona (R05); and two unnamed centres, one located at R16 and another at R07. These systems have been dated via crosscutting relationships, resulting in a relative chronology that places them as younger than the regional rifting of Parga Chasma. Additionally, the graben-fissure systems interpreted to be linked with the formation of local rift segments exhibit synchronous cross-cutting relationships with the individual rift faults comprising these segments. This result further supports a comparison to the Atlantic Rift System as a terrestrial analogue for understanding Venusian rifting.

In summary, each magmatic centre interpreted as the centre for local triple-junction rifting within the study area contains at least one primary graben-fissure system that exhibits synchronous age relationships to the associated local rift segments. The age relationships (Figure 4.17) of these same graben-fissure systems are also almost exclusively younger than the regional rift fault pattern marking the regional NE-SW extension of Parga Chasma (Figure 4.3). This result shows that while Venusian rift systems may appear as a single structure stretching over 1,000's of kilometres, they can be better understood as collections of local rifting events focussed on isolated magmatic centres along a regional system. 


\section{Chapter: Conclusions}

The Beta-Atla-Themis (BAT) region of Venus is enclosed by three major rift systems - Hecate, Devana, and Parga Chasmata - with lengths up to 10,000 km (Figure 1.3). Each rift system is associated with numerous tectono-magmatic structures, including: coronae (circular volcanic structures typically $\sim 200-500 \mathrm{~km}$ in diameter), mons (individual volcanoes $>100 \mathrm{~km}$ in diameter) and graben-fissure systems (marking underlying dyke swarms). A $1,500 \mathrm{~km}$ section of the Parga Chasma rift system was mapped in detail, and cross-cutting relationships assessed in order to reconstruct the tectono-magmatic history of the study area. The insights obtained from the study area were then applied to the BAT region as a whole.

The study area located within the coordinates of $260^{\circ}-275^{\circ} \mathrm{E}, 25^{\circ}-33^{\circ} \mathrm{S}$ is 1,500 $\mathrm{km}$ long and $800 \mathrm{~km}$ wide, covering an area of $\sim 1.2$ million $\mathrm{km}^{2}$. A general review of Venusian characteristics and its geology with a focus on the BAT region is provided in Chapters 1 and 2. This is followed by development and discussion of methodologies used (Chapter 3). ArcMap was used to map lineaments from the high resolution Synthetic Aperture Radar (SAR) images obtained from the Magellan mission (1990 - 1994). Criteria were presented to distinguish graben-fissure lineaments (thought to overlie laterally propagating dykes) from rift faults (Section 3.4), in addition to presenting criteria to determine relative age relationships between systems of grouped of lineaments (Section 4.1).

Relative chronology (Figure 4.17) was determined through the analysis of crosscutting relationships between interacting graben-fissure and/or rift fault lineaments (Section 4.2). While previous studies primarily focussed on mapping graben-fissure 
systems (e.g. Grosfils and Head, 1994a,b; Ernst et al., 2003; Studd et al., 2011), this mapping further included the identification of separate rift segments and detailed mapping of the associated individual rift faults. However, this presented the first challenge of this detailed mapping, as the radar-bright lineaments representing grabenfissures and rift faults can often appear very similar on SAR images.

Rift-distinguishing criteria was initially developed by Graff et al. (2014) and was further expanded upon using a terrestrial analogue during this research, the results of which are presented in Graff et al. (2015) and summarized in Section 3.4. Following these methods, rift faults were distinguished from graben-fissures on the basis of lineament thickness and sinuosity. Clusters of these rift fault and graben-fissure lineaments were then grouped into specific local rift segments and graben-fissure systems. Grouping rift fault lineaments into specific local segments also allowed them to be distinguished from regional rift faults. The regional rift faults are linked to the regional rifting along Parga Chasma, a process that is interpreted - on the basis of cross-cutting relationships - to have preceded local rifting events that are observed to extend from individual magmatic centres (marked by graben-fissure systems, often centred on coronae or large volcanoes). This interpretation of Parga Chasma is of particular importance to the development of a relative chronology because only the regional rifting can be considered as a singular event in time. This result can also have notable implications for further studies on Venus by providing a more detailed understanding of the tectono-magmatic history from the analysis of a greater diversity of geologic structures.

Applying the results from the generated chronology it is interpreted that Parga Chasma developed as a combination of two distinct rifting stages, beginning from a 
precursor NE-SW regional extension (Figure 5.1) and followed by multiple local events of triple-junction rifting extending from individual magmatic centres (Figure 5.8). This model of local triple-junction rifting events from isolated centres - as mapped in the study area along Parga Chasma - was then applied to the rest of Parga Chasma and the entirety of Hecate Chasma. Hecate Chasma was observed to contain 13 local rift segments (Figure 5.9), while Parga Chasma contained as many as 45 local rift segments (Figure 5.10).

A similar complex rift morphology can also be observed in examples from Earth, notably along the Atlantic Rift System (Figure 5.11), which is $\sim 15,000 \mathrm{~km}$ long comparable to Venusian rift systems. Along its full extent, the pre-spreading morphology of this giant terrestrial rift system exhibits similar discontinuities to those observed along the full extent of Hecate and Parga Chasmata (Figures 5.12 and 5.13). The rifting of the Atlantic Rift System can also be observed to have formed from the arrival of three separate major upwelling events (in this case, mantle plumes with ages of 200, 130, and $62 \mathrm{Ma}$ ) and several minor upwellings, each causing local triple-junction rifting that collectively develop the full morphology of a complete rift system. This observation supports our hypothesis, implying that major Venusian and terrestrial rift systems can be identified as a collection of local triple-junction rifting events from individual magmatic centres and can develop over a range of time (at least 10's of Myr). This demonstrates that the model developed to explain the complex morphologies of Venusian rift systems is also supported by a terrestrial analogue. 


\section{References}

Arvidson, R.E., Baker, V.R., Elachi, C., Saunders, R.S., Wood, J.A. 1991. Magellan: Initial analysis of Venus surface modification. Science, 252, 270-275.

Baer, G., Schubert, G., Bindschadler, D.L., Stofan, E.R. 1994. Spatial and Temporal Relations between Coronae and Extensional Belts, Northern Lada, Venus. Journal of Geophysical Research 99, 8355-8369.

Basaltic Volcanism Study Project. 1981. Basaltic Volcanism on the Terrestrial Planets. Pergamon Press, New York, N.Y. 1286p.

Bethell, E., Ernst, R.E., Samson, C., Buchan, K.L. 2016. Circumferential Graben-Fissure Systems of Venusian Coronae as Possible Analogues of Giant Circumferential Dyke Swarms on Earth. Lunar and Planetary Science XXXXVII (2016). Abstract 1471.

Buchan, K.L., Ernst, R.E. 2016. Giant Circumferential Dyke Swarms on Earth as Possible Analogues of Coronae on Venus. Lunar and Planetary Science XXXXVII (2016). Abstract 1183.

Burke, K., Dewey, J. 1973. Plume-Generated Triple Junctions: Key Indicators in Applying Plate Tectonics to Old Rocks. Journal of Geology 81, 406-433.

Chaisson, E., McMillan, S. 2010. Astronomy Today, Vol. 1 - The Solar System, $7^{\text {th }}$ Edition. Addison-Wesley Publishing, San Francisco, CA. Ch. 9, pp. 211-229.

Chapman, M.G., Kirk, R.L. 1996. A Migratory Mantle Plume on Venus. Implications for Earth?. Journal of Geophysical Research 101, 15953-15967.

Crumpler, L.S., Head, J.W., Aubele, J.C. 1993. Relation of Major Volcanic Center Concentration on Venus to Global Tectonic Patterns. Science 261(5121), 591-595.

Crumpler, L.S., Aubele, J.C. 2000. Volcanism on Venus. In Encyclopedia of Volcanoes. Academic, San Diego, California, pp. 727-770. 
Davey, S.C., Ernst, R.E., Samson, C., Grosfils, E.B. 2013. Hierarchical Clustering of Pit Crater Chains on Venus. Canadian Journal of Earth Science 50, 109-126.

Davies, M.E., Colvin, T.R., Rogers, P.G., Chodas, P.W., Sjogren, W.L., Akim, E.L., Stepanyantz, V.A., Vlasova, Z.P., Zakharov, A.I. 1992. The Rotation Period, Direction of the North Pole, and Geodetic Control Network of Venus. Journal of Geophysical Research 97, 13141-13151.

Dombard, A.J., Johnson, C.L., Richards, M.A., Solomon, S.C. 2007. A Magmatic Loading Model for Coronae on Venus. Journal of Geophysical Research 112 , E04006, doi: 10.1029/2006JE002731.

Donahue, T.M., Russell, C.T. 1997. The Venus Atmosphere and Ionosphere and Their Interaction with the Solar Wind: An Overview. In Bougher, S.W., Hunten, D.M., \& Phillips, R.J. (eds), Venus II: Geology, Geophysics, Atmosphere, and Solar Wind Environment. Tucson, AZ: University of Arizona Press, pp. 3-31.

Ernst, R.E. 2014. Large Igneous Provinces. Cambridge University Press, 653p.

Ernst, R.E., Buchan, K.L. 1997a. Giant Radiating Dyke Swarms: Their Use in Identifying Pre-Mesozoic Large Igneous Provinces and Mantle Plumes. AGU Geophysical Monograph 100, 297-333.

Ernst, R.E., Buchan, K.L. 1997b. Layered Mafic Intrusions: A Model for Their Feeder Systems and Relationship with Giant Dyke Swarms and Mantle Plume Centers. South African Journal of Geology 100, 319-334.

Ernst, R.E., Buchan, K.L. 2001. The Use of Mafic Dyke Swarms in Identifying and Locating Mantle Plumes. In Ernst, R.E. \& Buchan, K.L. (eds), Mantle Plumes: Their Identification Through Time. Boulder, CO: Geological Society of America, Special Paper 352, pp. 483-575.

Ernst, R.E., Buchan, K.L., Palmer, H.C. 1995a. Giant Dyke Swarms: Characteristics, Distribution and Geotectonic Applications. In Baer, G. \& Heimmann, A. (eds), Physics and Chemistry of Dykes. Rotterdam: Balkema, pp. 3-21. 
Ernst, R.E., Desnoyers, D.W. 2004. Lessons from Venus for Understanding Mantle Plumes on Earth. Physics of the Earth and Planetary Interiors 146, 195-229.

Ernst, R.E., Desnoyers, D.W., Head, J.W., Grosfils, E.B. 2003. Graben-Fissure Systems in Guinevere Planitia and Beta Regio $\left(264^{\circ}-312^{\circ} \mathrm{E}, 24^{\circ}-60^{\circ} \mathrm{N}\right)$, Venus, and Implications for Regional Stratigraphy and Mantle Plumes. Icarus 164, 282-316.

Ernst, R.E., Head, J.W., Parfitt, E., Grosfils, E.B., Wilson, L. 1995b. Giant Radiating Dyke Swarms on Earth and Venus. Earth Science Reviews 39, 1-58.

Ernst, R.E., Grosfils, E.B., Mege, D. 2001. Giant Dyke Swarms: Earth, Venus, Mars. Annual Review of Earth and Planetary Sciences 29, 489-534.

ESA Venus Express 2007a. Venus: Earth's Twin Planet. Updated on Nov. 28, 2007. http://www.esa.int/Our_Activities/Space_Science/Venus_Express/Venus_Earth_s twin_pl anet2.

ESA Venus Express 2007b. Caught in the Wind from the Sun. Updated on Nov. 28, 2007. http://www.esa.int/Our_Activities/Space_Science/Venus_Express/Caught_in the wind_fr om the Sun.

Graff, J.R., Ernst, R.E., Samson, C. 2014. Mapping and Analysis of the TectonoMagmatic Features Along the Hecate Chasma Rift System, Venus. B.Sc. Thesis. Department of Earth Sciences. Carleton University.

Graff, J.R., Ernst, R.E., Samson, C. 2015. Delineating Rift Faults on Radar Images in Hecate Chasma, Venus. Lunar and Planetary Science XXXXVI (2015), Abstract 2217.

Grosfils, E.B., Ernst, R.E., Galgana, G.A. 2014. Radiating Lineament System. Encyclopedia of Planetary Landforms, pp 1-10.

Grosfils, E.B., Head, J.W. 1994a. The Global Distribution of Giant Radiating Dike Swarms on Venus: Implications for the Global Stress State. Geophysical Research Letters 21, 701-704. 
Grosfils, E.B., Head, J.W. 1994b. Emplacement of a Radiating Dike Swarm in Western Vinmara Planitia, Venus: Implication of the Regional Stress Field Orientation and Subsurface Magmatic Configuration. Earth, Moon and Planets 66, 153-171.

Hamilton, V.E., Stofan, E.R. 1996. The Geomorphology and Evolution of Hecate Chasma,Venus. Icarus 121, 171-194.

Hansen, V.L., Olive, A. 2010. Artemis, Venus: The Largest Tectonomagmatic Feature in the Solar System?. Geology 38, 467-470, doi: 10.1130/G30643.1

Hansen, V.L., Young, D.A. 2007. Venus' Evolution: A Synthesis. In Convergent margin terranes and associated regions: a tribute to W.G. Ernst. Edited by M.Cloos, W.D. Carlson, M.C. Gilbert, J.G. Liou, and S.S. Sorensen. Geological Society of America Special Paper 419, pp. 255-273.

Head, J.W., Crumpler, L.S., Aubele, J.C., Guest, J.E., Saunders, R.S. 1992. Venus Volcanism: Classification of volcanic features and structures, associations, and global distribution from Magellan data. Journal of Geophysical Research 97, 13153-13197.

Herrick, R.R. 1999. Small Mantle Upwellings are Pervasive on Venus and Earth. Geophysics Research Letters 26, 803-806.

Ivanov, M.A., Head, J.W. 2011. Global Geological Map of Venus. Planetary and Space Science 59, 1559-1600.

Ivanov, M.A., Head, J.W. 2013. A History of Volcanism on Venus. Planetary and Space Science 84, 66-92.

Kiefer, W.S., Peterson, K. 2003. Mantle and Crustal Structure in Phoebe Regio and Devana Chasma, Venus. Geophysical Research Letters 30 (1), 1005.

Kiefer, W.S., Swafford, L.C. 2004. Rift System Architecture on Venus. $35^{\text {th }}$ Lunar and Planetary Science XXXV (2004), Abstract 1607. 
Kiefer, W.S., Swafford, L.C. 2006. Topographic Analysis of Devana Chasma, Venus: Implications for Rift System Segmentation and Propagation. Journal of Structural Geology 28, 2144-2155.

Kiefer, W.S. 2013. Making Ishtar Terra, Venus: Mobile Lid Tectonics, Continental Crust, and Implications for Liquid Water and Planetary Evolution. Lunar and Planetary Science XXXXIV (2013), Abstract 2541.

Leung, A., Ernst, R.E., Samson, C. 2013. Mapping Graben-Fissure Systems in the Tassig and Galindo Regions of Venus. B.Sc. Thesis. Department of Earth Sciences. Carleton University.

Lopez, I., Hansen, V.L. 2008. Geologic Map of the Helen Planitia Quadrangle (V-52), Venus. U.S. Geological Survey Scientific Investigations Map 3026, http://pubs.usgs.gov/sim/3026/.

Lopez, I., Lillo, J., Hansen, V.L. 2008. Regional Fracture Patterns Around Volcanoes: Possible Evidence for Volcanic Spreading on Venus. Icarus 195, 523-536.

Martin, P., Stofan, E.R. 2004. Coronae of Parga Chasma, Venus. Lunar and Planetary Science XXXV (2004), Abstract 1576.

Martin, P., Stofan, E.R., Glaze, L.S., Smrekar, S. 2007. Coronae of Parga Chasma, Venus. Journal of Geophysical Research 112, E04S03.

Masursky, H., Eliason, E., Ford, P.G., McGill, G.E., Pettengill, G.H., Schaber, G.G., Schubert, G. 1980. Pioneer-Venus Radar Results: Geology from the Images and Altimetry. Journal of Geophysical Research 85, 8232-8260.

McGill, G.E., Steenstrup, S.J., Barton, C., Ford, P.G. 1981. Continental Rifting and the Origin of Beta Regio, Venus. Geophysical Research Letters 8, 737-740.

McKinnon, W.B., Zahnle, K.J., Ivanov, B.A., Melosh, H.J. 1997. Cratering on Venus: Models and Observations. In Bougher, S.W., Hunten, D.M., \& Phillips, R.J. (eds), Venus II: Geology, Geophysics, Atmosphere, and Solar Wind Environment. Tucson, AZ: University of Arizona Press, pp. 969-1014. 
Nimmo, F., McKenzie, D. 1998. Volcanism and Tectonics on Venus. Annual Reviews of Earth and Planetary Science 26, 23-51.

Phillips, R.J., Hansen, V.L. 1994. Tectonic and Magmatic Evolution of Venus. Annual Review of Earth and Planetary Sciences 22, 597-654.

Saunders, R.S., Pettengill, G.H., Arvidson, R.E., Sjogren, W.L., Johnson, W.T.K., Pieri, L. 1990. The Magellan Venus Radar Mapping Mission. Journal of Geophysical Research 95, 8339-8355.

Saunders, R.S., Pettengill, G.H. 1991. Magellan Mission summary. Science 252, 247249.

Saunders, R.S., Spear, A.J., Allin, P.C., Austin, R.S., Berman, A.L., Chandlee, R.C., Clark, J., DeCharron, A.V., De Jong, E.M., Griffifith, D.G., Gunn, J.M., Hensley, S., Johnson, W.T.K., Kirby, C.E., Leung, K.S., Lyons, D.T., Michaels, G.A., Miller, J., Morris, R.B., Piereson, R.G., Scott, J.F., Shaffer, S.J., Slonski, J.P., Stofan, E.R., Thompson, T.W., and Wall, S.D. 1992. Magellan Mission Summary. Journal of Geophysical Research 97, 13067-13090.

Sawford, W.C., Ernst, R.E., Samson, C., Davey, S.C. 2015. Pit Crater Chains in the Nyx Mons Region, Venus. Lunar and Planetary Science XXXXVI (2015), Abstract 1283.

Sengör, A.M.C. 2001. Elevation as Indicator of Mantle-Plume Activity. In: Ernst, R.E., Buchan, K.L. (Eds.), Mantle Plumes: Their Identification Through Time. Geological Society of America Special Paper 352, pp. 183-225.

Sengör, A.M.C., Natal'in, B.A. 2001. Rifts of the World. In: Ernst, R.E., Buchan, K.L. (Eds.), Mantle Plumes: Their Identification Through Time. Geological Society of America Special Paper 352, pp. 389-482.

Smrekar, S.E., Kiefer, W.S., Stofan, E.R. 1997. Large Volcanic Rises on Venus. Lunar and Planetary Exploration Technical Report, NASA/CR-97-205865; NAS $1.26: 205865$. 
Solomatov, V.S., Moresi, L.N. 1996. Stagnant Lid Convection on Venus. Journal of Geophysical Research 101, 4737-4753.

Squyres, S.W., Janes, D.M., Baer, G., Bindschadler, D.L., Schubert, G., Sharpton, V.L., Stofan, E.R. 1992. The Morphology and Evolution of Coronae and Novae on Venus. Journal of Geophysical Research 97, 13611-13634.

Stofan, E.R., Bindschadler, D.L., Head, J.W., Parmentier, E.M. 1991. Corona Structures on Venus: Models of Origin. Journal of Geophysical Research 96, 20933-20946.

Stofan, E.R., Brian, A.W. 2012. Geologic Map of the Themis Regio Quadrangle (V-53), Venus. U.S. Geological Survey Scientific Investigations Map 3165, http://pubs.usgs.gov/sim/3165/.

Stofan, E.R., Head, J.W. 1990. Coronae of Mnemosync Regio: Morphology and Origin. Icarus 83, 216-243.

Stofan, E.R., Sharpton, V.L., Schubert, G., Baer, G., Bindschadler, D.L., Janes, D.M., Squyres, S.W. 1992. Global Distribution and Characteristics of Coronae and Related Features on Venus: Implications for Origin and Relation to Mantle Processes. Journal of Geophysical Research 97, 13347-13378.

Stofan, E.R., Smrekar, S.E., Bindschadler, D.L., Senske, D.A. 1995. Large Topographic Rises on Venus: Implications for Mantle Upwelling. Journal of Geophysical Research 100, 23317-23327.

Stofan, E.R., Smrekar, S.E., Martin, P. 2000. Coronae of Parga Chasma, Venus: Implications for Chasma and Corona Evolution. Lunar and Planetary Science XXXI (2000), Abstract 1578.

Strom, R.G., Schaber, G.G., Arkani-Hamed, J., Toksoz, M.N. 1992. Global Resurfacing of Venus. Lunar and Planetary Science XXIII (1992), Abstract 1379.

Strom, R.G., Schaber, G.G., Dawsow, D.D. 1994. The Global Resurfacing of Venus. Journal of Geophysical Research 99, 10,899-10,926. 
Studd, D., Ernst, R.E., Samson, C. 2011. Radiating Graben-Fissure Systems in the Ulfrun Regio Area, Venus. Icarus 215, 279-291.

Studd, D., Ernst, R.E., Samson, C., Grosfils, E.B., Head, J.W., Ivanov, M.A., 2010a. Radiating Graben-Fissure Systems in Ulfrun Regio: A Contribution to the Venus Global Dyke Swarm Map Project. Lunar and Planetary Science XXXXI (2010), Abstract 1950.

Studd, D., Ernst, R.E., Samson, C., Grosfils, E.B., Head, J.W., Ivanov, M.A., 2010 b. Mapping in the Ulfrun Regio Area: A Contribution Towards a Global Venus Dyke Swarm Map. CASI ASTRO Con. 15, \#03.

Studd, D., Ernst, R.E., Samson, C., Grosfils, E.B., Head, J.W., Ivanov, M.A., 2010c. Interaction Between Radiating Graben-Fissure Systems and Local Geology, Ulfrun Regio, Venus: A Contribution to the Venus Global Dyke Swarm Map Project. COSPAR Sci. Ass. 38, B-10-0000-10.

Taylor, F.W. 2014. The Scientific Exploration of Venus. Cambridge University Press, $295 \mathrm{p}$.

Turcotte, D.L. 1995. How Does Venus Lose Heat?. Journal of Geophysical Research 100, 16931-16940.

Waerden, B. 1974. Science Awakening II: The Birth of Astronomy. Springer, pp. 347

Young, C. 1990. The Magellan Venus Explorer's Guide. NASA-JPL, Publication 90-24, Pasadena, Ca. 